\title{
When the Sacred Hurts: Using Grounded Theory Analysis to Understand How Former Members Experienced Abuse of Religious Authority in Christian Groups
}

\author{
Karianne D. P. Bilsky \\ West Virginia University
}

Follow this and additional works at: https://researchrepository.wvu.edu/etd

\footnotetext{
Recommended Citation

Bilsky, Karianne D. P., "When the Sacred Hurts: Using Grounded Theory Analysis to Understand How Former Members Experienced Abuse of Religious Authority in Christian Groups" (2013). Graduate Theses, Dissertations, and Problem Reports. 587.

https://researchrepository.wvu.edu/etd/587

This Dissertation is protected by copyright and/or related rights. It has been brought to you by the The Research Repository @ WVU with permission from the rights-holder(s). You are free to use this Dissertation in any way that is permitted by the copyright and related rights legislation that applies to your use. For other uses you must obtain permission from the rights-holder(s) directly, unless additional rights are indicated by a Creative Commons license in the record and/ or on the work itself. This Dissertation has been accepted for inclusion in WVU Graduate Theses, Dissertations, and Problem Reports collection by an authorized administrator of The Research Repository @ WVU. For more information, please contact researchrepository@mail.wvu.edu.
} 
When the Sacred Hurts: Using Grounded Theory Analysis to Understand How Former Members Experienced Abuse of Religious Authority in Christian Groups

\author{
Karianne D. P. Bilsky
}

\author{
Dissertation submitted to the \\ College of Education and Human Services \\ at West Virginia University \\ in partial fulfillment of the requirements \\ for the degree of
}

Doctor of Philosophy

Counseling Psychology

\author{
Jeffrey Daniels, Ph.D., Chair \\ James Bartee, Ph.D. \\ Reagan Curtis, Ph.D. \\ Ian Kellems, Ph.D. \\ Christine Schimmel, Ed.D.
}
Department of Counseling, Rehabilitation Counseling, and Counseling Psychology

\title{
Morgantown, West Virginia \\ 2013
}

Keywords: Spiritual abuse; Religion; Psychology; Religious trauma Copyright 2013 Karianne D. P. Bilsky 


\begin{abstract}
When the Sacred Hurts: Using Grounded Theory Analysis to Understand How Former Members Experienced Abuse of Religious Authority in Christian Groups

\section{Karianne D. P. Bilsky}

The topic of spirituality has recently enjoyed increased popularity within the field of psychology (Pargament, 2007). However, there is an aspect of spirituality that the scientific literature has only started to address - trauma that occurs through religious manipulation. The current study utilizes a qualitative research design to develop an empirical definition and preliminary model of abuse of religious authority (ARA). Seventeen former members of Christian groups were interviewed by employing a semi-structured interview, and the results were analyzed using grounded theory analysis. All participants reported that the negative aspects of their experience outweighed the positive aspects. Participants provided a definition of ARA that included misuse of power, inappropriate use of God, and excessive authority. Participants reported a range of past and current negative emotional and psychological responses. Participants also reported current positive outcomes. The results of the grounded theory analysis were utilized to construct an empirical definition and preliminary model of ARA. Clinical implications, ethical considerations, and directions for future research are discussed.
\end{abstract}




\section{DEDICATION}

To my husband, Tim, who has always encouraged me to keep pursuing my doctoral aspirations. To my parents, Alan and Denise, who provided endless moral support.

To my advisor, Dr. Jeffrey Daniels, who mentored my research and professional development.

To the participants who were courageous enough to share their narratives.

To God, who ultimately granted me the ability and strength to realize this dream. 
Chapter 1: Introduction.

\section{Table of Contents}

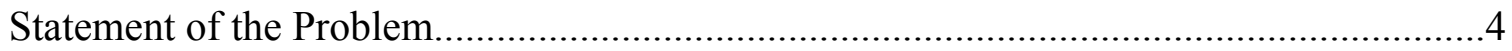

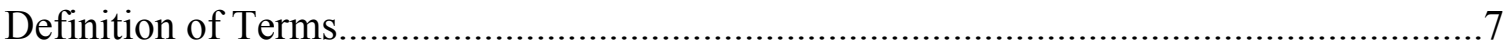

Overview of Popular Literature on Abuse of Religious Authority (ARA).......................12

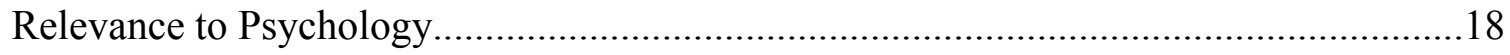

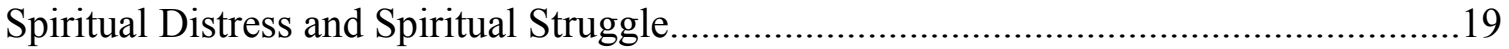

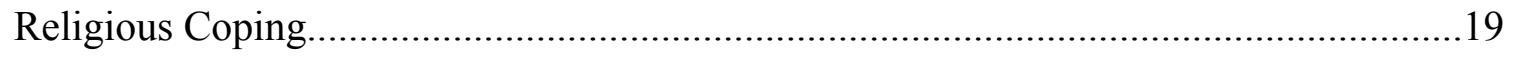

Research on Post-Cult Adjustment........................................................................20

Clergy Perpetrated Sexual Abuse..........................................................................21

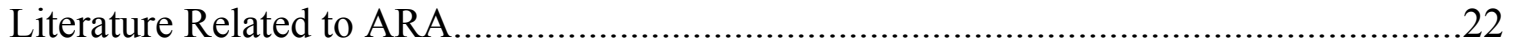

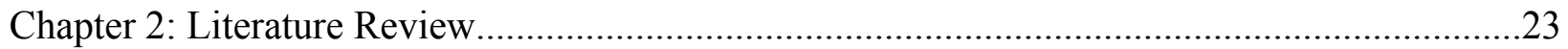

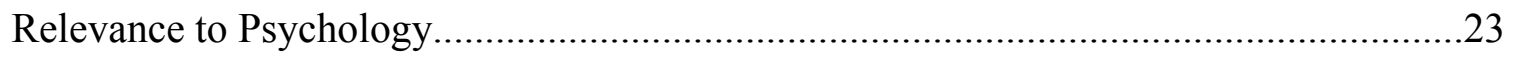

Spiritual transcendence as a personality feature............................................24

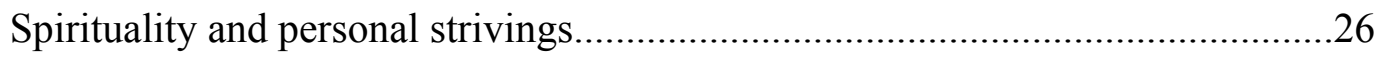

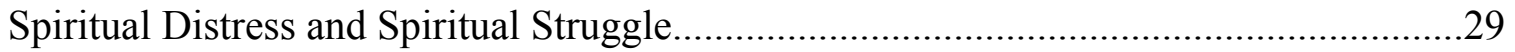

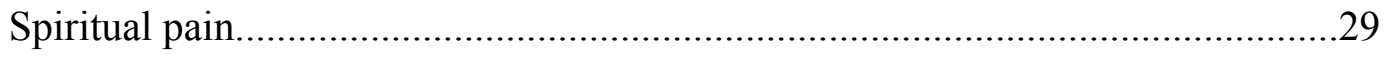

Religious strain and spiritual distress.....................................................32

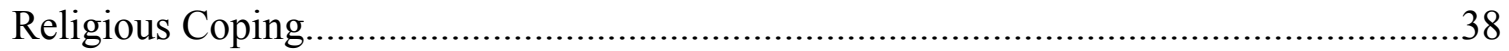

Positive and negative religious coping ...................................................41

Religious coping among religiously diverse populations.................................45

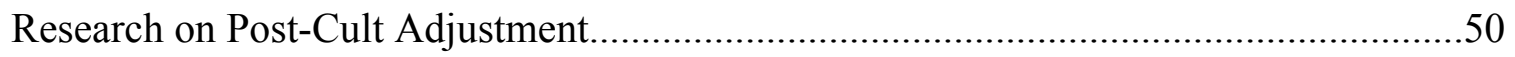

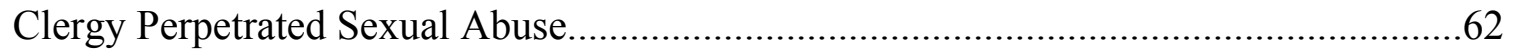

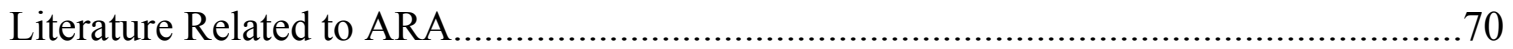




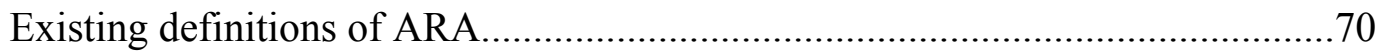

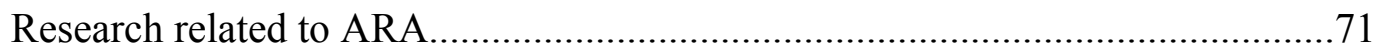

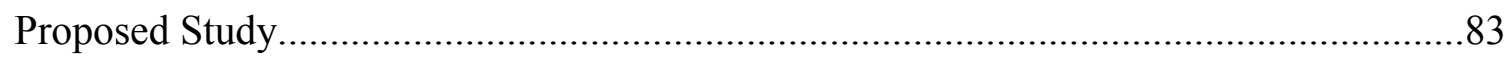

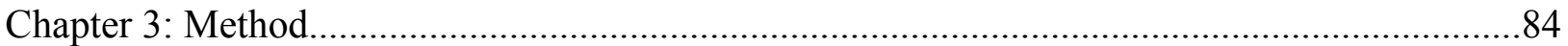

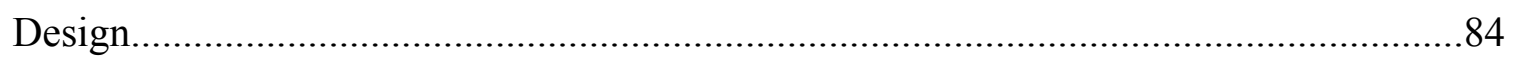

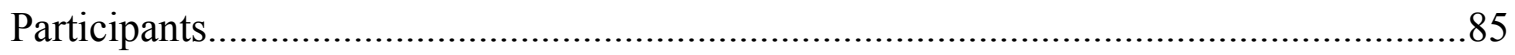

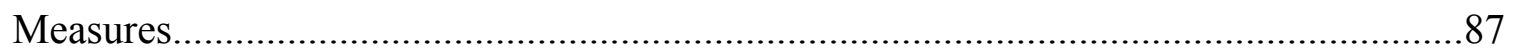

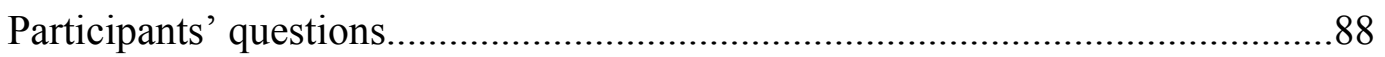

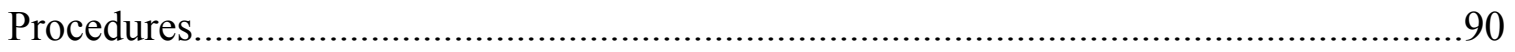

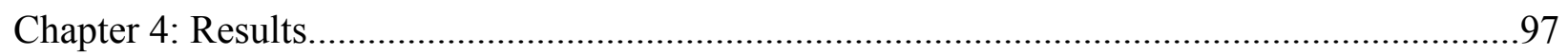

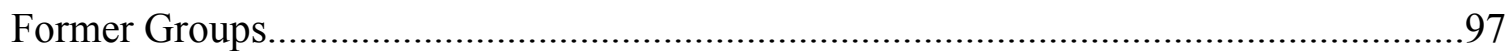

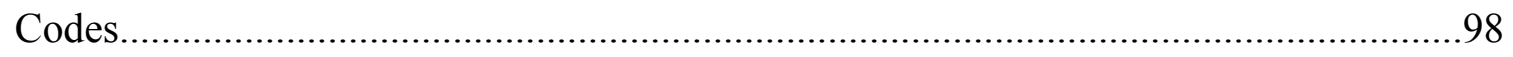

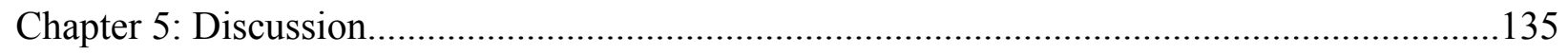

Definition of Abuse of Religious Authority............................................................136

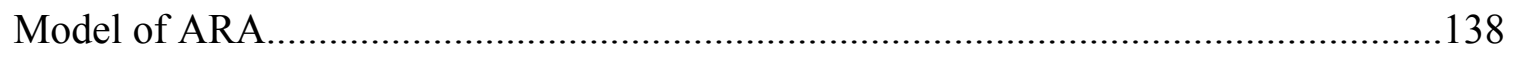

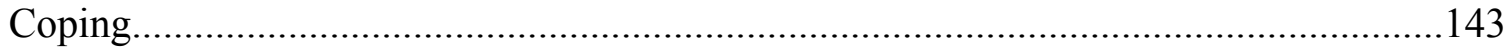

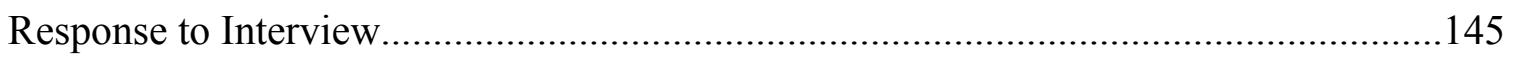

Participants' Recommendations for Helping Professionals...............................................146

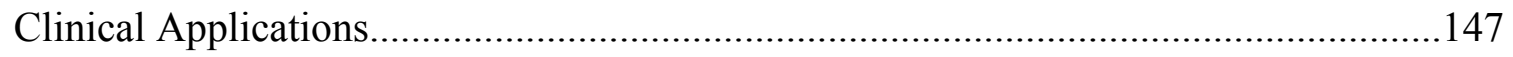

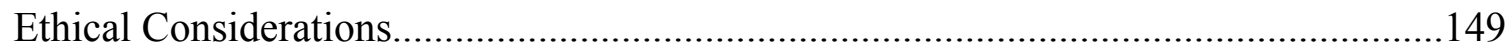

Strengths, Limitations, and Directions for Future Research...........................................149

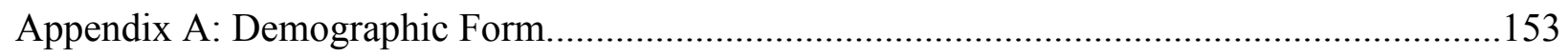

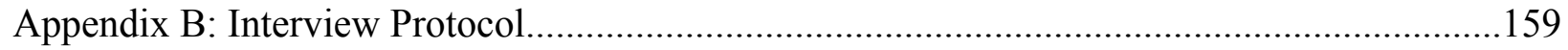


Appendix C: Forum Post/Email Message Text................................................................. 161

Appendix D: Summary of Research Project..................................................................... 162

Appendix E: Verbal Script for Direct Participant Recruitment............................................164

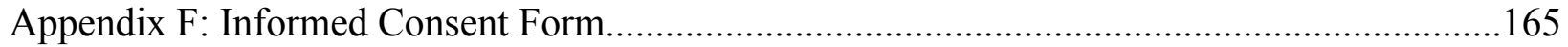

Appendix G: Letter of Explanation to Participants........................................................... 167

Appendix H: Text of Email to Forum Administrators, International Cultic Studies

Association (ICSA), The National Association for Christian Recovery (NACR), and Wellspring Retreat and Resource Center (WRRC) ........................................169

Appendix I: Telephone Information Conversation Protocol..................................................171

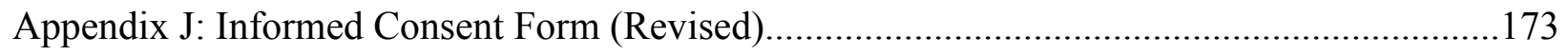

Appendix K: Letter of Clarification to Participants........................................................ 175

Appendix L: Letter Requesting Review of Analysis.......................................................176

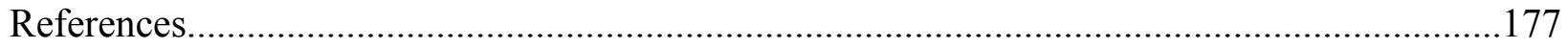




\section{Chapter 1}

\section{Introduction}

\section{Statement of the Problem}

The topic of spirituality has recently enjoyed increased popularity within the field of psychology (Pargament, 2007). However, there is an aspect of spirituality that the scientific literature has only started to address - trauma that occurs through religious manipulation. This phenomenon has been popularly referred to as "spiritual abuse" (VanVonderan \& Johnson, 1991). Although this term is meant to communicate that this type of trauma occurs along a distinct and unique dimension, it lacks the clarity that is necessary to accurately describe and investigate this phenomenon. Therefore, this study will employ the term "abuse of religious authority" (ARA) to denote the misuse of the power that is afforded to leaders of religious groups. The current study will focus on how former members of Christian groups experienced ARA, since individuals who pursue sacred strivings are especially vulnerable to this type of abuse. Particular emphasis will be placed on exploring how ARA impacted participants' sacred strivings and psychological functioning,

The religious component of ARA appears to play a central role in the perpetration and experience of the trauma. Several non-academic books and Internet sites have outlined the phenomenon of ARA, offering advice or support to individuals who identify as having experienced this type of trauma. The authors of these works have claimed that abused individuals suffer unique and detrimental psychological consequences as a result of the religious dimension of the abuse. At the same time, no empirical research has specifically investigated the nature of ARA or the lived experiences of those who identify as abused. Furthermore, the 
research lacks a consistent definition of ARA (Dehan \& Levi, 2009; Masis, 2004; Rauch, 2009; VanVonderan \& Johnson, 1991; Wehr, 2000).

Religious and spiritual concerns play a critical role in cognition, emotional experience, personality, adjustment difficulties, and clinical presentation in psychotherapy (Hill et al., 2000; Pargament, 2007; Pargament, Murray-Swank, \& Mahoney, 2008). A review of the research on spiritual stress and religious coping suggested that the spiritual dimension of human functioning possesses a unique association with psychological adjustment. This association does not appear to be better explained by other factors, such as personality configuration, demographic variables, or social support (Ano \& Vasconcelles, 2005; George, Ellison, \& Larson, 2002; Piedmont, 1999; Piedmont, 2001). A review of the literature on post-cult adjustment, clergy-perpetrated sexual abuse, and leadership abuse within churches indicated that individuals can experience psychological distress as a result of religious trauma. In response, several authors have noted the necessity of understanding how ARA might impact psychological adjustment and religious coping (Fogler, Shipherd, Rowe, Jensen, \& Clarke, 2008; Guido, 2008; Isely, Isely, Freiburger, \& McMackin, 2008).

Extant research has only marginally addressed the lack of an empirical definition of ARA. There is no research to substantiate a model of the unique relationship between this type of abuse and psychological adjustment, although multiple hypotheses have been offered (Cushman, 1986; Rauch, 2009; Wehr, 2000). Three research studies have explored issues related the ARA, but the researchers did not undertake the more fundamental task of constructing a definition and working theory. Gubi and Jacobs (2009) researched the experiences of mental health professionals who provided counseling to clients who experienced ARA. However, the research design was not intended to specifically explore the experiences of the clients 
themselves. Dissertation research conducted by Orlowski (2010) emphasized the process of recovery from ARA, but the research design employed only two items to inquire about the abusive situation and the emotional impact of the experience. In addition, the sample was limited to those individuals who had "recognized and processed their spiritual grief and pain and experienced spiritual recovery" (p. 139). Dissertation research conducted by Cudmore (2002) explored the experiences of individuals who had suffered from abuse by leaders within a Christian organization. However, Cudmore's sample was limited to individuals who had been employed by a Christian organization and who believed that they had been mistreated in that capacity.

The current study seeks to address these gaps in the literature by investigating the following research questions: (a) How do individuals who experienced abuse of religious authority (ARA) define the term "abuse of religious authority"; (b) What are abused individuals" current and past perceptions of personal experiences of ARA; (c) How did these individuals cope during and after the experience of ARA; and (d) What is the nature of the interaction between psychological well-being and the religious and spiritual dimensions of ARA? Furthermore, the current study will purposively sample individuals who experienced ARA while participating in a Christian group. The current study will employ a qualitative research design for the purpose of developing an empirical definition of ARA, as well as a psychological model of the experience and psychological impact of this type of abuse. Qualitative methods are recommended when it is necessary to develop a knowledge base from which to generate directions for future research (Heppner, Wampold, \& Kivlighan, 2008). In addition, knowledge of religious and spiritual beliefs has been identified as a relevant dimension of multicultural competence (Hays, 2008; Schlosser, Foley, Sein, \& Holmwood, 2010). Qualitative methods are preferred when 
conducting multicultural research, as they permit in-depth exploration of multi-faceted phenomena in complex contexts. Qualitative methods avoid imposition of a priori assumptions, instead relying on the participants' narratives to generate theories and research questions (Lyons \& Bike, 2010).

A careful, scientific exploration of ARA will contribute to the field of counseling psychology in several ways. First, it will provide an empirically-based definition of the phenomenon. Second, it will generate a theory of the relationship between psychological wellbeing and the religious and spiritual dimensions of ARA. The findings will facilitate future research regarding prevalence, adjustment, treatment, and prevention. In addition, the results will begin to build a body of research to which counseling psychologists can refer when providing services to clients who may have experienced ARA. It will also assist counseling psychologists to offer culturally sensitive, holistic, and appropriate services to such clients.

\section{Definition of Terms}

It is impossible to undertake the endeavor of researching a phenomenon without first examining some issues of definition. Sociologists, philosophers, and scholars of religion have attempted to define both religion and spirituality for more than a century, with little consensus. ARA is popularly referred to using the term "spiritual abuse," yet the term "spirituality" is notoriously difficult, if not impossible, to define due to its flexible and mutable nature (Bregman, 2004; Bregman, 2006). Its meaning has been transformed as a result of cultural and historical variables. Therefore, Bregman (2004) recommended that any attempt to understand the term "spirituality" must consider how it is applied within social and historical contexts.

Initially, the concept of spirituality was associated with theological doctrine and institutional religion. It functioned as a term that specifically denoted the relationship between 
an individual and a particular religious objective. Over time, this application of the term became obsolete, and spirituality was gradually divorced from expressly religious connotations. Instead, it functioned as a term that resembled the term "religion," but it enjoyed a broader and more subjective meaning. With the writings of Tillich (1957), spirituality began to encompass nonreligious aspects of life, and it grew increasingly independent from express association with religious doctrine. The concept of spirituality became affiliated with the notion of a private and universal human pursuit, distinct from religious institutions or dogma (Bregman, 2004).

More recently, the meaning of the term "spirituality" increasingly resembled the tenets of humanistic psychology. The capacity for spirituality was thought to be a universal human faculty, which was sometimes expressed through the avenue of religion. "Spirituality" began to address issues that had previously fallen within the purview of humanistic psychology, such as grief, loss, death, and meaning. Thus, "spirituality" emerged as a term that subsumed both existential and humanistic considerations. However, an increased emphasis on promoting psychology as a science contributed to neglect of these issues - and of spirituality - within the field of psychology (Bregman, 2004). In addition, psychological research often addressed religiousness in a one-dimensional manner, reinforcing the tendency to conceptualize religion and spirituality with a lack of nuance (Pargament, 1999).

In addition, use of the word "spirituality" expanded in American society as the trend toward secularization and individualization increased (Bregman, 2004; Bregman, 2006; Pargament, 1999). Religion had not historically been defined solely as an institutional experience; rather, it represented a broad concept that included both corporate and individual expressions of belief (Pargament). The decentralization and deinstitutionalization of religion within United States society paved the way for spirituality to be used to denote the private, 
subjective experience of individuals who no longer wished to be associated with public religion (Bregman, 2004). "Religion” began to represent a construct that was formal, institutional, and increasingly negative, while "spirituality" represented a positive, aspirational, and dynamic construct. Current application of the term indicates an emphasis on the individual, rather than an institution or unified doctrine, when selecting beliefs about the sacred or transcendent. These shifts in meaning and terminology contributed to the confusion about defining the terms "religion" and "spirituality."

Thus, the term "spirituality" accommodates several meanings, but its fluidity has made it challenging for researchers to operationalize the term effectively. Bregman (2006) noted that many professionals criticize the term as being too broad, general, and vague. Other criticisms include complaints that current applications of the term "spirituality" either exclude the religious or surreptitiously smuggle religion into the conversation. Bregman concluded that the term "spirituality" indicates an internal experience that is separate from mere identification with an external, public religious institution. This type of spirituality can encompass traditional interpretations of religious commitment, or it can refer to a synthesis of components from diverse belief frameworks.

Hill et al. (2000) attempted to clarify the issue and progress beyond merely defining the terms "spirituality" and "religion." They constructed a description of the terms that considered both similarities and differences. In an attempt to resolve the tension created by the apparent overlap between the terms "spirituality" and "religion," Hill et al. used the following criterion to define both spirituality and religion:

The feelings, thoughts, experiences, and behaviors that arise from a search for the sacred. The term "search" refers to attempts to identify, articulate, maintain, or transform. The 
term "sacred" refers to a divine being, divine object, Ultimate Reality, or Ultimate Truth as perceived by the individual. (p. 71)

Hill et al.'s definition of religion required additional criteria to delineate the manner in which religion diverges from spirituality. The description of religion included either or both of the following criteria:

1. "A search for non-sacred goals (such as identity, belongingness, meaning, health, or wellness) in a context that has as its primary goal the facilitation of [the above criterion]" (p. 71).

2. "The means and methods (e.g., rituals or prescribed behaviors) of the search that receive validation and support from within an identifiable group of people" (p. 71).

This definition supported the idea that spirituality is a primary component of religion while acknowledging that an individual's pursuit of spirituality need not necessarily involve religion (Hill et al., 2000). Pargament (1999) concurred, asserting that many individuals do not subscribe to the dichotomy between the terms "religion" and "spirituality", nor did the distinction appear to be consistent with actual practice. He noted that religious institutions are primarily concerned with spiritual affairs, and spiritual expression frequently occurs in corporate or social contexts - a notion that echoed Allport's (1950) sentiments.

Bregman (2006) later concurred that the term "spirituality" often carries connotations of searching for the sacred through individualized and personal means, whereas the term "religion" frequently brings to mind formalized rituals, organizations, and codified belief systems. However, Hill et al. (2000) also issued the caution that it is unhelpful to adopt definitions that polarize religion as formal and spirituality as informal. They argued that religious systems and institutions frequently pursue spiritual interests, and individual spirituality rarely occurs in 
complete isolation from a reference group. Thus, current cultural interpretations of the words "religion" and "spirituality" seem to represent concepts that simultaneously diverge and converge.

Given the degree of overlap between terminologies, Pargament (1999) concluded that the terms "religion" and "spirituality" described nested constructs rather than mutually exclusive ones. He defined spirituality as “...a search for the sacred” (p. 12) and defined religion as "a search for significance in ways related to the sacred" (p. 11). Significance refers to that which is valued, and the term sacred refers to objects that are perceived as holy or that take on a sanctified quality through association with or representation of the divine (Mahoney et al., 2005; Pargament, Magyar-Russell, \& Murray-Swank, 2005). Religion can focus on discovering a sense of significance in ways that are not related to the sacred, whereas spirituality possesses only one target - the sacred. Thus, Pargament defined religion as the broader term that subsumes spirituality. This contrasted with Hill et al.'s (2000) definition, in which spirituality subsumes religion. Pargament also theorized that the search for significance in ways related to the sacred is comprised of two dimensions. The first dimension involves the goal or destination of the search, and the second dimension involves the method or pathway used to reach the goal. Although Pargament's (1999) and Hill et al.'s (2000) definitions of religion and spirituality were somewhat dissimilar, they are particularly useful for a discussion of ARA because they highlight the avenue through which the abuse occurs. Pargament's pathway/means concept and Hill et al.'s second criterion for religion ("means and methods") allowed for the possibility that individuals or groups can approve specific ways to appropriately search for the sacred (Hill \& Hood, 1999). An individual who is seeking the sacred (Pargament's definition of spirituality) through means that are validated by a particular group (Hill et al.'s definition of 
religion) is vulnerable to abuse by those who legitimate, dictate, or administer those means. If the individual perceives that a leader or group possesses the authority to dictate valid pathways to the sacred, that leader or group possesses significant power over the individual's behavior, beliefs, and spirituality.

In some instances, a leader might hold an even more powerful position due to the teaching that he or she is a substitute or actual sacred figure himself or herself (Guido, 2008). Additionally, non-divine individuals, goals, objects, behaviors, attitudes, rituals, and relationships can be imbued with qualities that are associated with the divine in a process known as sanctification (Mahoney et al., 2005; Pargament \& Mahoney, 2005). The result of such sanctification is that the non-divine is afforded greater significance by virtue of possessing sacred qualities. In this way, a group leader's authority can extend beyond issues of deity and the sacred. Not only can the group leader be perceived as sacred, it is possible for the leader to sanctify non-sacred and secular aspects of life, such as parenthood and career (Hill et al.; Pargament, Magyar, Benore, \& Mahoney, 2005; Pargament et al., 2008).

For the purposes of this study, "religion" is defined as the pathway, means, methods, and goals: (a) that are associated with a search for significance in ways related to the sacred and (b) that are validated by another individual or group. This definition encompasses the non-sacred goals (i.e., belongingness, meaning) that are often related to the search for significance in ways related to the sacred. For the purposes of this study, "spirituality" is defined as a search for the sacred, which may or may not involve religion. The misuse of religious power and influence to the detriment of the seeker of the sacred constitutes ARA (VanVonderan \& Johnson, 1991).

\section{Overview of Popular Literature on ARA}

At this time, there is only limited research on the concept of ARA. In spite of the lack of 
academic literature on the topic, popular literature has offered a lay description of the features of this abuse. The most commonly cited characteristic is the misuse or abuse of power by an individual who possesses religious or spiritual authority (Enroth, 1992; Orlowski, 2010; VanVonderan \& Johnson, 1991; Wehr, 2000). This mistreatment frequently occurs in the context of a religious group, although it can also occur within the dynamics of an individual relationship (Wehr). ARA is distinguished from other forms of abuse in that it involves the manipulation of spiritual strivings, sacred text, and/or deity to justify or lend authority to the perpetrator's actions (Gubi \& Jacobs, 2009). However, other abuses might occur within the context of ARA, including character assassination and sexual or physical abuse (Gubi \& Jacobs; Wehr).

Abuse of religious authority is perpetrated by individuals who are perceived as capable of providing religious empowerment and support. This is often possible because others believe that these individuals possess a greater level of religious authority and leadership (Wehr, 2000). Many times, perpetrators are religious leaders or group members who possess governing and decision-making power. Ultimately, in order for an individual to possess sufficient power to perpetrate ARA, he or she must be seen as capable of legitimating appropriate pathways (i.e., rituals, rites, and behaviors) to search for the sacred and establish a relationship with the divine (Pargament \& Mahoney, 2005). However, VanVonderan and Johnson (1991) cautioned that, in some cases, the perpetrator believes that his or her approach is beneficial to the recipient of the abuse. The perpetrator may disagree that the manipulative behavior is abusive or harmful, instead perceiving it as righteous and justified action, or even as a necessary act of love. In fact, both the perpetrator and the abused individual might believe that the abusive behavior is desirable and beneficial. 
Once an individual who perpetrates ARA possesses sufficient power to legitimate pathways of searching for the sacred, that individual and his or her group tend to exhibit common characteristics. VanVonderan and Johnson (1991) listed several of these characteristics, many of which resembled Lifton's (1961) features of thought reform. The first common characteristic of a group exhibiting ARA is a leader who performs what VanVonderan and Johnson (1991) referred to as power-posturing. The leader invests significant energy in and attention to emphasizing his or her authority, drawing upon intimidation or a naturally confident demeanor to influence group members (Enroth, 1992). Group members are frequently prohibited from questioning or contradicting the leader's teaching, behavior, or demands, as doing so would constitute a challenge to the representative of the sacred within the group. This effectively grants the leader a position in which he or she is unassailable and unaccountable, functioning as the primary conduit in group members' lives for information about the sacred. The leader is therefore often idealized and revered (Enroth; Rauch, 2009).

As a result of power-posturing, leaders and members of groups that perpetrate ARA tend be preoccupied with performance (VanVonderan \& Johnson, 1991), over-emphasizing group members' compliance with leadership directives. The group interprets unquestioning obedience and submission to the sanctioned methods of searching for the sacred as a desirable sign of spiritual maturity. This feature resembles Lifton's (1961) "Demand for Purity," in which members must devote unwavering allegiance to preserving the group's definition of pure living. This involves strong discouragement of members who disagree with or deviate from the definition of purity. The focus on behavioral conformity communicates to group members that their behaviors are more salient than their identities or opinions (VanVonderan \& Johnson). Lifton referred to this as the "Doctrine over Person" tactic, in which an individual's identity is 
subsumed and redefined according to adherence to the group rules. These rules can extend to details of daily living that do not seem to be related to religious or spiritual matters.

Consequently, members of a group exhibiting ARA might suffer from perfectionism, feelings of being overwhelmed, chronic guilt, and excessively high expectations of self and others (VanVonderan \& Johnson).

Power-posturing and focus on performance operate together to generate an atmosphere of misplaced loyalty (VanVonderan \& Johnson, 1991). Dedication (as defined by the leader) to the abusive leader or group becomes synonymous with loyalty to one's faith, religion, or the divine. The leader ensures members' loyalty by instructing them that only their group has correct ideology. The leader might emphasize that leaving the group or disobeying directives is spiritually, and perhaps eternally, dangerous. The message is that disloyalty to the group will result in loss of spiritual standing, harm to oneself or one's family, and disruption or termination of one's connection to the sacred. Thus, failure to live up to loyalty expectations often generates inner personal turmoil and anxiety about one's spirituality. The leader might also publicly apply shame and guilt to punish those who do not demonstrate adequate devotion to the group, even to the point of instructing loyal group members to "disfellowship" disloyal members. In addition, compliance is assured by defining the abusive dynamics and actions as evidence of religious maturity, rendering the practices immune to any objections (Wehr, 2000). Failure to demonstrate compliance can then be interpreted as a sign of weakness or evil. Furthermore, religious devotion is often measured by criteria such as freedom from physical ailments, an absence of negative emotions, or willingness to engage in behaviors even when those behaviors conflict with one's inner experience. If group members exhibit physical illness, emotional distress, or reluctance to behave in a manner that is inconsistent with their conscience, they might be labeled 
as suffering from spiritual weakness, rebellion, demonic influence, or undisclosed sin (Rauch, 2009).

Lifton (1961) indicated that the misplaced loyalty strategy reinforces dichotomous thinking, which strengthens group cohesiveness. The issue of loyalty also seems to support the conclusion that groups exhibiting ARA illustrate another of Lifton's concepts - "Sacred Science." A leader who employs the concept of "Sacred Science" asserts that there are secret or more advanced teachings that group members can achieve through greater devotion to the group. The promise of reaching a rewarding goal - discovering and conserving the sacred - motivates members to comply with the leader's directives (i.e., maintain loyalty). However, a member who disagrees with the leader or group is often viewed as experiencing a personal deficiency or failing to achieve a more mature, advanced religious status. This definition and interpretation of disloyalty serves to decrease opposition, while simultaneously diminishing the member who disagrees and elevating the member who complies. This occurs in the context of a powerful leader who controls access to methods of discovering the sacred. Thus, the leader is in a position to wield significant power by distributing emotional punishments and rewards, including those related to self-esteem, spiritual status, belonging, and social support.

Separate from the challenging prospect of maintaining obedience to the leader's directives, group members must first ascertain the nature of the directives. This is a critical task, for groups exhibiting ARA display a tendency toward rigidity, and their leaders often apply highly subjective performance standards. The leader creates rules that are based on personal opinion, and then reinforces those rules in an inconsistent and extremely inflexible manner. Yet discovering the leader's standards and the group norms is a difficult task within a group exhibiting ARA (VanVonderan \& Johnson, 1991). Many of the rules are never actually 
verbalized; they are left unspoken or are only implied. An individual might not become aware of a rule until he or she unknowingly violates it. At other times, the group member might be instructed to do one thing but expected to do another, placing him or her in an untenable position (Enroth, 1992). When a group member violates a rule - whether spoken or unspoken - the response is often swift and harsh. Leaders may ignore and neglect an individual who does not conform to the group's rules, or the leaders might subject the member to public criticism and rebuke, impugning the member's religious dedication. Lifton (1961) called this approach "Dispensing of Existence," in which individuals who follow the group's teachings are considered worthy of existence and favor, while those who disobey the rules are not. Rauch (2009) noted that, as a result of this dynamic, members of groups exhibiting ARA go to great lengths to avoid eternal damnation, shame, or demotion within the group.

One particularly prevalent and powerful unspoken rule in systems that employ ARA is the "can't talk" rule (VanVonderan \& Johnson, 1991). The "can't talk" rule requires group members to remain silent about problems or inconsistencies within the system. If a group member identifies and draws attention to a flaw in the leader or system, that individual is labeled as the problem and is blamed for any negative consequences. The "can't talk" rule is also an example of a broader deficiency in clear communication. Group members must become proficient at detecting and decoding cryptic messages. In general, the coded communication functions to strip group members of their ability to clearly assess the system, while the "can't talk" rule prevents struggling group members from voicing their difficulties. In fact, group members are likely to interpret their confusion and turmoil as a sign of spiritual deficiency or demonic influence (Enroth, 1992), rather than as a mark of the group's abusive dynamics. A final common characteristic of groups exhibiting ARA is what VanVonderan and 
Johnson (1991) referred to as paranoia. The group leader and members believe that individuals outside the group will not understand that the group is more religiously mature and enlightened. This is again reminiscent of Lifton's (1961) concept of "Sacred Science," or the belief that the group possesses a uniquely enlightened revelation. As a result of this view, the group withholds certain information until an individual makes a commitment to the group and develops the spiritual insight necessary to comprehend its special status. This approach serves to generate a sense of insularity, secrecy, and superiority, making it difficult to leave the group or to obtain assistance from outside individuals and institutions. Thus, group members are confused, anxious, and isolated, all while being convinced that the source of these problems - the leader or the group itself - actually provides the answers that will alleviate the discomfort.

\section{Relevance to Psychology}

Some have argued that the influence of religion and spirituality on psychological wellbeing can be reduced to other psychosocial phenomena (Durkheim, 1915; Freud, 1927/1961; Leuba, 1933) or that religion is antithetical to optimal psychological health (Leuba, 1925; Freud; Skinner, 1953). However, several prominent figures in the history of psychology confirmed the salience of religious experience to psychological theory. William James (2002), Otto Rank (1998), Carl Jung (1933), and Gordon Allport (1950) called for psychology to embrace the study of religious and spiritual phenomena. They argued that religion and spirituality make unique contributions to personality structure and psychological well-being. Research on personality structure supported the conclusion that religious and spiritual factors function as a distinct feature of individual personality (Piedmont, 1999; Piedmont, 2001). This aspect of personality performs a central organizational function, facilitating the hierarchical ordering of personal strivings and providing a sense of coherence, meaning, and personal identity (Allport, 1950; 
Baker, 2003; Emmons, 1986; Emmons, 2005; Emmons, Cheung, \& Tehrani, 1998; Kiesling, Sorell, Montgomery, \& Colwell, 2008; Tillich, 1957).

\section{Spiritual Distress and Spiritual Struggle}

Accounts of ARA have described experiences of spiritual conflict and distress. Western conceptualizations of spirituality do not traditionally incorporate the concept of spiritual pain (Burton, 2003), and most of the literature on the topic encompasses clinical observations based upon work with individuals who are in hospice or are chronically ill (Burton; Millspaugh, 2005a; Millspaugh, 2005b; Morrison, 1992; Satterly, 2001). However, researchers have investigated how religious strain and spiritual struggle are related to psychological distress. Religious strain and spiritual struggle have been linked to a variety of negative psychological and psychosocial outcomes, including panic disorder and agoraphobia, depression, suicidality, anxiety, decreased self-esteem, poorer physical health, anger, paranoid ideation, obsessive-compulsive symptoms, somatization, and disrupted relationships (Bryant \& Astin, 2008; Exline, Yali, \& Lobel, 1999; Exline, Yali, \& Sanderson, 2000; McConnell, Pargament, Ellison, \& Flannelly, 2006; Trenholm, Trent, \& Compton, 1998).

\section{Religious Coping}

Research on religious coping has revealed that particular religious coping strategies are linked to positive outcomes, while others are associated with negative outcomes. These outcomes were not better explained by demographic variables or the social support of a religious community (Ano \& Vasconcelles, 2005; George et al., 2002; Tix \& Frazier, 1998). Negative religious coping involves a variety of attitudes and behaviors, such as self-blame, an insecure relationship with the divine, actions that are motivated by fear of punishment, and the belief that one has been abandoned by the divine or one's religious/spiritual community (Millspaugh, 
2005b; Pargament, Smith, Koenig, \& Perez, 1998; Ryan, Rigby, \& King, 1993). Negative religious coping has been correlated with depression, decreased life satisfaction, decreased quality of life, anxiety, poorer subjective health and problem-solving skills, increased emotional distress, and poorer mental health adjustment among individuals from diverse religious backgrounds (Khan \& Watson, 2006; Pargament, Koenig, \& Perez, 2000; Pargament et al.; Pargament, Tarakeshwar, Ellison, \& Wulff, 2001; Pargament, Zinnbauer, et al., 1998; Rosmarin, Pargament, Krumrei, \& Flannelly, 2009; Tarakeshwar, Pargament, \& Mahoney, 2003; Tix \& Frazier). A review of popular accounts of ARA (Enroth, 1992; Rauch, 2009; VanVonderan \& Johnson, 1991; Wehr, 2000) indicated that environments exhibiting ARA might promote and reinforce religious coping strategies that have been linked to psychological distress.

\section{Research on Post-Cult Adjustment}

Several of the characteristics described in popular accounts of ARA (Enroth, 1992; VanVonderan \& Johnson, 1991) resemble conceptualizations of cultic groups (Chambers, Langone, Dole, \& Grice, 1994; Dubrow-Eichel, 2002; Walsh, 2001). Groups exhibiting ARA might constitute a more mainstream and less extreme manifestation of the characteristics observed in cultic groups. In fact, popular accounts of the effects of ARA (Enroth; Rauch, 2009; VanVonderan \& Johnson; Wehr, 2000) resemble reports of psychological distress in former cult members. These adverse psychological symptoms included guilt, anxiety, fear, dissociation, intrusive thoughts, and difficulty trusting authority figures (Aronoff, Lynn, \& Malinoski, 2000; Ash, 1985; Buxant \& Saroglou, 2008; Dubrow-Eichel, 2002; Gaines, Wilson, Redican, \& Baffi, 1984; Malinoski, Langone, \& Lynn, 1999; Martin, Langone, Dole, \& Wiltrout, 1992; Swartling, 1992; Winocur, Whitney, Sorensen, Vaughn, \& Foy, 1997). Clinical accounts suggest that these symptoms are sufficiently distressing to prompt some former cult members to seek professional 
mental health services (Goldberg \& Goldberg, 1982; Goldberg, 2006; Lottick, 2008). Although Aronoff et al. concluded that former cult members did appear to manifest legitimate symptoms of psychological distress, they noted that the research on post-cult adjustment suffered from several significant definitional and methodological problems.

\section{Clergy Perpetrated Sexual Abuse}

Theological and psychological discussions of clergy-perpetrated sexual abuse (CPSA) have generated the assertion that sexual trauma perpetrated by a member of the clergy is compounded by religious trauma (Benkert \& Doyle, 2009; Doyle, 2009; Flynn, 2008; Francis \& Turner, 1995; Mart, 2004; Rossetti, 1995). The religious dimension of CPSA appears to magnify the psychological damage caused by the sexual assault, in addition to inflicting unique trauma of its own (Doyle). Two primary factors have been implicated in the distinct impact of the religious dimension - a heightened power differential (Francis \& Turner, 1995) and intense cognitive dissonance (Doyle; Festinger, 1957). Two quantitative studies on the effects of CPSA revealed that sexual trauma perpetrated by a member of the clergy is correlated with greater difficulty in one's relationship with God, impaired ability to participate in religious services or spiritual expressions, and difficulty trusting clergy (McLaughlin, 1994; Rossetti, 1995). Qualitative studies on the effects of CPSA suggested that survivors experienced a variety of negative emotions, difficulties with spiritual expression and resolution of spiritual problems, poor selfconcept, symptoms consistent with PTSD, somatization and eating disorders, impaired relationship skills, and confusion (Flynn, 2008; Isely et al., 2008; Mart, 2004). However, both the quantitative and qualitative studies suffered from problems with validity and reliability, and the studies sampled primarily Caucasian and Christian populations. 


\section{Literature Related to Abuse of Religious Authority}

The popular literature on ARA and the limited amount of empirical research on the topic both suffer from the lack of a consistent definition (Cudmore, 2002; Dehan \& Levi, 2009;

Enroth, 1992; Gubi \& Jacobs, 2009; Masis, 2004; Orlowski, 2010; Rauch, 2009; VanVonderan \& Johnson, 1991; Wehr, 2000). The professional literature that does exist either did not employ rigorous research methodology, failed to investigate the specific nature of ARA, or restricted samples in ways that limited generalizability. At the same time, the results revealed that individuals who experienced authoritarian and coercive religious communities reported a variety of negative outcomes. These outcomes included emotional strain caused by cognitive dissonance; difficulty trusting others or engaging in religious and spiritual practices; loss of faith, meaning, and a critical source of valued social support; intense negative emotions and confusion; and episodic self-blame and poor self-image (Cudmore; Masis; Orlowski). Combined with the research on personality and personal strivings, religious strain, negative religious coping, postcult psychological adjustment, and the effects of CPSA, the preliminary research on ARA supports the necessity of gaining a more detailed understanding of this unique type of trauma. 


\section{Chapter 2}

\section{Literature Review}

\section{Relevance to Psychology}

The question emerges of the relevance of religious and spiritual experiences - beneficial or adverse - to the study of psychology. It could be argued that research on ARA is more appropriately conducted by theologians and religious leaders than by psychological researchers. However, William James (2002) commented that, "To the psychologist the religious propensities of man must be at least as interesting as any other of the facts pertaining to his mental constitution" (p. 8). Otto Rank (1998) wrote that the soul is the object of psychology, although the inability to scientifically validate and describe the soul has often led to the assertion within psychology that the soul does not exist. Rank asserted that modern psychology indirectly acknowledges the existence of the soul through its efforts to comprehend the soul. Jung (1933) called for collaboration between clergy and psychotherapists, maintaining the insufficiency of a psychological theory that focused only on materialistic conceptualizations of human experience. He stated that individuals possess spiritual needs that must be addressed, for psychological disturbance could result from problems with one's religious perspective on life. Gordon Allport (1950) echoed the call for a détente between religion and the science of psychology in order to accomplish the mutual goal of understanding and improving human character. He observed that religion is relevant to psychology because religion is a nearly universal interest. Furthermore, he stated that the nature of individual temperament dictates desires, values, and the pursuit of meaning, which constitute subjective religious experience.

If religion and spirituality are relevant to the study of psychology, the next critical question is whether ARA is tantamount to psychological abuse. If ARA is solely a manifestation 
of psychological abuse, there is little to recommend the pursuit of research on ARA as a discrete topic. Yet religion could theoretically function as a unique psychological process due to its discrete substance and function in relation to the sacred. No other psychological process emphasizes the sacred, and non-religious social institutions do not function to explicitly promote the search for the sacred (Pargament, 2002). In fact, there is evidence to suggest that religious and spiritual experience represent a distinct psychological construct and that this construct is uniquely associated with indicators of mental health and psychological distress.

Spiritual transcendence as a personality feature. Piedmont (1999) noted that although spirituality is universal to human experience, there was a lack of clarity as to whether spirituality constituted a unique and separate facet of personality. He developed a scale that was designed to measure the construct of spiritual transcendence, which was conceptualized as including components such as connectedness, universality, prayer fulfillment, and existentiality. Piedmont then analyzed the results of his spiritual transcendence scale with responses to the NEO Personality Inventory - Revised (NEO PI-R), an instrument that measures the Five Factor model of personality. He also analyzed the results of his spiritual transcendence scale with responses to other established measures of interpersonal orientation, mental health, social support, and faith maturity.

After administration of the measures to two samples of undergraduate students, three of the spiritual transcendence subscales were significantly, though weakly, correlated with NEO PIR subscales. Piedmont argued that this correlation suggested that spiritual transcendence was similar to recognized facets of personality. In addition, combined factor analyses revealed that the spiritual transcendence subscale items aligned on a factor that was independent of the NEO PI-R subscale items. Hierarchical regression analyses demonstrated that the spiritual 
transcendence scale significantly increased predictive power beyond the NEO PI-R responses for the criterion variables of self-reported attitudes toward abortion, internal health locus of control, vulnerability to stress, perceived social support, interpersonal orientation, sexual attitudes, and prosocial behavior. Furthermore, the spiritual transcendence scale explained a statistically significant amount of variance beyond the NEO PI-R with respect to observers' ratings of participants' positive affect. On the basis of the findings from factor analysis and hierarchical regression, Piedmont concluded that spiritual transcendence was a distinct construct and was not better explained by the Five Factor model of personality.

Piedmont (2001) obtained similar results when he administered the Spiritual Transcendence Scale to 322 undergraduate students. In addition to completing self-report measures, including the NEO PI-R, the participants were instructed to also ask two close acquaintances to rate them using some of the same measures. The result of principal components factor analysis with orthogonal and oblique rotations demonstrated that items from Piedmont's Spiritual Transcendence Scale loaded on a separate factor than items from the NEO PI-R. Piedmont argued that these results lent further support to the theory that spirituality operates as a unique personality factor. Moreover, hierarchical multiple regression analysis revealed that scores on the Spiritual Transcendence Scale added significant explanatory power beyond NEO PI-R scores on self-rated measures of self-actualization, life purpose, and prosocial behavior. Scores from the Spiritual Transcendence Scale also added significant explanatory power beyond NEO PI-R scores on observer-rated measures of positive affect, affective balance, and life satisfaction. On the basis of this data, Piedmont concluded that spirituality represented a unique dimension in the study of individual differences. He proposed that it was possible to obtain a more complete perspective of individual functioning if information about spiritual transcendence 
were combined with data about other dimensions of personality.

Both of Piedmont's $(1999,2001)$ studies suffered from limitations, including crosssectional designs, overrepresentation of females in the samples, and homogeneity among the participants with respect to age, socioeconomic status, and religious orientation (Christian). However, Piedmont (1999) claimed that spirituality functioned in a manner that made it comparable to the personality factors of the Five Factor personality model. As a result, research on spirituality would represent a distinct endeavor that could not be undertaken solely through research of non-spiritual personological factors. Research by Emmons and colleagues (Emmons, 1986; Emmons, 2005; Emmons et al., 1998; Emmons \& King, 1988) appeared to support this inference.

Spirituality and personal strivings. Emmons, Cheung, and Tehrani (1998) conducted research based on the theory that personal priorities and goals determine subjective well-being. They advanced the idea that personality is organized as a process of goal achievement in which the goals are referred to as personal strivings (Emmons, 1986). Personal strivings are recurring goals that are based on enduring concerns; they orient an individual's choices and behaviors. They tend to be less focused on a specific end-state and emphasize attempts to achieve continuous attainment of a set of goals. For example, the goal of being more assertive in interpersonal relationships is a personal striving. Personal strivings provide meaning, since they are the fulcrum on which the individual balances effort and action. These strivings are associated with emotion and affect, and they interact reciprocally with the individual's social environment. In addition, personal strivings provide organization, integration, motivation, meaning, and a sense of a future self (Emmons; Emmons et al., 1998).

Spirituality qualifies as a type of personal striving in which the central defining 
characteristic is an emphasis on transcendence - an attempt to transcend the self and unite with a larger or higher power (Emmons et al., 1998). Emmons' (1986; 2005) construct of spiritual strivings resembled Pargament's (1999) definitions of religion and spirituality, in the sense that spiritual strivings represent goal-driven attempts to establish a relationship with the sacred (Pargament, 2002). In this sense, the personal striving of spirituality operates as an "ultimate concern" (Tillich, 1957). Proposed by Tillich, an ultimate concern is one that requires complete surrender and, in exchange, promises total fulfillment. Individuals invest significant time, effort, and personal resources in the pursuit of an ultimate concern. Emmons et al. argued that individuals invest maximum effort in spirituality and that spirituality wields the power to require relinquishment of personal will and to function as an anchor for individuals' lives. Therefore, as an ultimate concern, spirituality necessarily involves an individual's entire personality. For this reason spirituality is highly relevant to psychological research related to personality, psychological adjustment, and subjective well-being. In that vein, Emmons et al. reported results from an unpublished study in which spiritual strivings were associated with higher levels of subjective well-being in the areas of life purpose and life satisfaction, even after controlling for other variables such as attendance at religious services. Spiritual strivings also displayed a stronger correlation with subjective well-being than did non-spiritual strivings, such as intimacy and power. Finally, although spiritual strivings were rated as more important and requiring more effort than non-spiritual strivings, spiritual strivings were also associated with less ambivalence and a greater sense of meaning.

Emmons (2005) also stated that spiritual strivings hold particular importance as a result of their unique function within the organizational structure of personal strivings. They provide the framework to integrate and unify all other personal strivings, in addition to supplying a sense 
of purpose and meaning in life. Religion and spirituality have also been described as functioning to integrate personal experience into a cohesive whole, provide a sense of security, center an individual's life, and infuse meaning into all other aspects of experience (Allport, 1950; Baker, 2003; Piedmont, 1999; Tillich, 1957). An understanding of and relationship with the sacred also forms an integral part of personal identity and one's sense of self (Kiesling, Sorell, Montgomery, \& Colwell, 2008). Furthermore, religion has been described as the means through which individuals meet basic needs, such as managing pleasure and pain, developing a coherent conceptual system, establishing interpersonal relatedness, and building self-esteem (Hill \& Hood, 1999). These processes may be the mechanisms through which spirituality exerts a powerful impact on motivation, behavior, and well-being (Emmons et al., 1998). For example, meaningfulness has important relationships with positive psychological outcomes, as Melton and Schulenberg (2008) noted in a review of the literature related to individuals' sense of meaningfulness and psychosocial well-being. Meaningfulness was related to a variety of indicators of well-being, including greater emotional stability, positive attitudes toward life, lower anxiety and depression, and higher subjective ratings of happiness.

Thus, research on the constructs of spiritual transcendence and spiritual strivings provided evidence that spirituality is significantly and independently related to a variety of selfactualization, life purpose, prosocial behavior, positive affect, affective balance, and life satisfaction issues. Theoretical formulations of spirituality suggest that distress that is generated by spiritual stress or mistreatment will involve a disruption in an individual's sense of meaning, as well as in their developmentally foundational core of self-identity. As a result, spirituality has been conceptualized as playing a distinct role in psychological functioning. Consequently, exploitation of an individual's attempts to connect with the sacred and to develop a sense of 
spiritual meaning would have important psychological implications.

\section{Spiritual Distress and Spiritual Struggle}

The relationship among religion, mortality, and psychological well-being has traditionally received much research attention. Most recently this has included an emphasis on exploring the concept of spiritual distress. Anecdotal and popular descriptions of individuals who identify as experiencing ARA often reference distress that is specifically linked to spiritual struggle (Enroth, 1992; Rauch, 2009; Wehr, 2000; VanVonderan \& Johnson, 1991). Spiritual struggles have been defined as "efforts to conserve or transform spirituality that has been threatened or harmed" (Pargament, Murray-Swank, Magyar, \& Ano, 2005, p. 247). There are three types of spiritual struggles - interpersonal, intrapersonal, and divine. Interpersonal struggles involve conflict or disagreement with other individuals in one's social support system or faith community. Intrapersonal struggles involve the experience of doubt or uncertainty about one's spiritual beliefs. Divine struggles encompass disruption or conflict that is experienced in one's relationship with the divine. Popular accounts of ARA suggest that individuals might experience one or all of these types of spiritual struggle, often while suffering public or private shame for experiencing such struggles. Since individuals who report spiritual struggle also report a higher level of anxiety and negative emotion (Ano \& Vasconcelles, 2005), it is important to investigate the specific experiences of individuals whose spiritual struggles are precipitated by traumatic religious events.

Spiritual pain. The term "spiritual pain" has also been used to describe what individuals sometimes experience in relation to spiritual struggles. The lack of literature on this construct might reflect the impact of cultural influences on research agendas, for the idea of spiritual pain tends to receive more attention in Eastern religious and spiritual traditions (Burton, 2003). In the 
United States, the concept of spiritual pain gained prominence with the hospice movement and care of those who are chronically ill (Morrison, 1992). Although challenging to define, spiritual pain has been described as an experience in which a core part of an individual is destroyed, resulting in meaninglessness (Morrison, 1992). This can occur as a result of suffering (Millspaugh, 2005a); spiritual abuse (Burton); a substantial threat toward or failure to meet important spiritual needs such as love, faith, hope, virtue, and beauty (Bartel, 2004); or a discrepancy between an individual's perspective of his or her spiritual life and his or her daily experience (Burton). An associated definition describes spiritual pain as a response to disruption or damage in the relationship between an individual and the source of that individual's life (Satterly, 2001). If maintenance of a relationship with the divine holds primary importance, disruption of this relationship might contribute to beliefs that one is unlovable and shameful. The related concept of religious pain has been defined as guilt related to a perceived violation of religious codes or values, as well as to the belief that one has disappointed God (Satterly). This type of pain is highly individualized, although it commonly involves emotions such as guilt and fear.

In addition to weathering the distress associated with the precipitating event(s), individuals who are in spiritual pain must navigate the anguish of a shattered worldview and the disorientation of a disrupted source of meaning (Morrison, 1992). Therefore, spiritual pain is often multifaceted and can affect an individual spiritually, physically, emotionally, and psychologically. This impact includes emotional responses such as grief, anger, guilt, shame, doubt, despair, fear, helplessness, and fatigue (Bartel, 2004; Burton, 2003). Millspaugh (2005a) theorized that spiritual pain is composed of several dynamic and interactive components. He proposed an equation in which spiritual pain is represented by the following relationships: 
(Awareness of death + Loss of Relationships + Loss of Self)(Loss of Purpose + Loss of Control) Life Affirming and Transcending Purpose + Internal Sense of Control

Millspaugh stated that spirituality is a state of being, and, since being is defined by relationship, spirituality is relational. Therefore, the equation is not mathematical; rather, it defines the relationships among its components. This concept of spirituality is consistent with Pargament's description of spirituality as a search for the sacred in which individuals seek to discover the sacred and conserve a relationship to the divine (Pargament, Magyar, Benore, \& Mahoney, 2005; Pargament, Murray-Swank, \& Mahoney, 2008).

Millspaugh's (2005a) discussion of the equation's components resembles Yalom's (1980) psychodynamic theory of existential psychotherapy, suggesting that the concept of spiritual pain is of psychological value. Millspaugh argued that spiritual pain is connected to the awareness of death and the threat of non-being. Yalom also identified this threat - which he termed death anxiety - as a critical determinant of psychological distress and symptomatology. A related concept in Millspaugh's model is the loss of self, in which an individual loses a sense of identity or discovers that he or she has been operating with a false self. Abandonment of portions of selfidentity leads to excessive guilt, manipulative anger, and self-abusive behaviors. This concurred with Yalom's description of the failure to live authentically as a sin against the self, which could generate intense feelings of guilt and anxiety. In addition, Millspaugh's model suggested that loss of relationships with others, including that which is considered holy, contributes to spiritual pain. Yalom also described the difficulties and psychological suffering associated with an inability to resolve the basic condition of isolation in the world. In Millspaugh's model, the awareness of death, loss of self, and loss of relationships inevitably lead to a loss of meaning and control. This paralyzes the individual by compounding the extant spiritual pain and suppressing any desire to confront the pain. Yalom also provided a detailed discussion of the essential 
function of meaning in human experience, without which individuals suffer from increased psychopathology, helplessness, and lack of direction.

Religious strain and spiritual distress. The results of a phenomenological study of spiritual distress (Smucker, 1996) corroborated features of Millspaugh's (2005a) model of spiritual pain. Ten participants (five males and five females) who had experienced concern about the meaning of life, death, and/or beliefs were interviewed. The interviews were then analyzed utilizing a phenomenological approach. The results of the analysis suggested two distinct stages of spiritual distress. During the first stage, participants experienced a sudden or unexpected event that disrupted the cohesiveness of their life. Two of the primary features of this stage included emotional distress (such as feelings of pain, anxiety, fear, and disconnection) and a struggle to comprehend the experience. After the initially painful emotional and spiritual disruption, most participants described gradual recovery that included positive spiritual growth and rediscovery of meaning. Thus, the results appeared to be consistent with at least part of Millspaugh's model in that some individuals who suffer from spiritual distress may experience adverse psychological sequalae that are linked to a loss of purpose, control, and relationships. However, only one participant reported that the precipitating event involved a distressing religious encounter, limiting generalizability to individuals who identify as having experienced ARA. Moreover, the author did not provide information on how participants were identified or recruited, or the nature of their existential concerns. Therefore, it was unclear whether individuals who identified as having experienced ARA would report psychological distress of a similar nature, duration, and intensity.

At the same time, there is research evidence to suggest that certain types of religious strain are associated with psychological distress. One study investigated whether cognitive 
conflicts that result in feelings of guilt and fear of punishment operate as a factor in panic disorder (Trenholm, Trent, \& Compton, 1998). Sixty female participants were recruited for inclusion in one of three groups. The first group included females who were diagnosed with panic disorder and agoraphobia. The second group included females who were receiving psychotherapy for concerns other than panic disorder and agoraphobia, and the third group consisted of females who resided in the community and were not receiving psychotherapy. Participants who were diagnosed with panic disorder and agoraphobia reported significantly higher scores on a measure of negative religious conflict. However, the other two groups did not differ significantly from each other with respect to negative religious conflict. Discriminant function analysis demonstrated that negative religious conflict significantly distinguished participants with panic disorder and agoraphobia from the other two groups.

Trenholm et al. (1998) hypothesized that cognitions associated with negative religious conflict were also related to panic disorder. Specifically, these cognitions appeared to contribute to tendencies toward anxiety that was driven by a need for approval and fear of punishment. The authors suggested that such anxiety-provoking cognitions might be related to religious conflict stemming from a fear of inescapable punishment for transgressions. The authors ventured that this anxiety - whether consciously perceived or not - was sufficient to trigger the physiological symptoms of a panic attack. These conclusions are particularly relevant to ARA, given the rigid demands and high performance standards often attributed to groups that engage in ARA.

More recently, Exline, Yali, and Sanderson (2000) argued that aspects of religious life can lead to strain. They stated that views of a non-benevolent God, religious disagreement or rejection, and religiously motivated hopelessness or self-criticism could all contribute to depression or other negative emotions. Exline et al. investigated whether religious strain was 
associated with psychological distress, even if an individual generally experiences religion in a positive manner. In the first stage of the study, 200 undergraduate students of various religious and racial/ethnic backgrounds completed a scale of religious strain that was comprised of subscales measuring religious comfort, alienation from God, fear and guilt, and religious disagreements. Participants also completed a measure of religiosity and items from the Beck Depression Inventory. Religious strain was significantly positively correlated with depression, even after statistically controlling for self-reported religiosity and the degree of comfort derived from religion. However, the nature of the study did not lend itself to determining causality. Still, religious strain appeared to be uniquely associated with a measure of psychological distress. The results suggested the necessity of constructing empirically testable models of the etiology and resolution of religious strain (Exline, 2002), including that which originates from ARA.

In the second stage of the same study, Exline et al. (2000) recruited 54 adult participants who had sought mental health treatment. The participants were older than those in the previous sample, with a mean age of 40. Participants were primarily Latino/Hispanic and Caucasian/European-American, and the vast majority reported a Judeo-Christian religious background. Participants completed a religious strain scale, an abbreviated questionnaire about religiosity, and the Beck Depression Inventory. Religious strain was again significantly positively correlated with depression, even after statistically controlling for self-reported religiosity and religious comfort. In particular, alienation from God was most predictive of depression scores. Furthermore, religious strain was significantly positively correlated with suicidality after controlling for self-reported religiosity and religious comfort. Religious fear and guilt were the most predictive of suicidality, primarily due to the association between suicidality 
and the belief that one had committed a sin too big to be forgiven. Given the similar findings between two demographically and clinically distinct samples, the authors concluded that religious strain is associated with and can be a sign of psychological distress, in spite of whether religion functions as a source of comfort or is experienced positively. However, the nonexperimental, cross-sectional design of the study precluded an inference about whether religious strain causes psychological distress or vice versa.

At the same time, Exline et al.'s (2000) findings with respect to religious strain and psychological distress corroborated the results of an earlier study by Exline, Yali, and Lobel (1999). In an effort to explore the relationship among difficulty forgiving God, depressed mood, and anxiety, Exline et al. (1999) administered several measures to 200 undergraduate students of diverse racial/ethnic and faith backgrounds. Alienation from God was significantly positively correlated with depressive symptoms. Difficulty forgiving God was significantly positively correlated with anxiety, depressive symptoms, anger, and problems forgiving self and others. In addition, alienation from God partially mediated the relationship between difficulty forgiving God and depressed mood. However, the authors did not provide evidence for the validity of items that were developed to measure alienation from God and difficulty forgiving God. Furthermore, item responses did not demonstrate strong reliability, with Cronbach's alphas ranging from .67 to .77 for various measures. This problem was compounded by the fact that only a small subset of participants reported difficulty forgiving God, reducing the sample size for statistical analyses involving that variable. Nevertheless, Exline et al. (1999) concluded that alienation from God and difficulty forgiving God represented problems that could not be accounted for by general difficulties with forgiveness. These problems were also uniquely associated with the psychological symptoms of depressed mood and anxiety, although causal 
inferences could not be drawn due to the cross-sectional nature of the study.

Although preliminary research suggested a unique association between spiritual/religious strain and psychological distress, the studies suffered from insufficient sample size or unrepresentative samples. Two studies with college students appeared to address this gap in the literature. Citing a lack of research with individuals who have religious/spiritual concerns and who seek mental health assistance, Johnson and Hayes (2003) investigated the predictors of religious/spiritual concerns among college students at college counseling centers. The study utilized data from a nationally representative sample of 5,472 students who participated in the Research Consortium of Counseling and Psychological Services in Higher Education. Although the research was limited by the use of archival data, the results indicated that $26 \%$ of the sample experienced moderate to extreme distress related to religious/spiritual concerns. These students also reported statistically significantly more difficulty with disrupted relationships, suicidal ideation, and confusion about beliefs and values.

Bryant and Astin (2008) also investigated the relationship between spiritual struggle (defined as "intrapsychic concerns about matters of faith, purpose, and meaning in life" (p. 12)) and psychological functioning. Drawing upon two national, representative samples of college students, the results of regression analyses indicated that spiritual struggle was significantly associated with increased psychological distress, poorer physical health, decreased self-esteem and self-confidence, and less self-perceived spiritual growth. In spite of the advantage of large sample sizes, the studies by Johnson and Hayes (2003) and Bryant and Astin failed to specify the nature of college students' reported religious/spiritual concerns. Therefore, although the results supported earlier findings that religious/spiritual strain is correlated with psychological distress, the authors were unable to distinguish whether the nature of the psychological distress differed 
for normative religious/spiritual concerns as opposed to traumatic religious/spiritual experiences.

Finally, McConnell, Pargament, Ellison, and Flannelly (2006) also noted a link between spiritual struggles and psychopathology. Their analysis of the literature led them to conclude that spiritual struggles are frequently associated with psychological distress, particularly given the research on the co-occurrence of spiritual struggles, depression, and anxiety. For their research, they recruited a national convenience sample of 1,629 participants and administered measures of mental health, spiritual struggle, social support, and life stressors. The sample was predominantly composed of Caucasian participants, but it included individuals from a variety of religious/spiritual traditions. In this sample, spiritual struggles were associated with significantly higher levels of psychological distress after statistically controlling for demographic and religious variables. Spiritual struggles were not only related to greater anxiety and depression; they were also linked to greater paranoid ideation, obsessive-compulsiveness, and somatization. Therefore, spiritual struggles appeared to be associated with a variety of indicators of psychological distress.

In summary, recent research and theory have highlighted the importance of attending to the way in which spiritual struggles are associated with psychological distress. Individuals who experience spiritual struggles that involve interpersonal, intrapersonal, or divine conflict report a range of psychological symptoms. These symptoms include anxiety, depressed mood, panic attacks, obsessive-compulsiveness, paranoid ideation, and somatic complaints. Although these findings have been correlational in nature, the results suggested that exploration of spiritual struggles is a critical component of understanding psychological well-being. However, the psychological research on spiritual struggle has not specifically explored how psychological functioning is affected in an exploitative or traumatic religious/spiritual context. Furthermore, it 
is necessary to move beyond broad conceptualizations of religious/spiritual experience that obscure the nuanced details of how individuals implement and are affected by their religious/spiritual beliefs (McConnell et al., 2006). Global measures of religion/spirituality, such as attendance at religious services or frequency of prayer, will be inadequate in the effort to understand the relationship between religion/spirituality and psychological functioning. Therefore, it is essential to conduct specific inquiry into the variety of religious/spiritual experiences.

\section{Religious Coping}

The topic of religious coping emerged in response to the call for more multifaceted research on religious/spiritual processes (McConnell et al., 2006; Pargament, 2002). The literature on religious coping revealed that particular religious/spiritual coping strategies were linked to positive outcomes, while others were associated with negative outcomes. Negative forms of religious coping can be especially distressing given the power that religion/spirituality possesses to dictate ultimate and unalterable truth about existence (Pargament, Magyar-Russell, \& Murray-Swank, 2005). Popular accounts of ARA suggested that individuals who identify as abused might implement religious coping strategies that have been linked to poorer psychological outcomes. This reinforces the importance of conducting research about the environmental factors, motivations, processes, cognitions, and affective experiences associated with how individuals experience and cope with ARA.

Longitudinal research initially supported the relationship between religious coping and psychosocial outcomes. Tix and Frazier (1998) conducted a study that examined religious coping, life satisfaction, locus of control, and psychological distress. Participants included individuals who underwent renal transplant surgery and the one person who was closest to the 
patient at the time of the procedure. All participants completed measures three months postsurgery. Those patients who were living one year post-surgery completed the measures a second time. At both administrations, religious coping was significantly correlated with greater life satisfaction for Protestant participants and decreased distress for their significant others. The relationship between religious coping and life satisfaction was maintained after statistically controlling for the potential mediators of cognitive restructuring and internal locus of control. However, these results were not replicated with Catholic participants in the sample, suggesting that psychosocial outcomes might depend on a combination of contextual factors, religious/spiritual beliefs, and the type of religious coping implemented. In addition, the sample was comprised of predominantly Caucasian, Christian individuals who had undergone a significant medical procedure. Still, the results suggested that religious coping explained unique variance in patient life satisfaction and in the distress of significant others.

However, religious coping is a multidimensional process that can involve several strategies (Pargament, Smith, Koenig, \& Perez, 1998). It is defined in terms of the security of one's relationship with the divine. Positive religious coping generates and reflects maintenance of a secure relationship with the divine, while negative religious coping generates and reflects an insecure or conflicted relationship with the divine. In contrast to positive religious coping, negative religious coping involves "a less secure relationship with God, a tenuous and ominous view of the world, and a religious struggle in the search for significance" (Pargament et al., p. 712). This definition is consonant with other descriptions of coping with spiritual pain and religious guilt (Millspaugh, 2005b; Ryan, Rigby, \& King, 1993). Examples of negative methods of coping with spiritual pain include blaming oneself for displeasing God, framing the suffering as a spiritual attack, dissociating from the pain and negative affect (Millspaugh), and exhibiting 
certain behaviors out of apprehension or fear of punishment (Ryan et al.).

Problems in religious coping can also result from incompatibility between an individual's goals and the means employed to achieve those goals. It is possible for coping strategies to reflect problematic goals, problematic methods of goal attainment, or conflict between an individual and his or her religious system (Pargament, Zinnbauer, et al., 1998). Problematic goals can include excessive focus on one's own concerns or on concerns dictated by others. Problematic methods of goal attainment can include behaviors that are not compatible with the goals one is attempting to reach or with one's life situation. For example, an individual might adopt inaccurate perceptions about a situation based on religious beliefs, to the exclusion of alternate explanations or needs (Pargament et al.). This type of conflict among spiritual goals or between spiritual strivings and other personal strivings has been associated with negative affect, depression, anxiety, and somatic complaints (Emmons \& King, 1988). Finally, an individual's typical or preferred goals and methods of religious coping might conflict with the standards and prescriptions of his or her religious system.

Religious coping is also related to religious problem-solving style, since an individual's approach to solving problems typically involves a series of coping strategies (Pargament, Smith, et al., 1998). Three primary religious coping styles have been defined-self-directing, deferring, and collaborative. Individuals with a self-directing style tend to view themselves as solely responsible for solving the problem, and they are actively oriented toward finding a solution. Individuals with a deferring style perceive the divine being to be responsible for solving the problem, and these individuals adopt a passive orientation toward resolving the problem. Thus, individuals with the deferring style tend to rely more on rules and external authority. Individuals with a collaborative style tend to view problem-solving as a joint responsibility between 
themselves and the divine being. Thus, the collaborative style is characterized by a jointly active stance toward finding a solution, and individuals with this style tend to rely more on an internal relationship with the divine being (Pargament et al., 1988). VanVonderan and Johnson's (1991) description of groups that engage in ARA appeared to indicate that such groups might reinforce a deferring style of religious problem-solving, placing emphasis on adherence to all group rules as the pathway to maintaining a relationship with the divine. If the group encourages the use of negative religious coping, individuals within the group might be restricted to a limited coping repertoire that has been consistently associated with poorer psychological outcomes.

Positive and negative religious coping. In a multi-sample study that explored the relationship between positive and negative religious coping and health-related outcomes, 296 church attendees in Oklahoma City were administered measures of religious coping (RCOPE) and psychosocial adjustment after the bombing of the federal building (Pargament, Smith, et al., 1998). A separate sample of 540 college students who experienced a serious negative event in the previous three years completed the RCOPE, as well as measures of religious outcomes and physical and mental health. Finally, a sample of 551 general medical patients over the age of 55 completed a modified version of the RCOPE. In all three samples, factor analysis of the RCOPE revealed that positive and negative religious coping emerged as separate constructs. Positive religious coping included strategies such as seeking collaboration with God, strengthening one's relationship to God, and pursuing forgiveness or relief from anxiety. Negative religious coping included thoughts that one was being abandoned or punished by God, questioning God's love and power, demonic interpretation of the stressful event, and doubt about whether one had been abandoned by one's church.

The results for the Oklahoma City sample revealed that positive religious coping was 
significantly positively correlated with stress-related growth and positive religious outcomes (Pargament, Smith, et al., 1998). Negative religious coping was significantly correlated with increased PTSD symptoms. However, this latter correlation was of weak to moderate strength. In the college student sample, negative religious coping was also significantly, though weakly, associated with greater emotional distress, decreased physical health, and increased psychosomatic symptoms. Finally, in the hospital sample, negative religious coping was significantly correlated to decreased subjective health, increased depression, and decreased quality of life. Thus, individuals who experienced a variety of life stressors appeared to exhibit similar patterns of religious coping (positive or negative). Moreover, the most robust associations were observed between religious coping patterns and mental health outcomes. Specifically, negative religious coping was significantly correlated with poorer mental health outcomes. The cross-sectional nature of the study precluded inferences about the casual relationship between religious coping and mental health, and the homogeneity of the samples with respect to ethnicity (Caucasian) and socioeconomic status (middle-class) raised questions about the generalizability of the findings. However, the results were consistent across three separate samples in which participants encountered diverse life stressors.

These results were replicated in another multi-sample study that sought to identify indicators of problematic religious coping in response to crisis situations (Pargament, Zinnbauer, et al., 1998). The first sample was composed of 49 adults from a Roman Catholic church who had experienced a major negative life event in the previous few years. These participants were predominantly Caucasian females with a mean age of 50. The second sample was composed of 196 undergraduate students who had either experienced the death of a family member or friend, or who had experienced a personal injustice. The college student sample was also predominantly 
Caucasian, female, and of Judeo-Christian religious backgrounds, with a mean age of 20. All participants completed religious coping scales, measures of negative event outcome, and inventories of psychosocial outcomes. For both samples, the belief that the stressful life event was a punishment from God was significantly correlated with greater negative mood. Results from the church sample revealed the following significant correlations: anger at God was related to poorer mental health and event outcomes; religious doubts were related to increased anxiety, poorer event outcome, poorer problem-solving skills, and increased negative mood; conflict with church doctrine was related to decreased self-esteem, less spiritual growth, and increased alienation from God and the church. Results from the college students who had experienced the death of a family member revealed the following significant correlations: anger at God was related to poorer mental health and event outcomes; religious doubts were related to poorer event outcomes, religious outcomes, and problem-solving, as well as increased negative mood; and interpersonal religious conflict was related to poorer problem-solving and negative mood.

The authors (Pargament, Zinnbauer, et al., 1998) observed that the dimensions of coping that seemed to be the most problematic included those that involved one of the three types of spiritual struggle that were outlined by Pargament, Murray-Swank, et al. (2005). Specifically, these dimensions included anger toward God for culpability in the negative event; disagreement or conflict with family, friends, or congregation within a religious context; uncertainty about one's beliefs or God's existence; disagreement or conflict with clergy or the church about how to interpret and respond to the stressful event; and the perception that one was responsible for the negative event or that the event occurred was punishment for wrong behavior (Pargament, Zinnbauer, et al.). These dimensions of coping also typified the strategies that have been described in popular accounts of ARA (Enroth, 1992; Rauch, 2009; VanVonderan \& Johnson, 
1991; Wehr, 2000). At the same time, the authors acknowledged the limitations of the study, including its cross-sectional design and the uncertainty about whether the religious coping strategies reported by participants were employed on a long-term or short-term basis (Pargament, Zinnbauer, et al.).

Building on this knowledge base, researchers attempted to identify which specific clusters of religious coping methods appeared to represent positive and negative coping styles (Pargament, Koenig, \& Perez, 2000). A comprehensive measure of religious coping (RCOPE) was developed and validated with a sample of 540 college students who had experienced a negative or stressful event. The participants were predominantly Caucasian, Christian, and female. Results indicated that religious coping scores explained significant unique variance in measures of adjustment beyond demographic variables and global religiousness. Poorer mental health adjustment was significantly correlated with greater use of coping strategies that involved questioning God's power, doubt or uncertainty about God's love, questioning whether one had been abandoned by God, and redefining the stressor as punishment from God for sins. Greater emotional distress at the time of the event was significantly correlated with pleading for a miracle and questioning God's power. At the time of the study, greater emotional distress was related to the above-listed coping strategies, as well as to the experience of disagreement and dissatisfaction with, or rejection and abandonment by, clergy or the church. Overall, these negative forms of religious coping appeared to be associated with a variety of adverse emotional and physical adjustment outcomes beyond what could be explained by demographic variables or global religiousness alone.

Additional data suggested that the degree to which religion was salient to an individual's identity functioned as a moderating variable in the relationship between religious coping and 
psychological well-being (Pargament et al., 2001). Three nationally representative samples from the Presbyterian Church, USA, were obtained; 735 members and 823 elders were selected through the use of proportional sampling, and 1,260 clergy were selected using random sampling. Once again, negative religious coping methods predicted significant amounts of unique variance in depressive affect, even after statistically controlling for the effects of demographic variables, global religiousness, and the presence of a recent stressor. Furthermore, the interaction of religious coping and role (salience of religion to identity) significantly predicted depressive affect after statistically controlling for several variables. Overall, the utilization of negative religious coping (i.e., believing that one was being punished by God, questioning God's power, experiencing dissatisfaction with one's church or clergy) was significantly related to decreased positive affect, increased depressive affect, and decreased religious satisfaction.

Religious coping among religiously diverse populations. Given that the research on religious coping had drawn heavily from Caucasian and Christian populations, additional research was conducted with individuals from a variety of religious backgrounds. Based on the design and content of the RCOPE, another measure was developed to explore religious coping specific to individuals with Hindu religious beliefs (Tarakeshwar, Pargament, \& Mahoney, 2003). Following a pilot study, the instrument was administered to 164 Hindu adults in the United States. The participants had resided in the country for an average of 11 years, and many had completed graduate education. Exploratory factor analysis revealed that religious coping items loaded on three factors - God-focused, spirituality-focused, and religious guilt, anger, and passivity. The presence of three factors contrasted with the two-factor solutions (negative coping vs. positive coping) found in religious coping measures that were administered to Catholics and 
Protestants (Pargament, Smith, et al., 1998; Pargament, Zinnbauer, et al., 1998).

The results indicated that the religious coping subscales accounted for a significant amount of unique variance in life satisfaction and depressed mood (Tarakeshwar et al., 2003). Specifically, greater life satisfaction was associated with God-focused coping strategies, such as trying to collaborate with God to accomplish plans, surrendering to God, reinterpreting a situation as God's effort to instill strength, and looking to God for comfort. Greater life satisfaction was associated with decreased use of coping strategies that emphasized religious guilt, anger, and passivity. Greater depressed mood was also linked to increased employment of this coping style, which included belief that one was being punished by God, experiencing a sense of spiritual discontent with God, and reappraising God's power as inadequate to the situation. These results were maintained after statistically controlling for demographic variables and considering the potential influence of social desirability on responses.

Another measure designed specifically for Muslim individuals was developed based on a brief form of the RCOPE (Khan \& Watson, 2006). Religious coping items that reflected Muslim practices and beliefs were added to the items that were drawn from the RCOPE. The measure was administered in Urdu to 129 Muslim Pakistani university students who were asked to recall their reactions to a major difficulty in their life. The participants also completed the Brief Symptom Inventory and provided information about general religiousness and religious orientation. Confirmatory factor analysis generally supported a two-factor solution composed of positive religious coping and negative religious coping. Negative religious coping (i.e., believing that one was being punished by God, questioning God's power, questioning God's faithfulness/love, experiencing dissatisfaction with one's religious leaders) was significantly related to increased self-reported anxiety, depression, and hostility. However, interpretation of 
the results was limited by several factors. The measure was administered to Pakistani individuals of a higher socioeconomic class, casting doubt on its generalizability to Muslims from other countries or of different socioeconomic statuses. In addition, the study asked participants to retrospectively rate their religious coping strategies and psychological symptoms. At the same time, the results concurred with those obtained with samples of Christian and Hindu participants.

Most recently, a study was conducted to investigate whether the relationship between negative religious coping and psychological distress was present among individuals who were Jewish (Rosmarin, Pargament, Krumrei, \& Flannelly, 2009). The authors compiled items for a measure of religious coping that was specific to Jewish religious beliefs and practices. Instrument development and validation occurred with a sample of 468 Jewish individuals from various geographic regions within the United States. The validation sample was also comprised of a diverse range of Jewish religious affiliations (e.g., Orthodox, Conservative, etc.). Exploratory factor analysis revealed a two-factor solution that reflected a positive religious coping factor and a negative religious coping factor. Negative religious coping included strategies such as questioning God's power and care, experiencing internal conflict about religious beliefs, and expressing anger at God. The newly developed Jewish Religious Coping Scale (JCOPE) was then administered to 234 Jewish adults from Canada, the United States, Israel, and other worldwide locations. As with the validation sample, participants in this sample reported a variety of Jewish religious affiliations. The results of research with the second sample indicated that negative religious coping was significantly correlated with high self-reported worry, anxiety, and depression. These results remained stable after statistically controlling for general religiousness. 
In summary, research has established a clear relationship between religious coping and psychological well-being. This finding has been supported by a meta-analysis that indicated at least a modest effect size (Fisher's $Z=.22$ ) between negative religious coping and poorer psychological adjustment (Ano \& Vasconcelles, 2005). Although the majority of research has been conducted with individuals who are Caucasian and Christian, studies with individuals of other religious backgrounds tended to obtain similar results (Khan \& Watson, 2006; Rosmarin et al., 2009; Tarakeshwar et al., 2003).

The relationship between negative religious coping and negative psychological adjustment highlights the necessity of investigating the specific beliefs, stressors, contexts, strategies, and goals related to an individual's approach to religious coping (Tix \& Frazier, 1998). However, no research has been conducted to investigate the stressors encountered by individuals in groups that engage in ARA or the utilization of religious coping in response to those stressors. In addition, religious coping appeared to be particularly important for well-being when individuals possessed a strong religious identity. While such individuals might experience more of the benefits of religion, they might also suffer more when they struggle spiritually. Employing certain types of religious coping to manage this spiritual struggle might actually exacerbate the difficulty and contribute to increased psychological distress. Moreover, if religion is central to an individual's identity, spiritual struggle and the effects of negative religious coping might precipitate an identity crisis that threatens core self-concepts. Individuals who experience these struggles would benefit from a supportive and safe environment in which to share their difficulties (Pargament et al., 2001). However, popular descriptions of groups that engage in ARA suggested that the environment is actually hostile to admissions of spiritual struggle. Research is necessary to understand how individuals who experienced ARA experience, 
interpret, and respond to a spiritually distressing and traumatic situation.

A review of the research on religious coping also revealed that a sense of alienation from or abandonment by God and one's faith community is linked to psychological distress.

Pargament et al. (2008) stated that stressors disrupting an individual's connection with the sacred can propel that person into a state of spiritual struggle. This struggle often prompts the individual to deploy spiritual coping mechanisms in an attempt to maintain his or her relationship with the sacred. One of the common spiritual coping mechanisms is consultation with religious or spiritual leaders for guidance and support. In groups that engage in ARA, however, a leader might be more likely to interpret the individual's difficulty as a sign of spiritual weakness or failure to submit to the leader's teachings and rules (VanVonderan \& Johnson, 1991). This could heighten not only the group member's sense of being disconnected from the sacred but also his or her feeling of being responsible for the lack of attachment. As Lemoncelli and Carey (1996) suggested, this can function as the catalyst for a vicious cycle in which the individual believes he or she deserves to feel abandoned or punished due to the group's definition of spiritual failure. The leader that engages in ARA may indicate that if the group member is more faithful and tries harder, he or she will no longer experience anxiety about intimacy with the divine being. At the same time, the system continues to foster uncertainty about whether one is ever performing well enough to merit approval from the divine (VanVonderan \& Johnson). Thus, the group member is encouraged to feel personally responsible for anxiety that the group itself instills and to interpret this anxiety as a sign of disconnection from the sacred.

If an individual is unsuccessful in attempts to achieve or recapture a sense of attachment to the divine being, he or she may experience a spiritual vacuum or disengagement (Pargament et al., 2008). Some group members may eventually respond to this sense of spiritual alienation and 
disillusionment by exiting the spiritually abusive group that engages in ARA, which is often a painful and difficult event (VanVonderan \& Johnson, 1991). As a result, former members of such groups may experience anxiety, guilt, and shame associated with the spiritual struggle of leaving the group. They may also feel a loss of meaning in life, since spiritual identity appears to be a critical building block for many individuals' construction of meaning (Kiesling et al., 2008). Lack of spiritual resolution could be especially problematic for these individuals because the sacred is such an integral part of their values, emotions, and life structure. Studies on post-cult adjustment provide some insight into these processes, yet there is little empirical data to support the conclusions drawn by VanVonderan and Johnson with respect to individuals who leave groups that engage in ARA. The current study will address this gap in the research literature by inquiring about participants' experiences and perceptions before and after leaving a group that engaged in ARA.

\section{Research on Post-Cult Adjustment}

Research on the topic of post-cult adjustment further highlighted the need to investigate the experience of ARA and its relationship to psychological functioning. Based on professional clinical and clerical interactions, VanVonderan and Johnson (1991) offered detailed descriptions of the characteristics of ARA. Several of these characteristics resembled conceptualizations of cultic groups (Chambers, Langone, Dole, \& Grice, 1994; Dubrow-Eichel, 2002; Walsh, 2001). Based on these similarities, it seems possible that cults may represent an extreme form of ARA. Therefore, ARA might occur along a continuum of severity in a variety of spiritual and religious groups. In fact, Aronoff, Lynn, and Malinoski (2000) noted that it is useful, and perhaps more appropriate, to locate cultic groups on a continuum of abusive activity when conceptualizing potential harm. If this is the case, research on psychological adjustment in former members of 
cults might offer direction with regard to the current investigation of ARA.

Drawing upon anecdotal and clinical data, VanVonderan and Johnson (1991) proposed several possible effects of ARA. These effects included a shame-based spiritual identity, pervasive feelings of unworthiness, a severe disruption in one's ability to connect to the sacred, depression, anxiety, chronic guilt, fear, preoccupation with performance, problems with personal boundaries and personal responsibility, underdeveloped life skills (particularly in the educational and occupational arenas), problems with trust, and difficulty disagreeing with authority. In addition, some individuals might suffer from symptoms that resemble post-traumatic reactions, such as flashbacks, avoidance behaviors, and intrusive thoughts. Such reports of the effects of ARA bear a striking similarity to the research literature on the nature of psychological distress in former cult members. Former cult members have reported experiencing guilt, anxiety, fear, difficulty adjusting to daily demands and life tasks, dissociation, intrusive thoughts, and problems with trusting authority figures (Aronoff et al., 2000; Ash, 1985; Buxant \& Saroglou, 2008; Dubrow-Eichel, 2002; Gaines, Wilson, Redican, \& Baffi, 1984; Martin, Langone, Dole, \& Wiltrout, 1992; Swartling, 1992).

Descriptive research by Lottick (2008) suggested that these adjustment difficulties generate sufficient distress to prompt former cult members to seek professional services. Of 695 members of the Pennsylvania Psychological Association, 33\% reported professional experience providing treatment to active or former cult members (although it was unclear which definition of "cult" the researcher used). In addition, $20.4 \%$ of the respondents reported treating family and friends of cult members. Of professionals who had provided treatment to members of cults or their family and friends, between $83.8 \%$ and $88.7 \%$ indicated that cult-related problems were a focus of treatment. Some of the problems most commonly reported included anxiety, 
depression, guilt, dissociation, and fear of reprisal. Moreover, the respondents reported 36 cultrelated attempted suicides and seven completed suicides. However, a minority of the respondents in Lottick's study indicated comfort with their level of knowledge and competence to provide therapy for cult-related problems. The results of this study suggested the necessity of increased research on the psychological impact of groups that fall along a continuum of ARA activity, followed by dissemination of these results to mental health practitioners.

Articles based on case studies also suggested that former cult members can experience a range of negative emotions and psychological symptoms. Goldberg and Goldberg (1982) described the symptoms often encountered during group therapy with former cult members. These symptoms included guilt, fear of negative consequences for leaving the group, self-doubt, loneliness, loss of meaning, dissociative experiences, grief, sadness, and anger. Drawing from clinical work with two individuals who were second generation members of cultic groups, Goldberg (2006) highlighted the particular impact experienced by children when the cult experience becomes an integral part of personality.

Goldberg (2006) asserted that child members of cults experience an authoritarian parenting style from parents and learn to respond to the harsh authority with passivity and compliance. Additionally, the group leader(s) often assumes a parental role by virtue of his or her position and authority within the group. The child internalizes the critical and inconsistent behaviors and opinions of the leader(s), contributing to a sense of shame and inadequacy (Lemoncelli \& Carey, 1996). The child learns to be intensely self-critical and to suppress emotions, particularly negative emotions, to conform to the group's demands. Goldberg argued that the child will inevitably experience frequent negative emotions as a result of being consistently placed in a double-bind. The child is expected to be perfect yet is being told that he 
or she is in constant need of repentance. As a result, the child (and adults) resolves the conflict by engaging in splitting, perceiving the group as all good and viewing the self and certain emotions as completely bad. If the child attempts to maintain a sense of self by secretly rebelling, he or she experiences feelings of guilt and shame. Finally, the child learns that when his or her needs conflict with those of the group, parents are likely to prioritize the group out of a need to maintain approval and acceptance. This can further contribute to neglect, abuse, and feelings of shame and inadequacy (Goldberg).

Cushman (1986) advanced a description of how the cultic experience impacts adult identity, self-esteem, and a cohesive belief system. Although his hypotheses were based on clinical work with former cult members and their families, they were not subjected to empirical validation. Cushman stated that individuals routinely employ image management to protect and maintain self-esteem in response to personal, internal evaluation and the perceptions of others. When a conflict occurs between behavior and self-concept, an individual's self-esteem decreases, prompting the individual to resolve the conflict. Cushman asserted that "restrictive groups" promote or demand behaviors that conflict with an individual's self-concept. These groups increase the likelihood that the individual will perform the behaviors by casting doubt on the validity and acceptability of the individual's frame of reference, values, or worldview (i.e., self-concept). Any resulting disorientation within the individual leads him or her to search for stability and certainty, which the group and its leader(s) offer through specific doctrine. This doctrine is presented as the only resolution for the individual's real or perceived problems. The doctrine is also insulated from being disproven, since contradictory evidence is dismissed as erroneous or is discounted through ad hominem attacks against the source of the evidence.

After the initial stage in which an individual is convinced that the group's doctrine is the 
solution to his or her problems, the group and its leader(s) increase the conflict between the individual's behavior and self-concept. This occurs through the processes that Lifton (1961) outlined. The group engages in a "demand for purity," setting up impossible expectations and leaving an individual in a constant state of dissatisfaction and personal failure. Failure to fulfill the expectations set forth is presented as evidence that the individual is in need of guidance from the group and its leader(s). In other words, the individual's behaviors are interpreted to be inconsistent with a self-concept that he or she is competent or can rely on personal judgment. The practice of requiring confession of flaws and failures further eliminates the boundary between the self and the group. At the same time, the attribution of supernatural or absolute status to the group and its leader(s) silences disagreement with the demands. Questioning the demands is interpreted as evidence of personal unworthiness, ensuring group members' adherence to the group doctrine.

The processes outlined by Cushman (1986) tend to decrease autonomy and increase pressure to adhere to the mandated roles and behaviors dictated by the group and its leader(s). Once the group doctrine is accepted as absolutely perfect, individuals who still experience problems of imperfections can only conclude that their own inadequacy is responsible for such experiences. The individual is dependent on the group or leader(s) for self-definition, and the only way to avoid being negatively labeled is to achieve the impossible standard of perfect submission. The desire to preserve in-group status also reinforces members' conformity, as the group and its leader(s) offer acceptance and belonging that is increasingly dependent on adherence to group demands. At this point, the individual's self is likely fragmented, which contributes to the search for a way to unify personal identity. This self-integration is accomplished by seeking approval and attention through performance for the group leader(s). As 
these processes proceed, psychological separation from the group and its leader(s) becomes more threatening, intensifying the individual's vulnerability to influence and peer pressure.

At the same time, the individual experiences the strain of the conflict between personal integrity (being oneself) and the promise of fulfillment, belonging, acceptance, and identity in the group (Cushman, 1986). The conflict erects a no-win situation in which either choice results in the loss of something of great value. If the individual chooses compliance to the group, he or she loses integrity and self-esteem. If the individual chooses personal integrity, he or she loses affection, stability, and a sense of connection to the sacred. In many cases, individuals are discouraged from choosing to maintain personal integrity, for the group and its leader(s) engender anxiety about non-existence or termination - either from the group or from eternal reward - as a consequence of personal integrity. Resolution of the impasse between personal integrity and acceptance by the group requires either transformation of beliefs to conform to the group's behavioral demands or withdrawal from the group. When individuals transform their beliefs (described by Cushman as a conversion experience), they are likely to experience emotional relief from the inner turmoil generated by the internal conflict. Leaders often interpret this relief as evidence of divine intervention, further lending supernatural authority to the group's doctrine. However, individuals must constantly modify their behaviors in order to avoid dissonance with their self-concept. Attributing modified behaviors and beliefs to group pressure would reinvigorate the original conflict between personal integrity and group acceptance. Thus, group members are motivated to avoid the unpleasant experience of internal dissonance by accepting cues to interpret changed beliefs and behaviors as evidence of internal transformation.

The new self-concept that is based on group doctrine provides only temporary relief (Cushman, 1986). Since this self-concept is not authentic, it requires continual renewal and re- 
affirmation. This can be accomplished by engaging in repeated conversion experiences or maintenance behaviors. In other words, the member must constantly perform the required behaviors in order to secure approval and internal harmony. However, the group and its leader(s) foster further dependence by criticizing members' performance. The effect of this criticism is a destabilization of the self-concept, which perpetuates the conversion experiences, serves as vicarious instruction to other group members, and functions as "proof" that the group's doctrine is the only true teaching.

While Cushman (1986) advanced a fairly comprehensive theory to explain vulnerability to abusive group tactics, his hypotheses lacked empirical support. In addition, he failed to define the nature of a "restrictive group," making it difficult to clarify the types of groups upon which he based his theory. He also did not incorporate the religious/spiritual dimension in the conceptualization of group influence on self-concept. Therefore, it is impossible to determine whether the processes that Cushman outlined can be applied to understand the experiences of individuals who experienced ARA. At the same time, the work of Cushman, Goldberg (2006), and Goldberg and Goldberg (1982) represented early attempts to explain the adverse psychological outcomes observed in clinical work with former cult members. Empirical studies with former cult members appeared to provide additional support for the conclusion that some individuals experienced significant personal and emotional distress after leaving a cult.

An early study on the effects of cult membership (Gaines et al., 1984) sampled 75 former cult members to determine the incidence of health problems that were attributed to cult membership. Of the former members who were sampled, $20 \%$ reported health problems that they attributed directly to involvement in the cult. Of these health problems, mental health issues were among the most frequently cited. However, the authors did not report the nature of the 
mental health problems that were endorsed, nor did they provide any descriptive statistics beyond the percentage of respondents who identified health problems as a consequence of cult involvement. The retrospective, non-experimental nature of the study made it inappropriate to draw conclusions about the causal relationship between cult membership and subsequent health or mental health issues. Finally, the methodology of the study relied upon the self-report of attendees at a national meeting of former cult members. This reduced the validity of the results, as participants' responses might have been biased in an attempt to portray cults in a negative light.

Martin et al. (1992) conducted research with 124 former cult members who either participated in an educational workshop (13 participants) or received treatment at a residential facility (111 participants). All participants completed the Millon Clinical Multiaxial Inventory I, and 66 participants at the residential facility completed the MCMI-I before and after treatment. The profiles of most participants displayed characteristics of anxiety and a dependent personality, and the participants appeared to be experiencing higher than average levels of psychological distress. In fact, the authors pointed out that the sample's mean MCMI-I score fell above the median of the inpatient normative group for that measure. Furthermore, the scores of participants who had been physically or sexually abused while in the cult did not differ significantly from the scores of participants who had not experienced these forms of abuse. This suggested that the impact of membership in a cultic environment might be related to psychological distress apart from the effects of physical and sexual abuse. An alternate explanation was that psychologically distressed individuals were attracted to and more likely to join a cult. Finally, there was a significant decrease in the mean scores of 15 of the MCMI-I scales from pre-test to post-test. Martin et al. concluded that the change in MCMI-I scores 
argued against the idea that participants suffered from psychological distress prior to membership in a cult. However, the study did not employ a longitudinal, experimental design and therefore could not provide conclusions about causality. In addition, the authors did not account for the possible validity threats of participant self-selection or sample bias.

Given that the majority of the research with former cult members relied on informal case studies and survey research that lacked methodological rigor, Winocur, Whitney, Sorensen, Vaughn, and Foy (1997) undertook a study to address the lack of empirical evidence linking cult involvement to post-cult psychological distress. The authors developed an instrument designed to measure individual cult experiences. After review by an expert panel and pilot testing with graduate psychology students, the items were administered to three groups of participants. The first group consisted of 77 self-identified former cult members who participated in cult support groups. The second group was composed of 14 self-identified former cult members who had never participated in a cult support group. The third group was composed of 13 former or current members of non-cultic groups. The overall item scores displayed good internal consistency (Cronbach's alpha of .89) and correctly distinguished former cult members from non-cult members. The authors reported that cult members reported moderate levels of current distress. However, the cross-sectional design of the study precluded inferences about whether this distress was related to cult experiences. In addition, the small sample sizes in two of the groups likely restricted the variability of scores in those groups. If this led to an artificially low mean score in the non-cultic sample, the apparent discriminative validity of the measure might be explained by sample size rather than by personal experience in a cult.

Another study, conducted by Malinoski, Langone, and Lynn (1999), compared the responses of three samples of participants on several standardized measures of psychological 
distress. The authors recruited 15 former members of the International Church of Christ (ICC; also known as the Boston Church of Christ), which was alleged to be a group with cultic features. In addition, 23 former members of InterVarsity Christian Fellowship and 19 former members of the Catholic Church were recruited, as these groups were not considered to be cultic. The results of the study were limited by the small sample sizes, convenience sampling method, overrepresentation of female participants, and differences in the demographic variables of ethnicity and age. However, the authors found that former ICC members reported significantly higher levels of depressive symptoms, and a significantly higher proportion of these participants scored in the moderately to severely depressed range. Former ICC members also reported significantly higher scores on trait anxiety, dissociative experiences, and post-traumatic symptoms of avoidance and intrusion.

Overall, the literature on whether cultic environments lead to psychological harm must be interpreted with caution. Most studies on the psychological impact of cult involvement suffer from significant methodological flaws (Aronoff et al., 2000). A critical problem throughout the literature is the failure to employ a consistent or empirically-driven definition of the term "cult" when referring to a particular group. Until the introduction of the Group Psychological Abuse Scale (Chambers et al., 1994), there was no psychometrically-constructed instrument that could differentiate a potentially harmful group from one that was merely unconventional, but innocuous. Therefore, research conducted with current and former cult members did not account for potential variations in a group's level of totalism or cultic activity. Instead, researchers tended to classify all cultic groups into one category and failed to investigate whether different psychological outcomes could be related to differential levels and types of cultic activity.

Beyond definitional issues, Aronoff et al. (2000) identified several additional 
methodological problems with studies of cult members' psychological health. Researchers frequently failed to use standardized and psychometrically sound instruments, did not establish control or comparison groups, and drew conclusions from small sample sizes. Research with former cult members often relied on clinical impressions and non-random samples, and it included participants who received treatment from researchers, raising the issue of bias. Studies of former members also ignored the potential influence of deprogramming, exit counseling, and anti-cult literature on participants. Researchers exploring the psychological well-being of both active and former cult members also failed to routinely account for potential motivational factors in symptom reports. For example, active cult members might be reluctant to report symptoms due to a tendency to deny difficulties and doubt. An active cult member admitting that he or she experienced psychological distress might be tantamount to breaking rank with group leaders and teachings. On the other hand, former cult members who were disillusioned about their experience in the cult might exaggerate the negative impact of their membership in an effort to exact revenge.

Buxant and Saroglou (2008) also suggested that the difference in the presence of reported positive or negative psychological effects of cultic groups might be related to whether respondents were active or former members. Retrospectively evaluating former members' perceptions of their mental health, Buxant and Saroglou found that respondents reported feeling a strong sense of belonging while still in the group. However, respondents also reported that the group constituted their primary source of interpersonal interaction and social support. Leaving the group required a significant disruption in one's social network, and Buxant and Saroglou noted that former members reported decreased well-being, increased difficulty in reestablishing relationships, and problems with trusting others. Although these challenges appeared to resolve 
over time, former members continued to report feeling reluctant to join groups and seemed to interpret the overall experience as a negative life event.

After highlighting the limitations of research with current and former cult members, Aronoff et al. (2000) still concluded that although active cult members appeared to report satisfactory adjustment, former cult members appeared to manifest legitimate symptoms of psychological distress. Themes that emerged consistently in the literature on former cult members included negative emotional reactions, difficulties with adjustment, and greater incidence of psychological distress after leaving a cult. In addition, the problems reported by former cult members might be mediated by whether their exit from the group was voluntary or involuntary. Those who leave voluntarily might face pressure to remain, be labeled as "impure," and be ostracized. These individuals might confront psychological problems associated with a loss of friendships, the challenge of reestablishing relationships, guilt, and confusion about values and beliefs (Schwartz, 1985).

Given the indications of psychological distress in former cult members, it is important for psychologists to investigate the construct of ARA. This particular type of trauma seems to be capable of generating significant, negative psychological symptoms while simultaneously undermining an individual's sense of meaning and identity. In addition, abuse that occurs through spiritual means might also incapacitate an individual's ability to access spirituality as a core coping resource. As the methodological flaws in the literature on cult involvement demonstrate, an important first step in the process is a careful, systematic inquiry about the facets of the phenomenon under study. To date, there has been no published study that specifically explored the psychological impact of membership in a group that engaged in ARA whose practices were less overtly extreme than those of high-profile cultic groups. In addition, it is 
critical that the emerging literature on ARA not suffer from the same definitional limitations as the literature on post-cult adjustment. Although VanVonderan and Johnson (1991) have proposed a lay definition of ARA, their description has not been verified through research or tested through scientific inquiry. The goal of this proposed study is to address this task by using a qualitative research design to generate an empirical definition of ARA. The results of this study are expected to provide an initial theoretical framework that will serve as the basis for future research.

\section{Clergy Perpetrated Sexual Abuse}

Emerging research on the impact of clergy perpetrated sexual abuse (CPSA) provides additional impetus for an investigation of the impact of ARA. Professionals in the fields of theology and psychology have noted that, in addition to the severe emotional and psychological damage of sexual abuse, sexual violation by a member of the clergy generates spiritual wounds that magnify psychological distress (Benkert \& Doyle, 2009; Doyle, 2009; Flynn, 2008; Francis \& Turner, 1995; Mart, 2004; Rossetti, 1995). There appears to be a unique dynamic through which exploitation, betrayal, or abuse of power by a spiritual leader exerts a particularly damaging effect on psychological well-being. This harm is multifaceted and extends beyond a reluctance to engage in formal religious practices or to interact with members of the clergy (Doyle).

In their overview of the literature on CPSA of adults and children, Francis and Turner (1995) highlighted one component of this dynamic by emphasizing the power differential between clergy and church members. Church members often seek comfort, support, and guidance from clergy, frequently interacting with a pastor or priest during times of great vulnerability. The power differential is heightened when religious or spiritual doctrines lend 
divine authority to the clerical role (Doyle, 2009). For example, in the Catholic Church, the belief that a fundamental change in a priest's nature configures him to Christ affords priests a position of greater power. Teachings that presume a clergy member's superior access to knowledge or to the divine also invest power in the clerical position. Thus, belief in and obedience to the clergy member's pronouncements might be equated with belief in and obedience to God. Compliance with the clergy member's directives is seen as a way to please God, while disobedience is perceived as a sign of sinful rebellion against God. When the clergy member also possesses authority to dispense forgiveness, determine eligibility for religious and spiritual rites, and pronounce upon one's eternal destiny, the power differential expands exponentially. All of these factors increase the vulnerability of a child or adult when a member of the clergy engages in sexual abuse.

A second contributing factor in the unique psychological distress of CPSA is the cognitive dissonance that is generated (Doyle, 2009; Festinger, 1957). Describing the structure of the Catholic Church, Doyle asserted that the Church functions as the representation of the divine on earth. The organization and its leaders are expected to be incapable of inflicting suffering or engaging in such egregious wrongdoing as CPSA. When CPSA does occur, a child experiences severe cognitive dissonance between the horror of the abuse and perceptions of the clergy as divine representatives. Attempts to resolve this dissonance often involve the child blaming himself or herself, which can be reinforced by the perpetrator's statements. Lemoncelli and Carey (1996) described these psychospiritual dynamics as an adaptive but problematic bonding process in which a child's attachment with a parental figure is fraught with abuse, inconsistency, and punitiveness. In an attempt to meet the need for love and attachment, the child internalizes the abuse. This is an effort to maintain emotional contact with the parental 
figure (and, by extension, the divine) while preserving a positive image of the parental figure. If the child perceives the self as sinful, he or she can retain the belief in a "good" parental figure and avoid shattering his or her religious worldview. However, in this method of resolving the cognitive dissonance, the child pays a steep price in an existence of self-criticism and selfloathing for circumstances that are beyond his or her control.

The contradiction between what a religious leader is supposed to represent and what actually occurs in CPSA is thought to lead to a variety of additional troublesome outcomes (Doyle, 2009). The cognitive dissonance precipitated by CPSA can disturb the individual's spiritual core, which has been conceptualized as the central organizational structure of the personality (Allport, 1950; Baker, 2003; Kiesling et al., 1998; Piedmont, 1999; Tillich, 1957). If a member of the clergy uses position and power to coerce the victim into silence, the victim might experience intense conflict between the desire for self-protection and the value of obedience to the divine. At the same time, the victim might anxiously struggle to reconcile the concept of a benevolent, loving deity with the image of the abuser. Given the expectation that one can trust a member of the clergy and not be harmed by him or her, sexual abuse or mistreatment by clergy leads to shock, betrayal, shame, rage, confusion, and grief (Francis \& Turner, 1995). Furthermore, the very person whose vocation it is to provide guidance regarding wrongdoing and forgiveness might be manipulating the abused individual into committing what is perceived as "sin" in that religious/spiritual community. Finally, the abused individual might experience a sense of alienation from a valued source of support - the clergy member and the spiritual community. This connection might have been the primary, or sole, source of support. When the environment that is supposed to be safe becomes a place of harm, the abused individual is bereft of a critical resource in coping with the trauma. However, there has been 
little empirical research on the psychological impact of CPSA, and there is a paucity of evidence as to the question of whether the effects of CPSA are different from or more severe than other forms of sexual abuse.

The research that does exist offered a preliminary picture of the devastating effects of CPSA, due to the unique position held by clergy. One of the earliest studies explored the effects of CPSA on spirituality, relationship with God, and attendance at religious services (McLaughlin, 1994). The researcher utilized a sample of convenience, recruiting 43 Catholic and Protestant CPSA survivors and friends and family members of survivors. Participants were asked to retrospectively evaluate their spiritual experience by completing a survey and the Measure of Spirituality Test. However, the researcher did not report information on scale development or psychometrics for the Measure of Spirituality Test. Moreover, all of the Protestant respondents reported experiencing abuse as adults, a variable that might have affected the results of the study. The results indicated a positive significant correlation between CPSA and loss of relationship to God and to the religious institution. The researcher also asserted that Catholic participants reported a more negative experience of spirituality after CPSA. However, the researcher did not provide a rationale for determining the cut-off score to distinguish "negative" experiences from "positive" experiences. The article also did not contain standard descriptive statistics to support the claim that Catholic participants were more negatively affected by CPSA. Overall, the results suggested that the experience of CPSA might be associated with a perceived loss of relationship with the divine. However, the study suffered from several methodological flaws that cast serious doubt on the validity of the conclusions.

Rossetti (1995) conducted a more rigorous study on CPSA that also included comparison groups. Based on a pilot study and factor analysis, a survey was developed to investigate the 
experience of CPSA. The survey was distributed to a random sample of Roman Catholic adults in the United States and Canada. A total of 1,810 individuals responded. Although the sample over-represented females (68\%), participants also included adults who had not experienced child sexual abuse $(1,376)$, those who had experienced child sexual abuse by someone other than a priest (307), and those who experienced CPSA (40). The results of a MANOVA revealed that there was a significant difference among the three groups on the survey results. Participants who had experienced CPSA obtained significantly higher scores on subscales that purportedly measured relationship to God and trust in priests. In other words, individuals who reported a history of CPSA also indicated greater difficulty in their relationship to God and in trusting priests. It appeared that the variable of gender accounted for much of the difference in the reported increased difficulty in relationship to God. Females who had experienced CPSA reported significantly greater problems in their relationship to God than did males. In general, the results appeared to suggest that CPSA was related to a broader range of negative outcomes than sexual abuse perpetrated by non-clergy. However, the results were of questionable validity due to potential sampling bias (there was a low response rate).

More recent research has employed qualitative or case-study research designs in an effort to understand the complex experience and impact of CPSA. In a non-experimental, informal case report of 25 adult survivors of CPSA in the Roman Catholic Church, Mart (2004) documented the presence of great distress related to the issue of spirituality. Harm and betrayal that were perpetrated by a representative of the sacred appeared to exert a strong, negative influence on participants. The member of the clergy had been revered, which exacerbated the unexpected and confusing nature of the trauma. Since participants were traumatized through the avenue of their religious and spiritual activity, they reported significant difficulty approaching or 
participating in religious activities. As a result, many participants acknowledged negative emotions because they lacked a way to express their spirituality or to resolve the spiritual difficulties associated with their experience. This experience appeared to be particularly traumatic for participants who believed that the Roman Catholic Church was the only legitimate religious pathway. For example, several participants described an inability to attend religious services as a result of their history of abuse. However, these same individuals were highly anxious about their eternal destiny because they did not participate in the prescribed rites of the Roman Catholic Church. Although this study was limited by the lack of a rigorous qualitative research design and potential confounding factors (all participants were involved in litigation against the Roman Catholic Church), even a cautious interpretation of the results suggested that the religious and spiritual dimension of the abuse was salient to participants' psychological wellbeing.

Two qualitative studies that were published in the same issue of the Journal of Child Sexual Abuse also supported this conclusion. In one study, researchers conducted interviews with nine adult male participants (ages 31 to 67 ) who were identified and recruited through an advocacy group for victims of CPSA (Isely et al., 2008). All participants had experienced a sexual encounter with an ordained Catholic minister prior to age 16. The authors failed to describe the specific methods employed for sampling, development of the interview protocol, and data analysis. While this decreased the rigor of the study's qualitative design, the authors reported several findings that were consistent with prior research.

Participants described factors that appeared to increase vulnerability to CPSA and the subsequent negative effects (Isely et al., 2008). For example, the survivors reported a sense of reverence for the clergy member's status, as well as desire to feel attached to and receive interest 
from the clergy. Most participants reported symptoms that were consistent with Post-Traumatic Stress Disorder (PTSD), such as re-experiencing and avoidance. In addition, the participants noted feelings of inadequacy, shame, guilt, anger, and low self-esteem and self-worth. They also indicated ongoing challenges with trust, particularly since some participants reported that the perpetrator had referenced God to threaten or manipulate them in abusive situations. The authors did not specifically investigate the interaction among the context of the abuse, religious and spiritual beliefs and practice, and emotional or psychological difficulties. However, the researchers noted that commission of the abuse in God's name warranted greater attention to how the abusive experience affected spiritual beliefs and practice.

The second qualitative study explored the experiences of 25 adult females who had been sexually abused by members of the clergy (Flynn, 2008). All of the participants reported a Christian religious background, and all but one was Caucasian and had obtained a college degree. In addition, the majority of the women had experienced the sexual abuse as adults. The author conducted semi-structured interviews with the participants but did not explicitly describe the method of data analysis. However, the data analysis appeared to involve an effort to seek confirmatory evidence for symptoms of PTSD, rather than to reason inductively based on participants' accounts.

Flynn (2008) reported that the participants described re-experiencing symptoms that were consistent with PTSD. Participants also reported difficulty with affect regulation, problems with attention and concentration, somatization and eating disorders, and disruption in the ability to develop and sustain trusting relationships. These difficulties were compounded by the confusion and disruption of being harmed by an individual who was supposed to represent God. The participants reported distress due to the conflict between their internal perception and the 
clergy's response during the abuse. The women explained that the abuse did not feel "good" (p. 230), although the member of the clergy emphasized that it was good. In addition, the women struggled to reconcile what was actually occurring with societal expectations about the clergy member's character and behavior. Thus, it appeared that cognitive dissonance specific to the religious/spiritual dimension of the abuse was linked to the participants' experience of psychological distress (Doyle, 2009). In addition, the participants described a sense of isolation, feeling helpless to respond to the traumatic situation when leaders and fellow members of the religious community invalidated or blamed them for the abuse.

Overall, the small amount of published research on CPSA appears to support the idea that CPSA is a unique type of betrayal (Guido, 2008). The abused individual experiences multiple traumas that intimately involve the religious and spiritual dimension. One individual described the depth of this harm and the complex nature of trauma inflicted within a religious or spiritual context: “'Tell them,' he insisted, 'what he took away from me. Not just my innocence but my faith. I'm like a spiritual orphan, betrayed by what I loved, and I feel lost and alone'" (Guido, p. 256). At the same time, there is little information about the specific nature of the impact of the religious and spiritual dimension upon survivors' psychological adjustment, although several authors noted that this topic is an important direction for future research (Doyle, 2009; Isely et al., 2008; Rossetti, 1995).

The CPSA literature also suffers from significant methodological limitations associated with poor sample selection, measures of questionable validity, and failure to document adherence to accepted qualitative research methods. Furthermore, of the two early quantitative studies that explored the effects of CPSA on spirituality, religious activity, and relationship with God, one did not report the psychometric properties of the instrument utilized and the other employed an 
instrument that was un-standardized. However, CPSA survivors in these studies reported psychological distress that was inextricably linked to the religious and spiritual components of the abuse experience. Several of these unique struggles resembled popular accounts of the experiences of individuals who experience ARA (Enroth, 1992; Rauch, 2009; VanVonderan \& Johnson, 1991; Wehr, 2000). The current study seeks to investigate the closely related topic of individuals' current and past perceptions of non-sexual abuse by religious or spiritual leaders. This study addresses a gap in the CPSA literature by exploring the unique interaction between psychological well-being and the religious/spiritual dimension of such abuse. The study also attempts to rectify methodological limitations in the CPSA literature by employing rigorous qualitative methodology.

\section{Literature Related to ARA}

Existing definitions of ARA. In spite of the presence of popular literature and web sites that describe ARA, existing empirical research has only peripherally addressed the construct. The research that does exist is based on varying definitions of ARA, none of which have been empirically validated. Some authors utilized a definition that was similar to that advanced by VanVonderan and Johnson (1991), emphasizing the misuse or abuse of authority to meet personal needs or to control others (Enroth, 1992; Gubi \& Jacobs, 2009). Dehan and Levi (2009) employed a similar definition - "misuse of power in a spiritual context" (p. 1300) - to describe situations in which Haredi Jewish husbands attempted to impair or harm their wives' spiritual functioning. Wehr (2000) used an analogous definition, yet specified that abusive leaders misuse social and political power to undermine individuals' integrity. Cudmore defined abusive Christian leaders as individuals with “... some level of 'spiritual' authority [who] use their privilege or position to extract obedience or submission from another member, causing a sense of 
deep mistrust and suffering” (p. 1). Orlowski (2010) described ARA as “...emotional and spiritual distress under authoritarian and controlling church leaders..." (p. 139). Masis defined ARA as “... any type of physical, sexual, or psychological harm perpetrated by a spiritual or religious leader on a member of a spiritual or religious group" (p. 29). Rauch (2009) stated that religious abuse encompasses circumstances in which the individual must completely submit to authority in order to receive approval or belonging, and in which the authority punishes, humiliates, or exploits the individual in the name of God.

Thus, various authors have applied differing definitions that alternately emphasize the source and context of power, the motive and purpose of the abuse, personal characteristics of spiritual leaders, and effects among the group members. Many of these definitions were based upon personal experience or clinical and pastoral work with individuals who experienced ARA. However, none of the authors systematically elicited direct input or feedback about the definition from individuals who identified as having experienced ARA. The paucity of research on ARA precluded these researchers from culling a broad definition based on existing empirical findings. It is scientifically unsound to proceed with research on the topic of ARA without attempting to establish an empirical definition that outlines the construct. It is not anticipated that the current study will produce a comprehensive or immutable definition. Nonetheless, one of the purposes of the current study is to construct an empirical definition that incorporates the perspectives of individuals who identify as having experienced ARA. This will provide at least a preliminary operationalization of the construct, which will inform and guide future research efforts.

Research related to ARA. Gubi and Jacobs (2009) utilized a qualitative research design to explore counselors' reactions to providing therapy to religiously abused clients. The authors conducted semi-structured interviews with five counselors who self-identified as religious or 
spiritual, then used heuristic methodology and Interpretive Phenomenological Analysis to organize themes from the interview data. The results demonstrated that the participants conceptualized ARA as involving an abuse of power and the hostile or coercive application of sacred writings. The effect of these actions was disempowerment of the abused individual, resulting in dependence upon the abusive leader to access the sacred. Participants reported personal feelings of anger, sorrow, helplessness, and disconnection from their clients. They acknowledged a sense of confusion about whether the abuser or the divine being was responsible for the abuse. Although the participants indicated growth in their personal relationship with God, they also described increased hesitancy around placing trust in church leaders. The participants identified these reactions as secondary traumatization and listed several strategies for adaptively managing responses. In spite of the participants' assertion that supervision was an essential component in this process, they reported varied opinions about supervisors' competence in issues of spiritual diversity. In particular, the participants mentioned the challenge of locating a supervisor who was qualified to supervise therapy for ARA.

Although Gubi and Jacobs (2009) offered the first attempt at an empirical definition of ARA, the definition was limited to a sample size that was quite small for qualitative research (Hill, Thompson, \& Williams, 1997). The authors attempted to recruit participants from only one source (a professional publication) and limited the sample to only those counselors who had provided services to individuals who experienced ARA from a Christian background. Furthermore, the study did not directly investigate the experiences of individuals who experienced ARA or inquire as to their definition of ARA. At the same time, a review of the study suggested that treating clients who experienced ARA might be similar to treating other abused individuals with respect to secondary traumatization and compassion fatigue. 
Participants' difficulty in securing adequate supervision for work with clients who experienced ARA lends greater urgency to the necessity of informing clinical practice by constructing an empirical definition and model of ARA.

The earliest documented journal article that explicitly identified ARA as a factor was an autobiographical case study of the personal experience of the article's author in an American Zen Center (Masis, 2004). The author reported that the leader of the spiritual group alluded to possessing special knowledge, which afforded the leader sole authority to make spiritual and administrative decisions. The leader's position conferred the authority to engage in verbal criticism; restrict group members' occupations, education, and location of residence; monitor group members' speech and behavior; and denigrate members who engaged in critical thinking or questioned the group's doctrine. The author recalled group proscriptions, such as the mandate to avoid gossip and slander. This regulation was interpreted as an implicit and explicit prohibition against expressing anger, particularly toward the leader. Group members who experienced negative responses, such as confusion or turmoil, were encouraged to take psychiatric medication. Notwithstanding, members believed that devoted spiritual practice that followed the leader's guidelines would eliminate all mental health difficulties. Therefore, members who were advised to take psychiatric medication were perceived as less spiritually devoted. In addition, members were expected to present only positive outcomes and to refrain from sharing personal turmoil or distress. As a result, some members attributed negative emotions to personal flaws or failures.

Masis (2004) stated that public sharing of members' personal information and overt identification of their shortcomings reinforced the perception of personal flaws and lack of devotion. The leader encouraged group members to demonstrate self-sacrifice and spiritual 
maturity by engaging in increasing numbers of group activities. Masis reported that the leader praised members who completed tasks without complaint while ill. The leader expected full compliance to all commands, and members began to imitate the leader's interpersonal style and clothing. In general, this group appeared to exhibit many characteristics of restrictive and abusive groups that have been outlined elsewhere (Enroth, 1992; Rauch, 2009; VanVonderan \& Johnson, 1991; Wehr, 2000).

Masis (2004) noted that students of similarly authoritarian Zen teachers also experience feelings of confusion, low self-esteem, guilt, and depression. In addition, these individuals often suffer from shattered faith, a lack of trust in other human beings, and an aversion to spiritual practices. Masis noted that the psychological and emotional distress begins while an individual is still a member of the group. He hypothesized that the confusion and distress stem partly from efforts to manage cognitive dissonance. The individual experiences the strain of negative reactions and problematic experiences in the group, yet he or she attempts to preserve the integrity of the leader(s) and the group by engaging in denial of or self-blame for these experiences. The application of the concept of cognitive dissonance, as well as the associated symptoms, was also found in the literature on the effects of CPSA (Doyle, 2009; Flynn, 2008; Francis \& Turner, 1995; Isely et al., 2008; Mart, 2004; Rossetti, 1995). However, limitations in Masis's case study design cast doubt upon the reliability and validity of his conclusions. The use of a case study design is not necessarily biased toward verification, nor does it prevent generalization (Flyvbjerg, 2006). Nonetheless, the researcher must apply several methodological tools to increase the rigor of a case study design. In addition to its autobiographical nature, Masis's case study failed to include the use of multiple data sources for triangulation, a 
description of the data analysis and any associated audit trails, or a bracketing of assumptions and biases (Anthony \& Jack, 2009; Sorin-Peters, 2004).

Prior to Masis's (2004) autobiographical case study, Cudmore (2002) conducted a thesis that explored the experiences of individuals who had suffered from leadership abuse in a Christian organization. The purpose of the study was to obtain descriptive information about these individuals' struggles and coping strategies, and the characteristics of the leaders under whom participants were employed. Twelve individuals were recruited to participate in the study, although it was unclear how these individuals were identified. A total of nine individuals - five females and four males - completed the study. Participants' ages ranged from 24 to 57, all but one were married, and the time since the experience in question ranged from two to 20 years. All of the participants had been actively involved in a Protestant organization at the time of the abusive experience. Two of the participants had served as unpaid volunteers within the ministry of a Christian organization, and the remaining seven had been employees. Cudmore noted that participants represented three cultural backgrounds and six denominations but did not provide more specific data about these variables. All participants were screened to determine whether they met criteria for inclusion in the study, which included 1) suffering that occurred in a Christian organization and 2) the suffering was perceived as a painful and traumatic experience resulting primarily from the leadership.

Participants completed a semi-structured interview that was comprised of open-ended questions (Cudmore, 2002). They also completed a Perceptions of Personal Feelings questionnaire, Perceptions of Leader and Organization Questionnaire, four sections of the PTSD Interview, and the Lominger Card Sort (each card described a leader characteristic or skill). The first two questionnaires were designed by the author for use in the study. However, the only 
descriptive statistics reported for these questionnaires were frequencies, although the author provided means and standard deviations for the PTSD Interview results. In addition, the author did not conduct the full Lominger Card Sort, instead selecting the 19 cards that were listed as "career stallers and stoppers" (p. 65). Each of these cards represented a problematic leader characteristic or skill deficiency. While each card also contained the positive alternative to a maladaptive leadership trait, pre-selection of the most problematic traits unnecessarily restricted the range of responses.

The qualitative portion of the study (Cudmore, 2002) emphasized a biographical life narrative method that focused on a specific crisis event. The crisis event included chronic stressors that were associated with the perceived leadership abuse. Interviews were recorded and transcribed, and the transcripts were analyzed by bracketing meaning units (a single unit of thought), then grouping the units into larger themes. The themes were then ordered sequentially to document the narrative of participants' experiences. To address the issues of reliability and validity, participants were asked to review the transcript of their interview and verify the assigned themes. In addition, Cudmore reported the use of two external raters who obtained $75 \%$ agreement. It was not clear whether this agreement was between the two external raters or between the raters' analyses and Cudmore's analysis.

Cudmore (2002) found that most of the participants in the study had been actively and regularly involved in church activities for several years (though the exact length of time was not specified). Participants reported that they initially felt supported by their organization and recalled having a positive experience. This calm period was followed by a shift toward increased tension with the leader(s), to which participants often responded by attempting to maintain involvement and to accommodate the leader(s). The leader(s) was frequently described as non- 
empathic and distant, and participants perceived that standards and expectations changed unexpectedly. Increased efforts by the participants to resolve the tension appeared to be unsuccessful, contributing to the perception that the leader(s) were only further aggravated by attempts at appeasement or reconciliation. Participants reported that vocalizing their concerns to the leader(s) only seemed to exacerbate the situation. Moreover, there appeared to be a shift toward greater secrecy on the part of the leader(s), which led to a sense of alienation and decreased access to information among the participants. The participants also reported feeling isolated from other members of the organization. The chronically stressful circumstances often concluded with the participants' abrupt termination, to which the participants responded with shock, surprise, and betrayal.

Participants also noted their perception that the leader(s) blamed them for the turmoil associated with the circumstances (Cudmore, 2002). They stated that the leader(s) accused them of unforgiveness, unsubmissiveness, and insufficient faith. Following the height of the crisis situation, many participants reported that the leader(s) ignored or refused to interact with them. Other individuals in the organization(s) also remained silent, systematically excluded the participants, and withdrew support. Participants stated that the organization(s) then provided information to the membership that was designed to protect the reputation of the organization(s). Occasionally, this involved deceit or a prohibition to members against discussing the issue. In response to these events, all but one participant reported strong feelings of anger, confusion, devastation, and betrayal (Cudmore, 2002). Participants also described feeling overwhelmed, deceived, de-energized, alienated, and mistreated. Other prominent themes included sadness and a sense of being unable to communicate the events to others. Many participants discussed the loss of support from their religious community, as well as loss of 
meaning, joy, fulfillment, and spiritual identity. At least half of the participants noted that they blamed themselves at some point during the course of the events. In general, most of the participants reported experiencing a significant amount of distress, during which time they questioned God's omnipotence and benevolence. These results were consistent with research that indicated an association between psychological distress and alienation from God or uncertainty about God's power or love (Exline et al., 1999; Exline et al., 2000; Khan \& Watson, 2006; Pargament, Zinnbauer, et al., 1998; Pargament et al., 2000; Pargament, Tarakeshwar, Ellison, \& Wulff, 2001; Rosmarin et al., 2009). Participants reported a variety of strategies to cope with these experiences, which included seeking support from Christian friends, nonChristian friends, family, and professionals. Most participants also felt compelled to leave the organization, or they were instructed to leave. While faith in God was another primary coping strategy, three of the participants reported that their faith had been shattered or weakened.

Participants also described the characteristics of the leader(s) with whom they experienced the crisis situation (Cudmore, 2002). These characteristics were organized into five broad themes that included: 1) rigid, manipulative interpersonal style and claims of possessing holy authority; 2) highly effective command of verbal communication marked by deficits in empathy and listening skills; 3) willingness to lie and reluctance to accept blame; 4) insecurity; and 5) charismatic, generally liked, and perceived to be a strong religious person. Cudmore concluded that these characteristics contributed to an abuse of power that emphasized submission and loyalty. The leaders appeared to accept participants only as long as the leaders' authority was not challenged. The misuse of power resulted in acute and intense negative emotions, impairment in daily functioning, confusion, and personal loss among the participants.

Cudmore's (2002) research provided preliminary empirical evidence that individuals can 
experience psychological distress in the context of non-sexual abuse by religious or spiritual leaders. Many of the difficulties reported by the participants in Cudmore's study were similar to those proposed by authors of popular books on ARA (Enroth, 1992; Rauch, 2009; VanVonderan \& Johnson, 1991; Wehr, 2000). In addition, the personal characteristics and interpersonal style of the leaders described in Cudmore's (2002) research resembled the features of religiously abusive groups outlined by VanVonderan and Johnson (1991). The participants in Cudmore's study also appeared to experience a distressing, fundamental loss that involved spiritual selfidentity. ARA exacerbated the trauma of this experience because it involved mistreatment at the hands of individuals who were expected to be trustworthy and competent. Aside from the symptoms that resulted from the abuse itself, discovery that a religious or spiritual leader was not trustworthy and was actively generating anxiety and inner turmoil in group members led to greater psychological distress.

In related research, Pargament, Magyar et al. (2005) investigated perceptions of a life event as a sacred loss or desecration (i.e., violation). They found that the results of measures of sacred loss and desecration correlated with the results of scales measuring intrusion, avoidance, anxiety, and depression. In particular, sacred loss was associated with internalized emotional distress, post-traumatic stress symptoms, and (for some) growth. However, desecration - or the perception that the sacred was purposefully violated - was connected with anger, externalized emotional distress, avoidance, and less growth. Pargament, Magyar et al. hypothesized that the way an individual spiritually experiences stressful life events could lead to depression, anxiety, PTSD, and other negative psychological outcomes. Thus, it is possible that some individuals who experience abuse in a religious/spiritual context might manifest psychological symptoms at least partly due to the sense that something sacred was desecrated. 
However, Cudmore's (2002) sample was limited in that it was restricted to individuals who had experienced abusive treatment associated with their employment or status as a volunteer within the organization. It was also limited to individuals who participated in a Christian organization. The current study seeks to address these limitations by employing purposive sampling. One goal of this sampling method is to recruit participants with experiences in a variety of religious and spiritual groups. Furthermore, the current study will expand on Cudmore's research by exploring how participants define ARA, the nature of coping strategies employed during and after the ARA, and perceptions of the interaction between psychological distress and the religious/spiritual dimension of the abuse.

Subsequent to Cudmore's (2002) research, Orlowski (2010) conducted dissertation research to investigate the process of Christians' recovery from perceived ARA. A secondary purpose of the study was to discover the primary themes that contributed to negative effects among participants. Orlowski recruited participants through local contacts and web sites that addressed the topic of ARA. Individuals met criteria for inclusion in the study if they had experienced "emotional and spiritual distress under authoritarian and controlling church leaders," had left the congregation, and had "recognized and processed their spiritual grief and pain and experienced spiritual recovery" (p. 139). A total of 100 participants (42 males and 58 females) between the ages of 20 and 74 completed the study. The majority of the participants were between the ages of 40 and 59, and most of the individuals identified with Evangelical, Pentecostal, and Charismatic Christian traditions. Although a large percentage of participants resided in the United States and Canada, responses were received from several other countries. Orlowski reported that participants had regularly attended congregational services, and most assisted in their congregations by fulfilling ministry roles. 
Participants completed questionnaires that combined demographic questions and openended items inquiring about attitudes, beliefs, and behaviors since exiting the former congregation (Orlowski, 2010). The author did not describe a specific method of qualitative data analysis. Questionnaire responses were analyzed for categories and themes, but the author did not discuss any strategies to address the reliability and validity of the results. Participants' most common reason for leaving the congregation was the presence of an authoritarian and controlling pastor or leadership team, which was not surprising given the inclusion criteria for the study. The second most common reason for leaving included the leader's lack of accountability, followed by dissatisfaction with the degree of legalism within the congregation. Participants also reported the absence of a mechanism to express disagreement with the leader(s).

Three additional questionnaire items explored how the experiences impacted participants emotionally and how participants coped with the circumstances (Orlowski, 2010). Participants reported a range of negative emotional responses, the most common of which were anger, devastation, grief, isolation, guilt, shame, and feelings of exploitation, depression, and rejection. Primary coping strategies included leaving the congregation, re-evaluating one's beliefs and spirituality, and establishing alternate social support networks. However, the author failed to describe the full range of coping methods that participants utilized. When describing coping strategies, Orlowski provided selected excerpts from the questionnaires of six participants but did not offer information about overarching themes or frequency counts. Several participants also described experiencing positive reactions - such as relief, freedom, and spiritual growth - in response to their experiences. At the same time, it was not clear whether some participants experienced positive responses while others experienced negative responses, or whether participants tended to experience both positive and negative responses. 
Orlowski (2010) concluded that the results suggested a high level of emotional turmoil among participants after leaving an abusive church experience. The adverse impact of the trauma increased as a function of participants' increased vulnerability, which was a result of the heightened level of trust between a spiritual seeker and a spiritual leader. Expecting security and restoration, the spiritual seeker instead encountered a unique and deep betrayal. Moreover, participants described the additional trauma of being isolated from a primary source of emotional, social, and spiritual support. Similar to Masis's (2004) description of the impact of ARA, these conclusions echoed theoretical and empirical findings from literature on CPSA (Doyle, 2009; Flynn, 2008; Francis \& Turner, 1995; Isely et al., 2008; Mart, 2004; Rossetti, 1995). Orlowski's conclusions also reinforced Cudmore's (2002) findings, suggesting that a particular form of non-sexual abuse by a spiritual or religious leader is associated with significant psychological distress.

Nonetheless, Orlowski's (2010) research was limited in several respects. The emphasis of the research was on the process of recovery from ARA, not on the ARA itself. The sample was also restricted to Christian participants who considered themselves to be recovered from the ARA experience; many of these participants had joined another church congregation. It is possible that these issues of population definition obscured important information about the experiences of non-Christian individuals who identify as having experienced ARA or of individuals who do not consider themselves to be recovered. In addition, the author only used two items to inquire about the ARA situation and the emotional impact of the experience. In fact, the item that was intended to explore the nature of the ARA only inquired about the factors that influenced the decision to leave the church congregation. The use of a questionnaire format also prevented the researcher from engaging in immediate clarification of participants' meanings. 
For these reasons it was not possible to obtain a detailed understanding of how participants defined or perceived the ARA itself. The current study seeks to address the limitations of Orlowski's study by purposively sampling individuals from a variety of religious and spiritual backgrounds. Additionally, the current study will not restrict inclusion criteria to individuals who describe themselves as having completely recovered from the ARA. The implementation of a semi-structured interview format will permit in-depth exploration of participants' definitions and perceptions of ARA.

\section{Proposed Study}

The research questions and methodology of the current study are designed to remedy several gaps in the existing professional and non-professional literature about ARA. Prior research suffered from the lack of a consistent, empirical definition of ARA, and previous researchers did not conduct in-depth explorations of individuals' perceptions and experiences of ARA. The current study seeks to address these limitations by investigating the following research questions: (a) How do individuals from Christian traditions who identify as abused define the term "abuse of religious authority"; (b) What are abused individuals' current and past perceptions of personal experiences with ARA; (c) How did abused individuals cope during and after the experience of ARA; and (d) What is the nature of the interaction between psychological well-being and the religious/spiritual dimension of ARA? 


\section{Chapter 3}

\section{Method}

\section{Design}

To elicit a data-rich description of the phenomenon under study, the study utilized qualitative interview methodology and grounded theory data analysis. Qualitative methods are instrumental when fleshing out undeveloped constructs and when generating theoretical models (Greene, Caracelli, \& Graham, 1989). An empirical definition and theoretical framework are necessary to guide quantitative research endeavors. The available literature on ARA possesses neither of these prerequisites for quantitative research designs. Therefore, a qualitative research design is the most appropriate approach. In addition, the purpose of grounded theory methodology is to construct theories that are rich in detail and firmly "grounded" in the data (Corbin \& Strauss, 1990; Glaser \& Strauss, 1967), making this method the most appropriate strategy for data analysis. The data were analyzed in three phases: 1) Open coding, in which the transcripts are reviewed line-by-line to identify general themes; 2) Axial coding, in which the codes generated during open coding are analyzed for greater detail (i.e., when, where, why, with what consequences) (Boychuk Duchscher \& Morgan, 2004); and 3) Selective coding, in which the codes are organized around core categories across transcripts in a way that coherently links the themes in context.

The researcher, who is a doctoral student in counseling psychology, employed a semistructured interview to address the research questions. Use of a semi-structured interview allowed the flexibility to follow up on and clarify new information that emerged during the interview process. In addition, the interview format gave participants the freedom to disclose only that which they felt comfortable revealing. The researcher anticipated significant difficulty 
identifying potential participants who live in the same geographic region, and traveling to conduct interviews in person would likely incur considerable expense. Therefore, interviews were conducted remotely via telephone. The duration of the interviews was approximately one hour to one hour and 15 minutes. Each interview was scheduled based on the individual participant's preference. During the interview, the researcher was located in a closed, private room that was sufficiently removed from other individuals who could overhear the conversation. Participants were encouraged to choose a comfortable location with similar privacy arrangements in which to be interviewed.

\section{Participants}

Given the absence of an empirical definition of ARA with which to identify participants, the current study employed an adaption of the selection criteria utilized by Cudmore (2002) and Orlowski (2010). The following inclusion criteria were utilized: (a) the individual experienced emotional and spiritual distress that occurred in a religious or spiritual organization or group; (b) the distress was perceived as a painful and traumatic experience resulting primarily from authoritarian leadership; and (c) the individual is at least 18 years of age, resides in the United States, and speaks English fluently. Individuals were excluded if they did not reside in the United States or had not been members of a Christian group. The sample was restricted to former members of Christian groups in order to efficiently complete a manageable first step in the grounded theory research process.

It was challenging to locate and contact individuals who identify as having experienced ARA for several reasons. Individuals who have experienced ARA might be quite reluctant to disclose their identity due to fear of stigma or exploitation. For example, members of online ARA support forums sometimes do not use their real names out of concern that their former 
group will identify and harass them. Administrators of online discussion forums are therefore unlikely to release forum members' emails, which impacts the generation of a random sample. In addition, mental health professionals who treat individuals who experienced ARA cannot reveal their clients' identities without prior written permission from the client.

Given the challenges of generating a random sample with this population, convenience sampling was employed. Based on the recommendations of experts in the field of qualitative research (Hill, Thompson, \& Williams, 1997), the study sought to recruit a minimum of 15 participants for the study. However, more than 15 individuals expressed interest in participating in the study. Participants were selected based on inclusion criteria and timeliness of their response to the researcher's communications.

A total of 29 individuals responded to the request for research participation and participated in the initial telephone interview. Of these individuals, two did not meet inclusion criteria, one did not notify the researcher of the desire to participate in the research, four did not return the informed consent form, four withdrew from the study prior to data collection, one withdrew after data collection, and one was unable to complete the data collection. Therefore, a total of 17 participants completed the interview portion of the study.

Of the 17 participants who completed the study, 15 returned the demographic form (Appendix A). The following descriptive statistics are based on those 15 returned demographic forms. The mean age of participants was $45(\mathrm{SD}=12$, Range $=40)$, and $60 \%$ of participants were female ( 9 female, 5 male, 1 no response). Slightly over half $(53.3 \%)$ of the participants were married or partnered ( 8 married/partnered, 5 single, 1 cohabiting, 1 separated/divorced). The majority of participants (93.3\%) were Caucasian, non-Hispanic/non-Latino(a) (14 Caucasian, non-Hispanic/non-Latino(a), 1 African/African-American). All participants had 
completed at least some college or graduate school and were also employed (14 employed, 1 not employed). The distribution of household income was bi-modal, with the majority of participant households earning between $\$ 30,000$ and $\$ 69,999$ per year $(2 \$ 0-\$ 9,999 ; 2 \$ 10,000-\$ 19,999 ; 4$ $\$ 30,000-\$ 39,999 ; 4 \$ 50,000-\$ 69,999 ; 3 \$ 90,000+)$. Slightly over half of responding participants described their current religious/spiritual identification as Christian or Other Christian $(n=8)$, while the remainder identified themselves as agnostic, atheist, or not religious $(n=7)$. Similarly, $53.3 \%(n=8)$ of responding participants stated that they currently attend religious or spiritual services, while the remainder $(n=7)$ stated that they did not attend services. Of those who reported currently attending services, $75 \%(n=6)$ stated that they attended a Christian group.

\section{Measures}

To elicit a data-rich description of the phenomenon under study, qualitative interview methodology was used. Qualitative methods are instrumental when fleshing out undeveloped constructs and when generating theoretical models (Greene, Caracelli, \& Graham, 1989). The researcher employed a semi-structured interview to address the following research questions: (a) How do individuals from Christian traditions who identify as abused define the term "abuse of religious authority"; (b) What are abused individuals' current and past perceptions of personal experiences with ARA; (c) How did abused individuals cope during and after the experience of ARA; and (d) What is the nature of the interaction between psychological well-being and the religious/spiritual dimension of ARA? The use of a semi-structured interview allowed the flexibility to follow up on and clarify new information that emerged in the interview process. In addition, the interview format gave participants the freedom to disclose only that which they felt comfortable revealing. Items for the semi-structured interview were generated based on the research literature on cult involvement, post-cult adjustment, and cult-related psychological 
distress, as well as the lay literature on ARA. To ensure that items were relevant to the research question and were worded appropriately, an outside researcher who was experienced in the study of spirituality and psychology was asked to review the interview protocol. The researcher incorporated the reviewer's feedback into the final interview protocol.

Participants' questions. The interview protocol included a standard demographic form that was created for this study. It requested participants to provide information about their age, gender, race/ethnicity, marital/relationship status, occupation, years of formal education, socioeconomic status, and current and past religious affiliation. For the purposes of this study, the researcher was interested in gathering information about the extent of participants' involvement in groups that engage in ARA. Therefore, the demographic form also requested participants to provide the name of the group, whether the group was affiliated with a larger entity, the approximate size of the group, the average number of hours per week spent attending formal or informal group events, the average number of hours per week spent performing grouprelated activities or obligations, age at entry into the group, length of time in the group, length of time since exiting the group, and whether the participant held a leadership position in the group (and, if so, a brief description of that position). If the participant was a member of more than one group that he or she identified as engaging in ARA, this information was requested for each group. The demographic form can be found in Appendix A.

The protocol also included open-ended questions to elicit a description of participants' definitions of ARA, their engagement and involvement with the abusive group, their beliefs and expectations about the group, the nature of any traumatic experience(s) in the group, the process of exiting the group, post-exit adjustment experiences, and coping strategies. The following open-ended questions were utilized: 
1. What was it like for you being a member of religious group?

2. Could you tell me about some of the positive experiences, if any, that you had as a member of this religious group?

3. Could you tell me about some of the negative experiences, if any, that you had as a member of this religious group?

4. How did you first become involved as a participant or member of (name of religious group)?

5. What did you believe about your religious group when you first joined it? What expectations did you have about your religious group when you joined it?

a. Did these beliefs and expectations change while you were in the group?

i. If so, what led to this change?

6. What kind of rules did the group have? How did you learn them? How were they enforced?

7. What kinds of group-related activities were you involved in? Please describe your involvement.

8. Did you ever have any experiences in your group where you felt like your religious leaders, or those in positions of religious authorities, engaged in behaviors that were abusive?

9. What are some examples of abuse of religious authority that happened to you?

a. How did this affect you while you were in the group?

b. At the time, how did you cope with these effects?

10. Please describe the decision to leave the group. How did you leave and what was that experience like (i.e., how did the group respond, how did you feel, etc.)? 
11. How did your experience with this group affect you immediately after you left? What did you find difficult? What did you find easy, if anything?

a. At the time, how did you cope with these effects?

12. How does your experience in the group affect you currently?

a. How do you cope with these effects today?

13. Please describe how your experience in this group impacted your faith or spirituality.

If the participant was a member of more than one group that he or she identified as abusive, the participant was asked to respond to the question with the group that was most relevant to their experience.

\section{Procedures}

The research project was submitted to the West Virginia University Institutional Review Board (IRB) for approval. Materials that were submitted with the IRB application included the following: demographic form (Appendix A); interview protocol (Appendix B); text for a discussion forum post/email message that requests research participation and explains the purpose, procedure, and methods of the study (Appendix C); a one-page summary of the research project to be distributed to administrative personnel or mental health professionals who assist with recruiting participants (Appendix D); a script to guide those who assist with direct recruitment to explain the research to potential participants (Appendix E); an informed consent form for participants (Appendix F); and a letter explaining the research project's purpose, procedures, and methods to participants (Appendix G). To demonstrate sensitivity to the possibility that the participants who are being interviewed might demonstrate greater susceptibility to feelings of being exploited and misinformed, the informed consent included the following information: the researcher's qualifications, an explanation of confidentiality, a 
description of measures taken to ensure privacy, a copy of the interview protocol, a description of the methods of data collection and analysis, and a list of possible risks and benefits of participation. The letter of explanation to participants (Appendix G) and the informed consent form (Appendix F) provided the researcher's contact information, as well as the contact information for the faculty member who is sponsoring the research. The informed consent form also included contact information for the West Virginia University Institutional Review Board.

In order to achieve the desired sample size, the researcher attempted to inform potential participants of the study using multiple approaches. The researcher used online contact forms to send a summary of the research project (Appendix D) and the Forum Post/Email Message Text (Appendix C) to the following forums and organizations:

- $\quad$ www.christianrecovery/com/vs/forumdisplay.php? $\mathrm{f}=3$

- $\quad$ www.spiritualabuse.org/supportgroup/index.php

- http://expentecostalforums.yuku.com

- www.christiansurvivors.com/forums

- National Association for Christian Recovery

- Wellspring Retreat and Resource Center (a residential treatment center that specializes in treatment of individuals who experienced ARA)

- International Cultic Studies Association (ICSA)

A response was received from only two of the above-listed sources. The National Association for Christian Recovery declined to distribute the request for research participation to their listserv. The International Cultic Studies Association did distribute the request for research participation to their listserv. Since it was also probable that recipients of the request for research participation would know of other individuals who might qualify for the study, the 
researcher asked recipients to forward the information to individuals who might also qualify for the study (snowball sampling). However, all participants were drawn from direct recruitment from the ICSA distribution of the request for research participation.

The International Cultic Studies Association distributed a copy of the one-page research summary, the informed consent form, and the letter explaining the research using the Forum Post/Email Message Text (Appendix C) as the body of the email. These materials were distributed to the ICSA listserv via electronic mail. Individuals who were interested in participating in the research contacted the researcher via electronic mail to arrange a time for an informational telephone conversation. At the time of the informational telephone interview, the researcher confirmed that the potential participant received a copy of the informed consent form and letter explaining the research. If the potential participant had not received this information, the researcher proceeded with the informational telephone interview and provided the materials to the participant prior to gaining written informed consent. During the informational telephone conversation, the researcher confirmed that the potential participant met the inclusion criteria by briefly inquiring about the nature of the painful or traumatic experience that occurred, age, country of residence, and English fluency. During the informational telephone conversation, the potential participant also received a verbal explanation of the research using the Verbal Script for Direct Participant Recruitment (Appendix E). The potential participant was provided with the opportunity to ask questions about the research project. To decrease the likelihood that potential participants felt undue pressure to voluntarily participate in the study, they were encouraged to wait at least 24 hours after the informational telephone conversation before deciding whether to provide voluntary informed consent. 
Potential participants who expressed interest in participating after completing the informational telephone interview were mailed a copy of the demographic form, interview protocol, and informed consent form. If they indicated that they had not received the letter describing the research, this document was also mailed to them. They were asked to review the material, sign the informed consent form if they wished to participate, and return the informed consent form and demographic form to the researcher by U.S. mail.

Upon receipt of a participant's signed informed consent form and demographic form, the researcher assigned the participant an identification number. The researcher contacted the participant by telephone to schedule the interview. The interview time was based on the participant's preferences. At least one week prior to the interview date, the researcher mailed the participant a copy of his or her signed informed consent form. The researcher also mailed a list of behavioral healthcare resources that included a national suicide prevention hotline and three local behavioral health organizations or psychologists. The behavioral healthcare resources were identified through the Substance Abuse and Mental Health Services Administration online treatment facility locator and the American Psychological Association's online listing of psychologists. The researcher retained the original signed informed consent form.

One to two days prior to the interview date, the researcher contacted the participant by telephone to confirm the date and time of the interview, and to confirm that the participant received the list of local mental health providers. If the researcher was unable to reach the participant by telephone, a generic message was left with only the researcher's name and a request to contact the researcher by email. Confirmation was then obtained through email. At the time of the interview, the researcher contacted the participant via the agreed upon method. The researcher was located in a closed, private room that was sufficiently removed from any 
individuals who could overhear the conversation. Participants were informed that the researcher would attempt to immediately call back at least two times if the interview was interrupted for technical reasons.

The researcher confirmed that the participant had received the behavioral healthcare resources if she had been unable to do so prior to the interview. The researcher reminded all participants that they could discontinue the interview at any time, could skip any questions that they did not wish to answer, and could withdraw their information from the study prior to data analysis. The participant was then informed that the researcher was placing him or her on speakerphone and was beginning audio recording. The participant was then provided with instructions for utilization of the behavioral healthcare resources. The researcher also provided specific information about common limits to confidentiality, including the need to report suicidal or homicidal ideation, and ongoing or unreported child abuse or elder abuse.

Interviews were recorded using a small, high-quality digital voice recorder. The interview followed the finalized interview protocol, and the researcher utilized active listening, clarifying questions, reflection, and summarization to elicit a data-rich description of each participant's experience of ARA. The researcher occasionally asked specific open-ended questions and follow-up questions to gather additional detail. If the participant described past suicidal ideation, the researcher inquired about current suicidal ideation. No participants endorsed current suicidal ideation. Upon completion of the interview, participants were given adequate time to ask questions, discuss concerns, and engage in a debriefing. The researcher reminded participants of the list of local mental health providers. The researcher again reminded the participant of the contact information for the faculty member who sponsored the research, as well as for the West Virginia University IRB, should the participant wish to communicate any 
concerns or complaints about the research process. The researcher asked the participant whether he or she would like to receive a copy of the research results. Once the interview was finished, the participant was thanked for his or her time, and the audio recorder was turned off.

Upon completion of the interview, all audio recordings were downloaded to a passwordprotected computer. The audio files were encrypted and saved to a compact disc, and files were immediately erased from the digital audio recorder. Each compact disc was labeled with the participant's study identification number rather than with the participant's name. The researcher maintained the key that matches participants' names with the codes, and the key was stored with the signed informed consent forms in a locked container at the researcher's locked office or residence. All compact discs were stored in a separate locked container. The researcher transcribed all interviews verbatim, excluding unnecessary verbalizations such as "um" and "you know." Participants' names were not used in the transcript or for labeling the word processing files; the code assigned to their audio file was used instead. The word processing files were stored on a password-protected computer that was stored in this locked room in the researcher's residence. After transcription, the audio recordings were erased from the compact discs. A list of participants who wish to receive the results of the research, as well as their contact information, is accessible only to the researcher and is stored in a locked safe at the researcher's locked office or residence.

The interview transcripts were analyzed and coded using the grounded theory methodology (Glaser \& Strauss, 1967) outlined by Corbin and Strauss (1990). The validity and reliability of the researcher's coding was addressed by requesting that participants review their coded transcripts for accuracy. A letter requesting review of analysis (Appendix L) was mailed to each participant with that participant's coded interview data and a codebook that included 
code definitions. The reliability and validity of the coding is also being addressed through the use of the technique of bracketing. Bracketing involves “... an investigator's identification of vested interests, personal experiences, cultural factors, assumptions, and hunches that could influence how he or she views the study's data" (Fischer, 2009). Since the researcher is the primary means of interpreting the data, it is important to acknowledge the potential impact of such factors on data analysis.

The researcher in this study is a Caucasian female of middle-class socioeconomic status with a background in Protestant Christianity. She is currently active in a Free Methodist congregation. During her earlier years, she experienced a church group in which practices resembled those of a group that abuses religious authority, which was the impetus for the current study. The researcher perceives these experiences to have been negative and deleterious. The researcher acknowledges that this particular faith background could bias her literature review and data analysis toward an assumption that abuse of religious authority exists and can be harmful. However, it has been more than 10 years since the researcher exited this group, and the researcher also recognizes that individuals who participate in authoritarian groups might have beneficial and rewarding experiences. The researcher has spent a significant amount of time processing her past experiences so that they do not unduly influence data collection and analysis. Furthermore, the researcher specifically selected strategies (i.e., external review of protocol questions, participant review of coded material) to counter any potential bias.

After completion of the data collection and data analysis, the West Virginia University Institutional Review Board (IRB) requested that the researcher modify the informed consent form (Appendix J) to reflect specific information about common limits to confidentiality, including the need to report suicidal or homicidal ideation, and ongoing or unreported child 
abuse or elder abuse. The IRB also requested that a letter of clarification (Appendix K) be mailed to each participant to inform him or her of this clarification in writing. 


\section{Chapter 4}

\section{Results}

\section{Former Groups}

Of the 15 participants who returned the demographic form, 14 provided information on one former group and one provided information on three former groups. Therefore, participants described a total of 17 former groups. When participants responded to an item with a range, the highest value of that range was utilized to calculate the following descriptive statistics. This method was employed to avoid inconsistency and underestimation in the calculation of results.

Of the 17 former groups, $88.2 \%(n=15)$ were Christian or Other Christian. The remaining former groups $(\mathrm{n}=2)$ were classified as Other, although the participants considered them to fall under the purview of Christian teaching. The mean age at which participants joined the group was $16.9(\mathrm{SD}=13.0$, range $=40$; median $=18)$, and four participants noted that they were born into the group. The mean length of time spent in the group was 16.5 years $(\mathrm{SD}=$ 11.8$, range $=40 ;$ median $=13)$. The mean number of members in the group was $433.8(\mathrm{SD}=$ 1410.6, range $=4985 ;$ median $=90)$. Responding participants reported spending an average of 28.7 hours per week involved in formal group activities $(\mathrm{SD}=41.5$, range $=163$; median $=10)$ and an average of 27.7 hours per week involved in group-related activities outside of formal events $(\mathrm{SD}=33.1$, range $=131$; median $=15)$. Over half of the participants $(58.8 \%)$ reported that they did not hold a leadership position in the former group. Mean time since leaving the group was 9.0 years $(\mathrm{SD}=6.2$, range $=18.5$; median $=8.0)$.

\section{Codes}

A total of 1638 quotes were selected based upon the researcher's judgment of their relevance to the research questions, as well as notes regarding the participants' level of emphasis 
on the statement during the interview process. The quotes were initially coded into 698 open codes. Axial coding was then conducted, and the open codes were condensed to 157 axial codes. A total of 14 domains (conditional codes), plus the process of coping, were identified through the constant comparative method. The conditional and axial codes, as well as the number of participants for each code, are listed in Table 1. The domains and their relationships to each other are illustrated in Figure 1. The discussion of codes is organized by domain, and numbers in parentheses (represented by "k") include the total number of units included for each code.

Table 1

Conditional and Axial Codes With Frequencies

\begin{tabular}{|c|c|c|}
\hline Conditional Code & Axial Code & \# of Participants \\
\hline \multirow[t]{4}{*}{ Experience } & Initially Good & 6 \\
\hline & Positive and Negative & 3 \\
\hline & Leader as Voice of God & 4 \\
\hline & Comparison to Hell or Concentration Camp & 3 \\
\hline \multirow[t]{4}{*}{ Belief } & Benefit From Group & 3 \\
\hline & Group Positive & 9 \\
\hline & Sole Experience & 2 \\
\hline & Spiritual Pursuit & 6 \\
\hline \multirow[t]{5}{*}{ Expectation } & Assistance & 8 \\
\hline & Integrity & 1 \\
\hline & No Expectation & 2 \\
\hline & Safety & 3 \\
\hline & Spiritual Benefit & 3 \\
\hline \multirow[t]{12}{*}{ Positive Aspects } & Belonging/Direction & 2 \\
\hline & Community & 12 \\
\hline & Explanatory Model & 2 \\
\hline & Feeling Special & 4 \\
\hline & Love-Bombing & 2 \\
\hline & Met Spouse & 2 \\
\hline & Part of Larger Purpose & 5 \\
\hline & Positive Emotions & 4 \\
\hline & Provision of Home & 1 \\
\hline & Spiritual Activity/Change & 3 \\
\hline & Structure & 3 \\
\hline & Travel & 4 \\
\hline
\end{tabular}


Definition of Abuse of Religious

\begin{tabular}{|c|c|c|}
\hline Authority & Abuse & 11 \\
\hline & Abuse of Trust & 1 \\
\hline & Blaming Member & $\underline{6}$ \\
\hline & Deception & 4 \\
\hline & Difficult to Acknowledge & 1 \\
\hline & Ex-Communication & 2 \\
\hline & Excessive Authority & 5 \\
\hline & Felt Normal & 1 \\
\hline & Financial Exploitation & 6 \\
\hline & Fostering Dependence & 2 \\
\hline & Inappropriate Use of God & 6 \\
\hline & Lack of Accountability & 2 \\
\hline & Leader Over Members & 3 \\
\hline & Life Restriction & 2 \\
\hline & Misuse of Power & 6 \\
\hline & Public Shaming & 4 \\
\hline & Spiritual Justification & \\
\hline & Uncertain & 3 \\
\hline & Unquestioning Obedience & 4 \\
\hline$\underline{\text { Rules }}$ & Appearance & 5 \\
\hline & Approved Media & 4 \\
\hline & Arbitrary & 3 \\
\hline & Ask Permission & 2 \\
\hline & Attendance & 3 \\
\hline & Avoid Outside Institutions & 4 \\
\hline & Confess All & 2 \\
\hline & Deny Negative Emotions & 3 \\
\hline & Don't Discuss Leadership's Flaws & 2 \\
\hline & Don’t Question Authority & 9 \\
\hline & Don't Talk Back & 2 \\
\hline & Endure All Suffering & 3 \\
\hline & Lack of Explicit Rules & 2 \\
\hline & Leader Is Ultimate Authority & \\
\hline & Obedience & 7 \\
\hline & Social Rules & 4 \\
\hline & Spiritual Activities & 4 \\
\hline Enforcement Tactic & Abuse & 4 \\
\hline & Ex-Communication/Shunning & 10 \\
\hline & Lecturing By Leader & 9 \\
\hline & Peer Pressure & 6 \\
\hline & Public Shaming & 12 \\
\hline & Religious Consequences & 7 \\
\hline & Social Isolation & \\
\hline Change in Beliefs/Expectations & Discrepancy and Disappointment & 4 \\
\hline & Outside Contact & \\
\hline
\end{tabular}




\begin{tabular}{|c|c|}
\hline \multirow{3}{*}{ Negative Aspects } & Overburdened \\
\hline & Abuse \\
\hline & Avoid Critical Thinking \\
\hline & Blame Member \\
\hline & Brainwashing \\
\hline & Constant Monitoring \\
\hline & Criticism/Public Shaming \\
\hline & Dependence on Group \\
\hline & Doctrinal Demands \\
\hline & Ex-Communication \\
\hline & Excessive Control \\
\hline & Excessive Work \\
\hline & Family Disruption \\
\hline & Financial Pressure/Mismanagement \\
\hline & Invasion of Personal Space \\
\hline & Lack of Informed Consent \\
\hline & Lack of Physical Needs \\
\hline & Lack of Support From Group \\
\hline & Leader Characteristics \\
\hline & Loss \\
\hline & Manipulation \\
\hline & Negative Emotions \\
\hline & Not Being Good Enough \\
\hline & Relocation \\
\hline & Self-Labeling \\
\hline & Social Restriction \\
\hline Leaving & Acknowledging Reality of Doubts \\
\hline & Ambivalence \\
\hline & Benefits Outweigh Risk \\
\hline & Breaking Point \\
\hline & Contact With External World \\
\hline & Difficult \\
\hline & Gradual Process \\
\hline & Group Pressure \\
\hline & Negative Emotions \\
\hline & Negative Response by Group \\
\hline & Outsmarting Leader \\
\hline & Positive Feelings \\
\hline & Reason for Leaving \\
\hline & Shunned \\
\hline & Suicide Attempt \\
\hline Past Impact & Negative Emotions \\
\hline & Negative Self-View \\
\hline & Physical Effect \\
\hline & Psychological Symptoms \\
\hline & Social Damage \\
\hline
\end{tabular}




\begin{tabular}{|c|c|c|}
\hline & Suicidal/Self-Harm & 7 \\
\hline \multirow[t]{7}{*}{ Immediate Impact } & Desire to Die & 2 \\
\hline & Financial & 2 \\
\hline & Negative Emotions & 11 \\
\hline & Psychological Symptoms & 6 \\
\hline & Relief & 3 \\
\hline & Social Damage & 6 \\
\hline & Spiritual Fear & 4 \\
\hline \multirow[t]{9}{*}{ Current Impact } & Caution/Mistrust & 5 \\
\hline & Negative Emotions & 12 \\
\hline & Negative Self-Views & 6 \\
\hline & Pervasive & 3 \\
\hline & Positive & 11 \\
\hline & Practical & 5 \\
\hline & Psychological Symptoms & 5 \\
\hline & Situational Difficulties & 6 \\
\hline & Social Damage & 6 \\
\hline \multirow[t]{20}{*}{ Spiritual Impact } & Avoid Religion & 5 \\
\hline & Avoidance of Legalism & 2 \\
\hline & Cautious & 2 \\
\hline & Change in Religious Beliefs & $\underline{2}$ \\
\hline & Church Attendance & 4 \\
\hline & Disrupted Relationship With God & 6 \\
\hline & Empathy For Others & 1 \\
\hline & Independence & 3 \\
\hline & Loss & 1 \\
\hline & Maintained Faith & 2 \\
\hline & Mistrust & 5 \\
\hline & Modified Faith & 2 \\
\hline & More Inclusive & 3 \\
\hline & More Spiritual & 1 \\
\hline & Negative & 2 \\
\hline & Negative Emotion & 3 \\
\hline & Questioning & 5 \\
\hline & Questioning God & 3 \\
\hline & Spiritual Abuse & 4 \\
\hline & Strengthened & 3 \\
\hline \multirow[t]{5}{*}{ Past Coping } & Active Coping & 11 \\
\hline & Non-Disruptive Coping & 5 \\
\hline & Suppression & 5 \\
\hline & Detachment & 4 \\
\hline & Religiously-Focused Coping & 3 \\
\hline \multirow[t]{3}{*}{ Post-Group Coping } & Active Coping & 11 \\
\hline & Avoidance Coping & 2 \\
\hline & Church & 2 \\
\hline Current Coping & Focus on Present & 4 \\
\hline
\end{tabular}


Helping Others 3

Reading/Study 8

Talking 6

Therapy 9

Other 14

Figure 1

Model of Abuse of Religious Authority

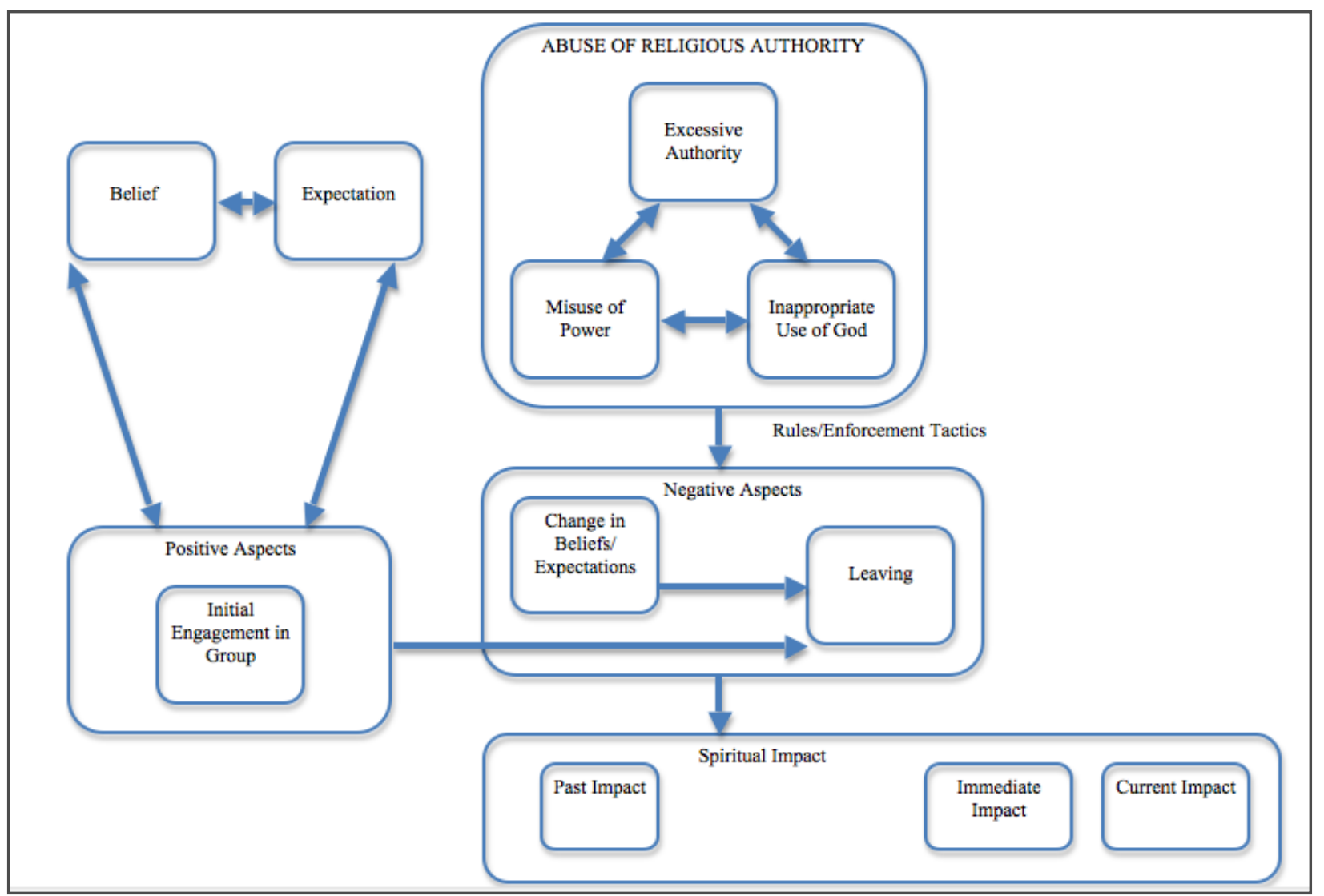

\section{Experience.}

When asked to describe their experience in the group, the majority of participants described negative experiences. These statements were largely categorized into the domain "Negative Aspects". However, the following codes emerged as unique to the domain of "Experience". 
1. Initially Good $(\mathbf{k}=\mathbf{8})$. This code involves participants' recollections of having positive feelings or experiences at the beginning of involvement in the group. One participant stated: "In the early days, it did not seem at all like a cult. It was a nice Bible study. It did not seem....and it was nowhere near as controlling, authoritarian, enmeshed...it had not yet evolved into what it would become.”

2. Positive and Negative $(k=6)$. Statements about having both positive and negative experiences in the group were coded in this category. One statement was: "I had times of joy in the group, and I had times of fear and frustration as well."

3. Leader As Voice of God $(\mathbf{k}=\mathbf{8})$. At least four participants emphasized ways in which the leader's word carried the authority of God. One participant stated: "See there was the Godlike image that we had of those in authority being God. And that they were a source of all authority and counsel and all knowing."

4. Comparison to Hell or Concentration Camp $(k=4)$. Three participants compared their experience as a member of the religious group to being in hell or a concentration camp. As one participant described the experience: “...it had...sometimes even had kind of the feel of like a concentration camp or something."

\section{Belief.}

1. Benefit From Group $(\mathbf{k}=\mathbf{6})$. This code represented participants who described their belief that the group would provide care, help, or positive benefits. As one participant stated: "I really believed that I would get help there.”

2. Group Positive $(\mathbf{k}=\mathbf{1 5})$. As might be expected, many participants reported that they initially believed that the group was positive, trustworthy, accurate, or special. One participant 
stated: "And I believed that they were trustworthy." Another explained: "I believed that they were the only true religious group in the world and that everybody else was wrong."

3. Sole Experience $(\mathbf{k}=\mathbf{3})$. Two participants reported that they did not know of any other possibilities with respect to beliefs. One of these participants stated: “...it was my only reality, so I thought that was what the world was like."

4. Spiritual Pursuit $(k=10)$. This code was used to categorize responses that indicated the participant believed the group was a place of spiritual purity, eliteness, or belonging. As one participant reported: "I thought that these were true Christians."

\section{Expectation.}

1. Assistance $(\mathbf{k}=\mathbf{1 4})$. Several participants noted their expectation that the group would be the source of healing, positive life change, identity, and guidance. Similar to the code "Belief - Benefit From Group", this code was illustrated by the following quote: "I expected that they had information or there was some guidance there that was going to help me with my life."

2. Integrity $(\mathbf{k}=\mathbf{1})$. Although only one participant reported this expectation, it appeared to be an assumption underlying other participants' beliefs and expectations about their group. As stated by one participant: "I had an expectation that they would behave according to Biblical principles.”

3. No Expectation $(\mathbf{k}=\mathbf{2})$. This code was applied when the member noted a lack of expectations for the group: "I didn't really have any expectations."

4. Safety $(k=3)$. This code represented the expectation that the group would be a place of safety and security. One participant stated: "I expected the people to be safe and sane."

5. Spiritual Benefit $(k=4)$. A small number of participants described their expectation that the group was the path to God's blessing, spiritual development, or heaven. One of these 
former members explained: "But at the time I thought, well, this is going to do a work on the inside of me, and I'm giving it unto the Lord, and that I will be more transformed into the likeness of Christ."

\section{Positive Aspects.}

1. Belonging/Direction $(k=2)$. Two participants specifically reported that a positive experience was that the group provided a sense of belonging or direction. As one of these participants described it: "You know, I kind of felt like I knew what the hell I was doing in life."

2. Community $(\mathbf{k}=\mathbf{1 8})$. Most of the participants mentioned the sense of community, camaraderie, or having a connection with others in the group. This was the most commonly cited positive aspect of the group. One participant stated: "And because it was small, there was a sense of community, a sense of family.”

3. Explanatory Model $(k=3)$. This code was used to categorize reports that the group answered questions or helped the member to make sense of life. One former member explained this positive aspect as follows: "I felt like there were answers to a lot of unknowns. The religious group kind of supplied a lot of answers to a lot of questions, you know, mystery type questions. So that kind of felt good."

4. Feeling Special $(k=8)$. Some participants noted that they felt a sense of specialness as part of the group. One of them stated: “...it tugged at our hearts to want to be elite and special."

5. Love-Bombing $(\mathbf{k}=\mathbf{3})$. Two participants specifically used the term "love-bombing" to describe the love and positive attention they received from the group. For example, one participant stated: “...but what happened was they love-bombed us.”

6. Met Spouse $(\mathbf{k}=\mathbf{3})$. Two participants specifically cited the fact that they met their 
spouses in the group as a positive experience. Simply stated: "I met my wife there."

7. Part of Larger Purpose $(k=6)$. This code involves a participant's sense that the group allowed them to participate in something beyond themselves. There was an experience that the participant had a mission or greater purpose. One participant stated: "I was quite amazed that there was something larger than me and I was part of it."

8. Positive Emotions $(k=6)$. Statements about the group contributing to positive feelings were coded under this category. These positive emotions included feelings such as confidence, excitement, hope, and happiness: "So I really had some ecstatic moments when I first joined the group."

9. Provision of Home $(k=1)$. Although only one participant specifically mentioned this as a positive aspect of the group, other participants referred to the fact that the group provided them with a place of residence. Specifically, one participant explained: “...they helped me get off the streets."

10. Spiritual Activity/Change $(\mathbf{k}=4)$. This code was used to categorize statements about a participant's former appreciation for the spiritual practices of the group. It also included statements about opportunities for spiritual transformation. One participant stated: "That I had found a community of believers and could be trained up in the Bible."

11. Structure $(k=3)$. Three separate participants indicated that the group provided structure and order. One of these participants noted: "So I really liked that structural piece, and it made life a lot easier 'cause I really didn't have to make any choices of my own."

12. Travel $(k=4)$. Some participants mentioned the opportunity to travel to other geographic regions or countries. As one participant stated: "I saw a lot of parts of the world. I went on kind of some mission trips with them and got kind of a broader perspective on the 
world."

\section{Definition of Abuse of Religious Authority.}

1. Abuse $(\mathbf{k}=\mathbf{3 0})$. The majority of participants described abuse of religious authority as incorporating aspects of physical, psychological, emotional, social, sexual, and verbal abuse. One statement was: "So there was that verbal, mental, emotional abuse." Another participant elaborated on physical abuse: "And the spankings in particular were just long and hard, and they hurt. The paddle board." Regarding psychological abuse, the same participant remarked: "We were abused in psychodramas." Emotional abuse was described as follows: "So just a lot of emotional abuse, I guess, that also just had religious components to it that was very, it was all just very mixed up together." Social abuse encompassed the following: "There was a certain sort of social abuse that I talked about where you were limited in the amount of time that you could see your families and encouraged not to have outside friends." Sexual abuse was described as follows: "The pastor ripping off my clothes because I had a hole in my pants. The pastor giving me very intense... because he said he used to be a doctor, which I absolutely don't believe. But he would give me personal exams, which were really horrifying creepy." Finally, verbal abuse was illustrated by one participant's quote: "It was a constantly verbally abusive place. Yeah. I mean, it was...it was like trying to describe water to a fish. It was what you were swimming in. Swimming in verbal abuse at that place. It was nasty. [The leader] was very sarcastic. He was rude. He was hurtful."

2. Abuse of Trust $(\mathbf{k}=\mathbf{1})$. This was a statement by a participant that the leader misused the participant's trust in the leader. This participant stated: "You sort of just give them trust automatically. But I know so clearly now that that's the Velcro hook that the bad guy uses. That he's supposed to be trusted by default. And people give them their trust automatically." 
3. Blaming Member $(\mathbf{k}=7)$. Participants described the use of criticism or condemnation to blame the member of feelings of doubt or for failure to uphold excessive expectations. One member explained: "I'd get nauseous and then the saddest part about that is that everybody made me feel that I was the one that was bad..."

4. Deception $(\mathbf{k}=4)$. These were statements that the leader(s) was not transparent or was engaged in deception: "A lot of duplicity and non-transparency and just lying and covering things up."

5. Difficult to Acknowledge $(k=1)$. One member described having particular difficulty acknowledging that the leader was abusive. This was exemplified by the following quote: “...there were a lot of things that we could positively really work on together. But that made it all the more hard to also realize that he was capable of some of the other stuff he would do..."

6. Ex-Communication $(\mathbf{k}=2)$. These were references to the practice and process of rejecting a member from the group. One participant noted: “...but the church excommunications certainly were abuses of authority."

7. Excessive Authority $(k=10)$. Participants described that leaders possessed or emphasized an excessive amount of authority over members' lives. One participant stated: “That sense of if you don't tow the party line, we will crush you. You will, your resistance will be eliminated. You just won't stand up against this kind of sheer, brute power that we have as authority. It's that kind of Orwellian world that both these guys created."

8. Felt Normal $(\mathbf{k}=\mathbf{1})$. One participant reported that, at the time, the experience of abuse of religious authority did not feel out of the ordinary. That participant stated: “... at the time of course it all felt natural, just like somebody who suffers serious abuse, like sexual abuse and that kind of thing. It seems like it's normal when you're going through it I think." 
9. Financial Exploitation $(\mathbf{k}=\mathbf{1 7})$. These were statements that mentioned leaders exploiting group members for money and property, or referring to leaders who misused financial resources. One participant stated: "And then the other thing was the financial abuse. They would say that you had to give them money, that it was your duty to support the minister and that if you were poor, it was really your fault. You just didn't have enough faith.”

10. Fostering Dependence $(k=4)$. Some participants referenced leaders' attempts to counter independence or member confidence. One participant explained: "You're constantly kept in check and always trying to do more just to feel secure."

11. Inappropriate Use of $\operatorname{God}(\mathbf{k}=7)$. Six participants referred to leaders inappropriately using God or the power of God to assure member compliance. Samples of some quotes from participants include: "I mean, when you use God to justify what you're making people do, it's the biggest trump card you can play," and “...it uses the power of God, which is to many people the ultimate power, to turn their minds and their resources towards this man. It's not designed to give, it's completely designed to take."

12. Lack of Accountability $(\mathbf{k}=\mathbf{3})$. This code was used to refer to leaders not being accountable to a higher authority. One participant stated: "And the leadership would not rein [the leader] in."

13. Leader Over Members $(\mathbf{k}=3)$. Three participants described this aspect of abuse of religious authority as when leaders' needs took precedence over members' needs. One of these participants reported: “...so we were all supposed to be about sharing and community, but it was only about sharing and community when it benefitted [the leader] pretty much. And if it was going to benefit you, then it wasn't about that."

14. Life Restriction $(k=3)$. These were references to the members' experience of being 
restricted from engaging in an unapproved activity, such as college or marriage. For example:

“...you were told not to go to college, you were told not to get a high-paying job..."

15. Misuse of Power $(k=14)$. These statements referred to leaders' misuse of religious authority to control members or to gain compliance. For example: "She overpowered us, rather than empowered us," and, "And so I went to him, my youth pastor, and I just told him, and he just sort of got super concerned and was like, 'Clearly you are possessed by demons. That is sign number one of that.' And so instead of asking me questions or using his authority to find out what was going on in my life in terms of stress in the home or anything, like I feel like it could have gone so many other ways other than, "Clearly you're possessed by demons."'

16. Public Shaming $(k=7)$. This code was applied to statements describing experiences when the leaders publicly criticized or made examples of members. "So they kind of made examples of people.”

17. Spiritual Justification $(k=4)$. One participant made several mentions of this theme, stating that the leader provided a spiritual rationale for engaging in abusive or controlling behavior. "But the thing is, no matter how crazy what they do might be, there's always a spiritual justification for it."

18. Uncertain $(k=5)$. These were references to being unsure about whether an experience qualified as abuse of religious authority. One participant stated: "So I don't know if those [examples of my experience] would be considered abuse of religious authority."

19. Unquestioning Obedience $(k=6)$. Participants described leaders requiring complete submission. This included the content of a member's thoughts and beliefs. To illustrate this concept, a participant stated: “...those in authority it was, 'Do what I say or else,' and it didn't matter what it is."” 


\section{Rules.}

1. Appearance $(\mathbf{k}=\mathbf{5})$. This code was used to categorize statements about members being required to dress or look a certain way. This often applied to female group members, although one participant recounted: "We all had to possess and maintain a good and look good. Appearing fine on the outward, on the outside."

2. Approved Media $(k=4)$. These were statements about the member being encouraged to read or study only from approved materials. The use of specific curricula for home education was included in this code. "They discouraged reading anything outside of what...'cause they produce their own literature and they really only want you to read what they produce."

3. Arbitrary $(k=7)$. Participants described the rules as being random or variable. Part of this arbitrariness was the fact that participants would describe not knowing the rules until they were enforced. "...there was just all the time random, random rules."

4. Ask Permission $(k=2)$. This code was used to categorize requirements that the member ask the leader(s) for permission for everything. As one participant stated: “...so the rules became pretty much that all the power is in the hands of the leader and you have to ask permission for everything and pretty much the group controls you and controls your life..."

5. Attendance $(\mathbf{k}=\mathbf{6})$. These were references about rules specifically regarding attendance at group-related activities, whether inside or outside of the group facilities. "...full participation in every activity was required."

6. Avoid Outside Institutions $(\mathbf{k}=\mathbf{8})$. Participants described being discouraged or forbidden to interact with non-group members. However, this code categorized instances in which the member was taught to avoid medical professionals, government assistance, higher education, counselors, or public education. This rule was applied even when medical, 
educational, psychological, or financial assistance was warranted. One participant explained:

“...you're not supposed to get therapists or anybody else outside help because they for sure will lead you astray, and tell you that what you're in is bad. So you're not supposed to get any help from the outside, that's another rule I didn't say. You're not supposed to talk to anybody on the outside or get any help because they're wicked and they'll want us to be wicked and leave."

7. Confess All $(k=3)$. Two participants mentioned a rule that group members were required to reveal all wrongdoing, doubts, and life experiences to the group leader. "There was having to confess every sin and bad thought you ever...that ever came across your mind, which was one of the ways of holding mental and emotional control over people. And there was...that was a huge rule."

8. Deny Negative Emotions $(k=4)$. One of the rules dealt with the suppression of negative feelings, such as discontent, sorrow, or anger. Instead, the member was expected to project well-being and happiness. As one participant summarized: “Don't complain, don't be jealous, don't feel bad, don't be mad, don't be sad."

9. Don't Discuss Leadership's Flaws $(k=2)$. This code dealt with the rule that the member was prohibited from talking about leader(s)'s errors or wrongdoing. One of the participants referred to this type of conversation as "gossip": "One of the other rules was you didn't gossip. So a lot of these things never...people never talked about these things. So nobody knew what was going on, and if somebody did find out, they would just leave. And nothing was said."

10. Don't Question Authority $(k=13)$. These were statements related to members being required to accept the leaders' authority without condition. It incorporated the concept that members should not voice doubts or challenges to the leaders' authority: "You do what you're 
told and when you're told without question."

11. Don't Talk Back $(k=2)$. Similar to Don't Question Authority, these were references to the members not being permitted to respond to the leaders. Simply stated: “... and you'd better just be quiet."

12. Endure All Suffering $(k=7)$. This code was utilized to capture the concept that members should follow the rules and remain dedicated to group teaching no matter what happened. Regardless of how difficult things became, the member was expected to not deviate from the rules. One participant described this rule as follows: "So I guess my expectations were that when shit happens, you still just go through it. You just do what you're required to do...somewhere down the line."

13. Lack of Explicit Rules $(k=2)$. These were two statements about the fact that the rules were not explicitly stated or that the group emphasized its lack of rules: “...the group was fond of saying that they didn't have any rules."

14. Leader Is Ultimate Authority $(k=2)$. One participant specifically mentioned the existence of a rule solidifying the leader's position as the sole authority to make decisions or interpretations. This participant recalled: "And [the group leader] always had the final say."

15. Obedience $(\mathbf{k}=\mathbf{1 0})$. One participant stated: "You had to obey those in authority over you." This code was used to categorize statements about the importance of obeying the rules and the leaders.

16. Social Rules $(k=4)$. This code captured references to requirements that members avoid romantic relationships, adhere to the social hierarchy, and avoid non-members. Speaking specifically about the social hierarchy, one participant stated: "The rules were divine order. Like I told you, the God in the head, then the man, then the woman, then the children." 
17. Spiritual Activities $(\mathbf{k}=\mathbf{5})$. These were statements about expectations to be involved in activities such as fasting, evangelism, prayer, and reading of approved literature. "Oh, and you had to pray. Had to pray. Get on your knees and ask for help in the morning and at night."

\section{Enforcement Tactic.}

Participants were asked to describe how the above-listed rules were enforced. Participants described the following methods of assuring compliance with group norms and rules.

1. Abuse $(\mathbf{k}=\mathbf{5})$. This encompassed the use of physical punishment, verbal attacks, or psychological labeling. While group leaders were the primary actors in these experiences, some participants also described parents engaging in similar behaviors. One former member said: "And in terms of how they were enforced, I guess just like if you did not go along with it, you just pretty much had hell to pay. No pun intended (laughs). Like, he would just get really angry, and just very verbally not pleasant."

2. Ex-Communication/Shunning $(\mathbf{k}=\mathbf{2 0})$. A commonly mentioned method of enforcing rules involved ejecting an individual from the group and withholding contact from that individual. This was referred to as "disfellowshipping," "ex-communication," or "shunning." One participant stated: "So...there was also being shunned. No talking or eye contact from anybody."

3. Lecturing By Leader $(\mathbf{k}=\mathbf{1 2})$. Several participants described leaders offering verbal correction, lectures, or reproof. This correction by the leader ranged in degree from mild to severe: “...but you learned what the rules were because if you stepped outside them, she would criticize you and tell you that, well, by now you should know better." Another participant 
recounted: “...I sat in that office for over an hour getting screamed at and hollered at."

4. Peer Pressure $(k=14)$. These were references to social pressure from other group members who exercised verbal or social influence that resulted in conformity. One participant stated: "The rules were enforced a lot by peer pressure." Another explained: "You would either be rebuked by somebody, taken aside and somebody would clarify to you."

5. Public Shaming $(k=13)$. This code included quotes about the leaders publicly criticizing, demeaning, or revealing personal information about a member. In an effort to illustrate this method, one participant recalled: "They told you that from the pulpit on Sunday, naming people or etcetera or intimidating them."

6. Religious Consequences $(k=15)$. Participants described leaders who communicated to members that failure to follow the rules would result in negative religious consequences. These consequences included being abandoned or punished by God, going to hell, or experiencing spiritual danger: "And I said to the assistant pastor, 'I am not calling you and anymore.' And he said, “Well, if you don't call us [that] anymore, you're losing your covering. And you will be out in the realm of Satan, and you will be in danger."

7. Social Isolation $(\mathbf{k}=\mathbf{5})$. This code referred to statements about being socially rejected or forbidden to speak to other group members while still in the group. One participant stated: "And sometimes you were forbidden to talk to other people. There were a few people who were confined to their room for a week, not allowed to talk to anybody..."

\section{Change in Beliefs/Expectations}

As noted earlier in the Results section, participants described a variety of generally positive initial beliefs and expectations about the group. Several participants described a change in these beliefs and expectations, precipitated by the following factors. 
1. Discrepancy and Disappointment $(\mathbf{k}=11)$. The most common trigger for a change in beliefs and expectations was that the member perceived a difference between what was said and what was done in the group, or the member had disappointed expectations. One participant very succinctly reported: "The group was not what it seemed to be."

2. Outside Contact $(\mathbf{k}=\mathbf{5})$. A few participants mentioned that interactions with nongroup members or unapproved reading materials contributed to a shift in beliefs and expectations: “....and I started also making some new friends and realizing that people weren't what I was always taught to believe that they were."

3. Overburdened $(\mathbf{k}=9)$. This code described participants who experienced the group's requirements or behavior as excessive. The burden of attempting to meet the expectations or follow the rules started the transformation of beliefs and expectations. One participant reported: “... and then when you get home or back to the ministry there, I wasn't allowed to rest or anything."

\section{Negative Aspects.}

1. Abuse $(k=16)$. Several of the participants mentioned experiencing various forms of abuse as a negative aspect of their time in the group. One participant stated that their negative experience included "...the physical, emotional, and sexual abuse."

2. Avoid Critical Thinking $(\mathbf{k}=\mathbf{6})$. These were references to the member not being allowed to form personal opinions or to ask questions. This was illustrated by the following quote: "If you have a thought of your own, then that's wicked."

3. Blame Member $(\mathbf{k}=4)$. Another negative aspect was that some members were blamed for negative experiences. "You know, 'You don't read your Bible enough. You don't go out and service enough. You don't pray enough. You don't...” 
4. Brainwashing $(\mathbf{k}=\mathbf{5})$. Five separate members described feeling brainwashed:

"Because if you had told me, if you had seen me when I was in the middle of all that oppression and brainwashing..."

5. Constant Monitoring $(\mathbf{k}=\mathbf{8})$. These were statements about members feeling that their behavior was constantly watched by leaders or other group members. One participant described this as follows: “....and I always had to watch out for everybody else, 'cause everybody else would run to the pastors about anything you would do or say or anything like that..."

6. Criticism/Public Shaming $(\mathbf{k}=\mathbf{1 8})$. This code was used to categorize references to direct criticism from the leader. It also included public criticism or shaming, such as being belittled in front of other group members. One participant recalled the negative experience of “...getting preached about from the pulpit.”

7. Dependence on Group $(k=9)$. Some participants recounted the negativity of being dependent on the group for physical or spiritual well-being. One participant stated: "I think that the group definitely tried to foster a sense of dependency."

8. Doctrinal Demands $(\mathbf{k}=\mathbf{6})$. Participants also discussed the negative experience of being required to engage in behaviors base on doctrinal teachings. For example: "And because the church did not celebrate Christmas, Easter, or Halloween, sort of the dogma, the doctrine."

9. Ex-Communication $(\mathbf{k}=\mathbf{2})$. One participant described that the process of leaving and rejection by the group was highly negative: “....and also the ex-communication. He would...you could never leave on good terms, ever. Nobody ever left on good terms."

10. Excessive Control $(k=7)$. Another negative aspect mentioned by participants was the leader's excessive control. One participant stated: "There was a very unhealthy authoritarianism about it. There was too much control." 
11. Excessive Work $(\mathbf{k}=2)$. One participant described being required to engage in excessive amounts of work for the group. This participant reported: "We were worked very hard. We were paid very little."

12. Family Disruption $(k=19)$. These were references to experiences of disconnection with one's family, family disruption, or family discord. Participants viewed these experiences as being caused by the group or the group leaders. For example: “... and that was probably the worst. And so you can imagine, I mean, we had no family. And so we were literally cut off physically."

13. Financial Pressure/Mismanagement $(k=6)$. This code was used to represent how the group leaders mismanaged funds or exerted pressure on the participants to turn over finances. One member reported: "So money was a big focus, and they were always talking about money and giving, giving, and giving sacrificially..."

14. Invasion of Personal Space $(\mathbf{k}=4)$. These were statements about the negative experience participants had due to lack of privacy or encroachment on personal space. "So there was no sense of privacy or emotional boundaries or mental boundaries or sexual boundaries. No boundaries were allowed to me, and as soon as I built one up they were systematically destroyed."

15. Lack of Informed Consent $(\mathbf{k}=\mathbf{9})$. These were references to the participants not being informed about group rules or practices prior to engaging in the group. This code represented the absence of information about the group, which contributed to members being unaware of group dynamics. As one participant said: “...but I didn’t know what I was getting into exactly."

16. Lack of Physical Needs $(k=8)$. A few of the participants noted that they lacked 
sufficient sleep, food, safety, or acceptable living conditions. For example, one participant stated: "And we weren't getting much sleep."

17. Lack of Support From Group $(k=3)$. One participant noted that a very negative experience resulted from unfulfilled promises the group made. This participant reported that the group promised social support and did not abide by this agreement: "And those men were so cruel. Convince him that they were his spiritual family... and these guys abandoned my husband."

18. Leader Characteristics $(\mathbf{k}=\mathbf{5})$. Two participants described aspects of the leaders' behavior or personality as being negative. This included the leaders' inconsistency, selfishness, corruption, or abusiveness. “.... and the bad side was that the leadership was engaged in corrupt practices and abusive practices and that's ultimately why we left."

19. Loss $(\mathbf{k}=\mathbf{9})$. These were references to loss of motivation, sense of self, self-esteem, or social connection. Speaking about this topic, one participant stated: "It's the desire that's even lost during all this."

20. Manipulation $(\mathbf{k}=\mathbf{6})$. This was a straightforward code that included statements about manipulation, such as: "The perpetuation of manipulation that happened."

21. Negative Emotions $(k=35)$. By far the most commonly cited negative experience, this code was used to categorize a range of negative emotions. These emotions included feelings such as fear, guilt, hopelessness, loneliness, shame, terror, and worry. Representative comments include: "And so it was really terrifying"; "And you already feel hopeless from all of the beating down that you've taken"; “And when I started doubting and questioning, I mean, I basically got letters that like the devil's getting into you, and believe me it was quite unsettling Because it's like I trust this...I believe this man. This man of God is telling me that Satan is getting into me, 
and it was terrifying. It was terrifying."

22. Not Being Good Enough $(\mathbf{k}=\mathbf{1 2})$. Another theme was that several participants felt that their efforts were never sufficient to please the leaders. As one participant reported: "No matter what I would do, it was never good enough."

23. Relocation $(\mathbf{k}=\mathbf{4})$. This code was used to represent the negative experience of relocating for the group: "I mean, the relocating was huge..."

24. Self-Labeling $(\mathbf{k}=\mathbf{6})$. These were references to participants blaming themselves for negative experiences or emotions generated by the group or the group leaders. For example: "Bad things were happening, so I apparently must have been bad, and so the devil was going to get me or God was going to punish me and that was consistently in my head."

25. Social Restriction $(k=5)$. Five different participants noted the negative experience of not being permitted to have friends outside of the group. One of these participants stated: "We were encouraged not to have any outside friends. There were relationships allowed in the group, but they were kind of supervised."

\section{Leaving.}

1. Acknowledging Reality of Doubts $(k=2)$. This code represented the participant's sense that his or her questions and feelings became real. "This is real. My feelings were real. My soul was telling me the truth."

2. Ambivalence $(\mathbf{k}=\mathbf{2})$. These were statements about the participant having feelings of ambivalence about leaving. As one participant reported: "I wanted to get out so bad, but because leaving meant separation from my family, I didn't have the guts to do it for a long time."

3. Benefits Outweigh Risk $(k=7)$. These were references to the benefits of leaving and the costs of remaining in the group. Overall, participants judged that the benefits were stronger 
than the consequences of leaving, even if one of those consequences was hell. "I just said, I cannot take it anymore, and I realized, I said, 'If God's going to strike me dead, he's going to strike me dead. I'm going to die. I'm just...my spirit is going to be killed in me if I have to continue to go to that church anymore."”

4. Breaking Point $(\mathbf{k}=\mathbf{1 0})$. Multiple participants spoke about an event - either internal or external - that suddenly caused them to decide to leave. One participant stated: “That's when I finally said, 'I've had it.'”

5. Contact With External World $(\mathbf{k}=9)$. These were references to participants' contact with a non-group member or with cult literature. This contact contributed to the decision to leave. One participant mentioned: "...I started going to the library and reading books."

6. Difficult $(\mathbf{k}=9)$. Some participants specifically reported that they found leaving to be devastating, very difficult, or frightening. One said: "It was the most painful thing I ever did in my life."

7. Gradual Process $(k=6)$. A few participants stated that leaving the group was a gradual process that occurred over a period of time, ranging from months to years. For example: “...so we had been slowly distancing ourselves. We hadn't made a conscious decision, but it was kind of an unconscious thing."

8. Group Pressure $(k=3)$. Although several participants spoke of being avoided by other group members, two participants reported that the group attempted to convince them to return. One participant noted: "And then a few, they were like, 'Oh, when are you coming back? We miss you.' Doing sort of the love-bombing thing to try and get me to come back. But and then the elders started calling..."”

9. Negative Emotions $(\mathbf{k}=\mathbf{3})$. These were references to feelings such as fear, loss, and 
pain that were experienced while leaving: "And so it was very painful."

10. Negative Response By Group $(\mathbf{k}=\mathbf{5})$. These were statements about the group or leaders' negativity. One participant stated: "I mean, they were demanding me to come to meetings and explain myself."

11. Outsmarting Leader $(k=4)$. Four participants described feeling as though they were able to outwit the group leader during the process of leaving. One of these quotes is as follows: "But I think it's the one time that I actually outsmarted her..."

12. Positive Feelings $(k=4)$. There were a few references to participants experiencing positive feelings while leaving. These included emotions such as joy and a sense of control: "There are so many wonderful things about it because I was finally out, and I was getting a life and finding myself...”

13. Reasons for Leaving $(k=12)$. This code was used to capture the variety of reasons participants provided for leaving the group. These reasons included realization of abuse, the decision to pursue personal interests, disillusionment, excessive demands, or fear of physical death in the group. One participant stated: "I reached the point where I did not want my children to join the church. I did not want that pastor having authority over them.”

14. Shunned $(k=11)$. Several participants described being shunned by the group or by their family (who was part of the group). This could range from cessation of regular contact to complete avoidance of and refusal to interact with the participant. As one participant noted: "So nobody, nobody had anything to do with us."

15. Suicide Attempt $(k=2)$. One participant reported attempting suicide after leaving. This participant stated: “I tried to kill myself because I didn't know, because in my head I'm like, 'Oh my God, they're right."' 


\section{Past Impact.}

1. Negative Emotions $(\mathbf{k}=\mathbf{4 6})$. This code was applied to quotes discussing feelings such as anger, brokenness, confusion, disappointment, disgust, distress, fear, frustration, helplessness, hopelessness, pain, shame, and worry. A few representative quotes are as follows: "I was a mess emotionally"; "And my anxiety, fear, and doubt grew daily"; "I was constantly terrified".

2. Negative Self-View $(\mathbf{k}=\mathbf{9})$. These were statements referencing self-blame or a participant's sense of failure: "So I always felt like there was something wrong with me."

3. Physical Effect $(\mathbf{k}=2)$. Although there were few participants who mentioned this code, it was used to capture statements about physical illness or tiredness while in the group. One participant stated: “And as I say, I got burned out. I got physically tired..."

4. Psychological Symptoms $(k=15)$. These were references to symptoms of psychological distress, such as depression, dissociation, eating problems, problems focusing, nightmares, and sleep loss. For example: "I ended up being very depressed..."

5. Social Damage $(\mathbf{k}=\mathbf{5})$. This code was used for statements about isolation, loneliness, and trouble fitting in. One participant reported: "I felt isolated, alone, and far removed from society being in [the group], and then if I left I would never fit in again."

6. Suicidal/Self-Harm $(k=10)$. One participant stated: "And I also became very suicidal also." This code includes references to a desire to die or a need to engage in selfharming behaviors.

\section{Immediate Impact.}

1. Desire to Die $(\mathbf{k}=4)$. These were statements about a desire to die or the experience of 
suicidal ideation: "But I wanted to die. I didn't want to live."

2. Financial $(\mathbf{k}=4)$. Some participants spoke about the need to achieve financial security and the difficulty they experienced finding work. One remarked: "I was trying to work a lot "cause I was trying to get money to feel safer."

3. Negative Emotions $(\mathbf{k}=\mathbf{2 7})$. This code was used for statements about feelings such as anger, confusion, exhaustion, fear, feeling lost, guilt, numbness, pain, powerlessness, shock, and sorrow. This wide range of negative feelings and the depth of emotion was captured by one participant's statement: "I cried and wailed like I had never cried before..."

4. Psychological Symptoms $(k=15)$. These were references to symptoms such as depression, binge eating, agoraphobia, disorientation, dissociation, nightmares, panic, PTSD, sleep loss, substance use, and weight issues. Describing the sense of dissociation, one participant reported: "I really had a floating feeling, like I felt very detached from myself."

5. Relief $(k=4)$. A few participants mentioned that immediately after leaving the group, they experienced a sense of freedom and relief. One participant noted: "And so in one sense I would scream for joy "cause I felt so free..."

6. Social Damage $(k=7)$. Similar to the code Past Impact - Social Damage, this code represented experiences of loneliness and difficulty fitting in. For example: "But for a long time, I was kind of lonely "cause I had lost all my friends.”

7. Spiritual Fear $(\mathbf{k}=\mathbf{5})$. Four participants described fear of religious or spiritual consequences immediately after leaving the group. One stated: "I felt like I was going to hell because I had left...”

\section{Current Impact.}

1. Caution/Mistrust $(k=7)$. Some participants discussed that they currently exercise 
caution or that they feel mistrustful of people or certain practices or groups. As an illustration:

"It's really hard for me to be in a group, a closely-knit group, no matter what it is. I do have my guard up."

2. Negative Emotions $(\mathbf{k}=\mathbf{2 4})$. Similar to the codes Past Impact - Negative Emotions and Immediate Impact - Negative Emotions, this code included a range of feelings. These emotions included anger, confusion, exhaustion, fear, guilt, hostility, panic, regret, and shame. One participant stated: "I still don't feel safe in the world, and I kind of have given up hope that I ever will."

3. Negative Self-Views $(k=9)$. These were references to negative perceptions about the self, including brokenness, being injured, feeling like a failure, and self-doubt. For example: "I feel like there's just this constant feeling of shame and failure..."

4. Pervasive $(k=4)$. A few participants reported that the current impact of their experience in the group impacts everything, all the time: "It affects everything. Affects everything."

5. Positive $(\mathbf{k}=\mathbf{1 7})$. A well-populated code, this represented statements about negative experiences that eventually resulted in positive qualities or experiences after leaving the group. Examples include the participant helping others as a result of his or her experience, or qualities such as self-protection, relief, freedom, and wisdom. One participant remarked: "I believe I'm a way more rounded, experienced person in so many, many ways."

6. Practical $(k=7)$. Some participants mentioned the practical implications of their history in the groups. These implications involved confronting issues such as financial hardship, delayed child-bearing, and job considerations. One participant stated: "I'm still terrible with money." 
7. Psychological Symptoms $(\mathbf{k}=11)$. Similar to the codes Past Impact - Psychological Symptoms and Immediate Impact - Psychological Symptoms, participants reported symptoms such as depression, PTSD, and substance use difficulties in the present. For example: "I have been diagnosed with Post Traumatic Stress Disorder.”

8. Situational Difficulties $(\mathbf{k}=\mathbf{8})$. This code was employed to describe problems with specific situations that participants viewed as linked to their experiences in the groups. These included difficulties dealing with authority figures, death, emotions, males, and self-care. One participant reported: “And issues with authority figures. I don't really trust that they have my best interest, and so I guard my heart a lot with people..."

9. Social Damage $(\mathbf{k}=\mathbf{8})$. Similar to Past Impact - Social Damage and Immediate Impact - Social Damage, this code was applied to statements about feeling isolated, withdrawing from others, missing family and a sense of connection, and difficulty fitting in. As a former member described: "I depended on church so much for my social thing, for a while there I was kind of in the middle, like what do I do now?"

\section{Spiritual Impact.}

1. Avoid Religion $(\mathbf{k}=\mathbf{5})$. These were references to participants' avoidance of religion: "I just don't really want to have anything to do with religion right now."

2. Avoidance of Legalism $(\mathbf{k}=2)$. Two participants remarked that they avoid experiences in which religion attempts to control members. As one of these participants stated: "I shy away from any sort of legalism now."

3. Cautious $(\mathbf{k}=\mathbf{2})$. This code refers to a sense of carefulness and self-protection regarding religion: "So I kind of am always on my guard against fundamentalistic thinking."

4. Change in Religious Beliefs $(\mathbf{k}=\mathbf{3})$. These were statements about the participant 
holding completely different views about religion or spirituality. One participant reported: "I've changed my whole approach about my spirituality."

5. Church Attendance $(k=5)$. Four participants mentioned decreased attendance at religious/spiritual services or lack of attendance at services. For example: "How it's affected me is I don't go to church at all."

6. Disrupted Relationship With God $(k=9)$. These were statements about participants experiencing disruption in their connection to God. This included feelings of anger, betrayal, disbelief in God, disconnection, or difficulty trusting God. As one participant noted: "I didn’t know if I had left God. I kind of thought I had. By leaving the group, I had left God."

7. Empathy For Others $(\mathbf{k}=\mathbf{2})$. One participant mentioned that his or her experience made him or her more sensitive to others' suffering: "I know that the Lord allows us to suffer things so that we can comfort others, and that's the biggest lesson I've learned. But sometimes I still don't understand that."

8. Independence $(k=4)$. These were remarks about feeling a sense of freedom from dependence on others to determine participants' religious or spiritual identity. One participant stated: "It's like I'm trying to forge my own path now. Forge my own spiritual path."

9. Loss $(k=2)$. One participant noted a deep feeling of loss and a sense that something is missing: "So I think there's just like constant, always there underlying sadness of something is missing. There's definitely a piece missing."

10. Maintained Faith $(\mathbf{k}=\mathbf{2})$. Two participants stated that their faith continues to remain stable and unchanged through their experiences. One of these participants reported: "So my faith, my faith hasn't faltered..."

11. Mistrust $(k=7)$. These were statements about participants having difficulty trusting 
religious institutions or people. For example: “...it made me distrust any organized religion and any group of people.”

12. Modified Faith $(\mathbf{k}=\mathbf{5})$. Some participants reported that they possess a sense of faith that is different from what they had while in the group. This represented a more moderate adjustment in beliefs than the code Spiritual Impact - Change in Religious Beliefs. To illustrate this concept, one participant's quote is as follows: "And I mean, it's changed the way I view what my spirituality's about and what my faith's about too."

13. More Inclusive $(\mathbf{k}=\mathbf{5})$. These were statements regarding participants holding broader or more inclusive beliefs about God or religion. As one participant said: "I just really am become more inclusive in my beliefs about God."

14. More Spiritual $(k=2)$. One participant reported a sense of greater spirituality than in the past: "I feel like that I'm more spiritual than I've ever been in my whole life, and I'm not in any religion and I love it that way."

15. Negative $(\mathbf{k}=\mathbf{2})$. These were general statements about the overall effect on faith being negative: “...my faith suffered a blow, certainly. And I was very despairing of whether or not I would get any faith back."

16. Negative Emotion $(\mathbf{k}=4)$. This code was used to categorize statements about experiencing negative emotions, such as confusion and fear, in a spiritual context. For example: “...it's been scary too, because even now sometimes I'll go, 'Have I really apostasized?' Because I don't do all the things that you're supposed to do, what they tell you to do."

17. Questioning $(\mathbf{k}=\mathbf{1 1})$. These were references to a practice of asking more questions or being uncertain about one's beliefs. One participant remarked: “I don't... as far as a God, I don't even know if I believe one. Right now, I just want to use my time to kind of explore.” 
18. Questioning God $(\mathbf{k}=4)$. Three participants reported that they wondered where God is currently, where God was in the past, or how God could allow the negative experience to happen. In illustration, one participant explained: “And I truly, truly wonder why the real God allows this to happen."

19. Spiritual Abuse $(k=4)$. Four participants spontaneously used the term "spiritual abuse" to describe their experience in the groups. For example: “... and I found that it was called spiritual abuse at least from what I found."

20. Strengthened $(\mathbf{k}=3)$. A small number of participants indicated that their experience in the group strengthened their faith: "So it made my faith stronger."

\section{Coping.}

1. Active Coping $(\mathbf{k}=49)$. One method of coping that participants described involved actively seeking to address the problem or to alleviate the negative impact. Participants stated that such coping strategies involved actions such as connecting socially, expressing anger, seeking information on the Internet, taking medication, and self-harm. Some participants found that reading, talking to a trusted individual, journaling, or participating in therapy was helpful. For example, one participant stated: "So I started reading that book, and I found comfort in a strange way from reading that book and seeing how that people would give up their lives and be beaten and stoned and hung and burned. Then they would go to heaven."

2. Non-Disruptive Coping $(\mathbf{k}=\mathbf{1 0})$. This code included statements about acceptance or rationalization of group beliefs, as illustrated by one participant's quote: "I mean, you rationalized a lot. See this is the thing. You think you're doing all this for the kingdom of God, so it seems like you're doing the right thing. And even when you're dressing people down and being verbally abusive to them yourself, you believe that you're doing it for their own good. 
Because [the leader] does it to you, and he does it for you for your own good." As another participant described this coping strategy: "It's like all these little things, so it's like they're into everything. When you're in the midst of it, you think, 'Oh well, they're just trying to protect me and to keep me right with God."”

3. Detachment $(\mathbf{k}=\mathbf{6})$. Some participants spoke of coping through detachment, dissociation, or numbness. For example, one participant stated: "And so I just went into a place inside of myself, and I just...the only way I could cope with that was just to go into a detached mode..."

4. Suppression $(k=8)$. Participants described actively attempting to suppress their emotional experience. One participant explained it as follows: "Stuffed it. That's how I coped. I stuffed it. I took the blame, and I stuffed it."

5. Religiously-Focused $(k=7)$. Participants discussed religiously-focused coping that emphasized prayer, reading Scripture, or trying to trust God. One participant stated:

"Memorizing Bible verses. Going over and over and over, just saying the same verse and just...I guess they call it faith, but that's all I had." Another participant described the experience of trying to trust God: "Okay. God is going to take care of this. 'I'm trusting you, God.' And somehow I would make it to the next day. I don't really know how I did it. It was impossible."

\section{Post-Group Coping.}

1. Active Coping $(\mathrm{k}=\mathbf{3 6})$. This form of coping sought to directly address emotions in a healthy and positive way. For example, participants discussed strategies such as accepting emotions, looking to friends for support, extending forgiveness, reading, talking about the experience, and attending therapy. As examples: "I also read a lot of books about cults" and "I also saw a counselor for about 7 months, and she had some understanding of cult issues. 
Enough. And she helped me just sort out a lot of things."

2. Avoidance Coping $(k=4)$. These were statements about employing avoidance, dissociation, or compartmentalization to cope with the immediate impact after leaving the group. As one participant explained this: "And the way that I coped with it is I just dissociated. Shut down. And I went into a trancelike mode to deal with the loss..."

3. Church $(k=3)$. Two participants described finding comfort or assistance in a different religious community. As one of these participants stated: "And when I went, I had to find...the only way I ever connected to this other church was because it was so incredibly completely different in every way. I mean, that it just, it was just something completely unexpected. And I mean, for some reason or another that kind of made an end run around all my defenses, and I was kind of able to do that."

\section{Current Coping.}

1. Focus on Present $(k=4)$. A few participants mentioned the helpfulness of concentrating on the present rather than on past experience in the group. This appeared to be focused on an acknowledgement that participants could not change the past but did have a sense of agency about the present: “...'cause there's nothing I can do about the past. The past is gone. I can't fix it."

2. Helping Others $(k=7)$. This code was employed to categorize statements about assisting current or former members of authoritarian groups. These statements were often focused on raising awareness or providing support after leaving a group. One participant spoke of helping others as follows: "So I think that's one of the ways that we cope with it, is that we're sort of making lemonade if you will, taking a bad experience and turned it around and we're using our experience as a way to help other people. So that gives kind of a redemptive quality to 
the whole thing."

3. Reading/Study $(\mathbf{k}=\mathbf{1 3})$. These were references to engaging in reading or study, often about cults or abusive religious leadership, or reading inspirational material. The centrality of this coping strategy is illustrated by one participant's quote: "I read a lot, you know, I actually studied what was going on. Surviving that kind of experience."

4. Talking $(\mathbf{k}=\mathbf{1 0})$. These were statements about talking to others, including other exmembers, about the experience in the group or post-group adjustment. One participant remarked: “And I think that that's part of...for me, has been part of the healing process. I mean, I kind of tucked away those years until, well, it would come up periodically, and talking about it has really helped."

5. Therapy $(k=11)$. Several participants described participating in therapy or counseling. One participant stated: “And I think that has been invaluable to me...It hasn't been focused this entire time on processing old things, but just having it there for whatever I needed it to be there has been really helpful."

6. Other $(k=45)$. The majority of participants' remarks represented a variety of coping strategies that did not cluster easily into more specific codes. These strategies included confronting one's fear, connecting socially, disengaging from spirituality, participating in outside organizations, taking medication, and journaling, among other coping methods. For example: "So I think having some understanding and going to [ICSA] - which it's not a Christian organization, it's secular and it's scientists that really have studied and understand - helped me probably more than anything else." In addition, another participant explained: "So I'm seeing the connection between getting out there and making yourself available for something and just in spite of the negative feelings, in spite of all those old tapes of you're not enough, you're bad, you 
can't do this, you're too weak, you're crazy...all the messages that I got all those years." 


\section{Chapter 5}

\section{Discussion}

The purpose of the current study was to address limitations of prior research on abuse of religious authority (ARA). Specifically, the current study sought to develop a consistent, empirical definition of ARA, in addition to conducting an in-depth exploration of individuals' perceptions and experiences of ARA. In accordance with these goals, the following research questions were posed: (a) How do individuals from Christian traditions who identify as abused define the term "abuse of religious authority"; (b) What are abused individuals' current and past perceptions of personal experiences with ARA; (c) How did abused individuals cope during and after the experience of ARA; and (d) What is the nature of the interaction between psychological well-being and the religious/spiritual dimension of ARA?

The results of the current study included 14 domains, plus the process of coping over time. These domains and their relationship to each other are illustrated in Figure 1. In summary, participants reported an initial positive perception of the religious group where the ARA occurred. The positive beliefs, expectations, and experiences contributed to engagement in the group, as well as to continued involvement in group activities. Participants described the frequency and intensity of negative experiences as eventually outweighing the positive experiences. The negative experiences, which included psychological distress and painful emotions, contributed to a change in beliefs and expectations that subsequently led the participants to leave their respective groups. Overall, these domains combined to result in various consequences over time (i.e., while in the group, immediately after leaving, and at the present time). These consequences were largely deleterious and required ongoing efforts to cope with the continued impact. 
This study contribute substantially to the literature on ARA. First, it established an empirical definition of ARA. Second, it offered a theoretical model of ARA. Third, it explored the experiences of individuals who directly experienced ARA, addressing a research question that Gubi and Jacobs (2009) had not investigated. Fourth, it expanded the studies conducted by Orlowski (2010) by conducting an in-depth exploration of the abusive situation itself and participants' reactions to those circumstances. Fifth, it extended Cudmore's (2002) research by utilizing a more inclusive sample.

\section{Definition of Abuse of Religious Authority}

Participants' opinions about what constituted ARA were elicited by asking them for examples of ARA that happened to them. It is noteworthy that some participants vocalized their uncertainty about whether an experience constituted ARA. This strongly highlights the necessity of a consistent definition to which both professionals and non-professionals can refer.

Overall, the accounts that participants provided appeared to focus on three primary factors: Excessive Authority, Misuse of Power, and Inappropriate Use of God. Combined with secondary factors, these primary factors constitute ARA (Figure 1). There are bidirectional dynamics among these three factors, such that each factor influences the other two factors. For example, the first of these factors - excessive authority over participants' lives - facilitates and is facilitated by misuse of power. The quality that makes this type of excessive authority and misuse of power unique is that it incorporates an inappropriate use of God to assure compliance. Inappropriate use of God is illustrated by the following quote: “...it uses the power of God, which is to many people the ultimate power, to turn their minds and their resources towards this man. It's not designed to give, it's completely designed to take." Therefore, inappropriate use of God represents the use of divine authority to achieve personal ends. It also employs the name of 
deity in a way that drains those over whom the power is exercised, rather than empowering or benefitting them. This application of divine power was illustrated more fully through the code Experience - Leader as Voice of God. When an individual or group of individuals inappropriately exercised authority that was portrayed as divine, it justified the misuse of power and excessive authority without recourse.

There were also secondary factors that comprised participants' definitions of ARA. These secondary factors represented actions or behaviors that were facilitated by the primary factors. For example, the most prevalent secondary factor - coded as Abuse - took place in the context of excessive authority, inappropriate use of God, and misuse of power. The actions that constituted the physical, verbal, emotional, sexual, or psychological abuse were possible because of the presence of the primary factors. Thus, participants spoke of leaders who fostered dependence, engaged in public shaming, and practiced financial exploitation. These leaders demonstrated a lack of sensitivity to members' needs, did not have adequate accountability, and required unquestioning obedience. Exercising these behavioral features over a group of people was facilitated by the leaders' stature as spiritually superior.

Thus, a definition of ARA must include both the behaviors that are considered abusive, as well as the dynamics through which those behaviors are made possible. Therefore, the following definition of ARA is proposed: a) The misuse of excessive authority and power (derived from a divine source) that b) exploits, harms, controls, or shames an individual with less power. This definition is consistent with that of other researchers who have written about ARA (Cudmore, 2002; Dehan and Levi, 2009; Enroth, 1992; Gubi \& Jacobs, 2009; Rauch, 2009; VanVonderan \& Johnson, 1991). At the same time, it is more specific than other definitions that have been advanced (Masis, 2004; Orlowski, 2010; Wehr, 2000). It is also consistent with the features of 
abusive groups that have been set forth by VanVonderan and Johnson (1991), as well as Lifton (1961). Counseling psychologists can draw upon this definition to recognize ARA, at least among former members of Christian groups, and to operationalize the concept for future research.

\section{Model of ARA}

Overall, participants described an initial positive experience of their groups, which secured their initial engagement with their respective group. The exception to this occurred when individuals were born in the group or joined at an early age as the result of parents' choices. In these cases, participants frequently reported a neutral or negative experience in early childhood, with a transition to a definite negative experience during adolescence or early adulthood. However, individuals who were not born in the group reported that they held generally positive expectations and beliefs prior to joining the group. For example, participants reported expectations of assistance, integrity, safety, and spiritual or practical benefit. Many participants believed that their group was positive and would be a place of spiritual purity or belonging. As illustrated in Figure 1, Belief and Expectation exercised a mutual influence on each other. Each also possessed a bidirectional influence with Positive Aspects. In other words, the positive aspects of the group, such as community and spiritual activity, tended to build positive beliefs and expectations, at least in the beginning.

As represented in Figure 1, participants began to experience ARA after the progression of time. Described in the previous section, ARA was constituted of mutually influential relationships among the primary factors of Excessive Authority, Misuse of Power, and Inappropriate Use of God. However, ARA also incorporated the broader, secondary factors, which are represented by the larger region surrounding the primary factors in Figure 1. Rules 
and Enforcement Tactics were the core mechanisms through which ARA was implemented. For example, the rule coded Don't Question Authority is an expression of both Excessive Authority and Inappropriate Use of God. Leaders who reportedly implemented this rule would capitalize on their stature as spiritually superior or as God's spokesperson (inappropriate use of God) to demand total compliance from members (excessive authority).

Interestingly, some of the same facets that participants formerly perceived as positive were later viewed as abusive. For example, some participants mentioned that the structure provided by the group was a positive aspect of their experience, at least initially. However, excessive control over life choices and daily activities represented one of the negative aspects discussed by participants. It is possible that the degree of structure and rigidity increased with time. Given that one of the negative aspects participants cited was lack of informed consent, it is more likely that many participants were not fully aware of how the group functioned when choosing to join the group. Thus, group characteristics would seem to be innocuous or even beneficial at the outset. Perceptions became more negative when participants later realized the full impact of these characteristics.

Another interesting observation relates to how the positive aspect of community was transformed to enforce ARA through its use as an enforcement tactic. Participants described the application of peer pressure and public shaming as means to enforce group rules. Therefore, the most commonly mentioned positive attribute - community - was also the source of reinforcing ARA. Withdrawal of community support and approval was also part of the ultimate punishment, as exemplified by ex-communication and shunning.

Thus, through rules, enforcement tactics, and exploitation of a sense of community, ARA contributed to the negative aspects that participants experienced. However, at the time of the 
ARA, not all participants believed that the group was the source of the negative experience. For example, some participants described attempts to rationalize or accept the ARA. After time and several negative experiences, most participants begin to experience a change in beliefs and expectations. This modification contributed to decision to leave the group, but the positive aspects of the group also influenced this choice. Some participants described feeling ambivalent about leaving due to the influence of positive experiences. One participant explained that he or she delayed the decision to leave the group in the hope that the positive experiences would resume. Ultimately, each participant chose to leave the group, frequently as the culmination of a gradual process.

Therefore, answering the question of how participants were impacted by their experiences requires consideration of how all the components of the model interact. Past impact, immediate post-group impact, and current impact are the results of how ARA created negative experiences through rules and enforcement tactics. These experiences eventually became so severe that some participants were willing to risk eternal damnation to escape them. When this occurred, the benefits outweighed the risks of leaving. At the same time, the reality of positive experiences made it difficult for many participants to change their beliefs and expectations, and made it challenging to leave the group. Thus, a discussion of impact requires a comprehension of these intertwined dynamics, all within the context of threats of spiritual failure, abandonment by God, and eternal loss.

The current perceptions of ARA reveal the dominance of negative experiences. Although not specifically solicited by the study protocol, many participants referred to their former groups as "cults". Overall, participants also reported a host of negative emotions and psychological symptoms that are consistent with existing post-cult adjustment literature (Aronoff et al., 2000; 
Ash, 1985; Buxant \& Saroglou, 2008; Dubrow-Eichel, 2002; Gaines et al., 1984; Malinoski et al., 1999; Martin et al., 1992; Swartling, 1992; Winocur, Whitney et al., 1997). It is particularly important to note that some participants were especially fearful of severe religious or spiritual consequences immediately after leaving the group. In general, the negative experiences continued to exert an effect on participants from the time they were in the group until the present. It is critical for counseling psychologists to understand the phenomenological experience of individuals in similar circumstances, because it is likely that such individuals will display similar symptom profiles and emotional challenges. Counseling psychologists can be of assistance by helping each individual to address his or her particular constellation of negative emotions. In addition, providing evidence-based psychotherapy for psychological symptoms, such as depression or anxiety, will help individuals to cope with psychological distress. Finally, it will likely be important to sensitively help the individual to navigate social reconnection in a way that is safe and rewarding.

Participants described a range of ways in which their experiences in the groups impacted them spiritually. The most frequently cited spiritual consequences included questioning one's beliefs, experiencing a disrupted relationship with God, and having a sense of mistrust toward religion or religious individuals. The presence of an insecure connection to God has been linked with poor psychosocial adjustment (Khan \& Watson, 2006; Millspaugh, 2005b; Pargament et al., 1998; Pargament, Zinnbauer et al., 1998; Pargament et al., 2000; Pargament et al., 2001; Rosmarin et al., 2009; Ryan et al.,1993; Tarakeshwar et al., 2003; Tix \& Frazier, 1998), which may account for part of why participants continued to experience negative effects. However, several participants reported feeling positively about their change in spiritual beliefs, including those who no longer subscribed to the idea of God. Therefore, the link between participants' 
sense of connection to God and psychological well-being was more complex than merely assuming that lack of connection to God equated to psychological distress. It is possible that psychological well-being, to some extent, is dependent on an individual's current perception of the relevance of a connection with deity.

Another explanation for how the religious/spiritual dimension of ARA might impact psychological well-being is found in Millspaugh's (2005a) spiritual pain equation:

(Awareness of death + Loss of Relationships + Loss of Self)(Loss of Purpose + Loss of Control) Life Affirming and Transcending Purpose + Internal Sense of Control

Participants cited the loss of relationships through ex-communication and shunning. In addition, many participants had described their group as a source of purpose. However, participants' accounts revealed that they did not perceive their leaders' behaviors to be life affirming. Furthermore, loss of the group could lead to associated loss of purpose. Thus, ARA impacted three components of this equation, likely contributing to greater spiritual pain. Religious strain and spiritual struggle have been linked to a variety of negative psychological and psychosocial outcomes, including panic disorder and agoraphobia, depression, suicidality, anxiety, decreased self-esteem, poorer physical health, anger, paranoid ideation, obsessive-compulsive symptoms, somatization, and disrupted relationships (Bryant \& Astin, 2008; Exline et al., 1999; Exline et al., 2000; McConnell et al., 2006; Trenholm et al., 1998).

However, some participants reported that the experience with ARA led to greater spirituality, strengthened faith, or a positive spiritual perspective that did not include God or Christianity. These participants appeared to experience spiritual post-traumatic growth. Counseling psychologists will need to be aware of the range of spiritual effects individuals who experience ARA might report. It would be erroneous to assume that every participant wishes to avoid religion or that those who choose to avoid religion will suffer psychologically due to the 
loss of faith. Counseling psychologists should be aware that each individual's spiritual journey will differ, and some - but not all - individuals will need to re-negotiate their relationship to religion or God. This is likely to be a gradual process that involves a significant questioning of previously held beliefs. Finally, counseling psychologists must consider that individuals may or may not experience spiritual post-traumatic growth. Therefore, it would be best for psychologists to periodically and respectfully check with individuals regarding the status of spiritual/religious beliefs. If those beliefs are changing, it would also be helpful to inquire about individuals' perceptions of the process of re-evaluation.

\section{Coping}

Overall, participants described a wide variety of coping methods, the majority of which were active. While participants were still in the group, they engaged in active coping strategies such as taking medication, reading, engaging in suicidal ideation, therapy, or talking to individuals who were trustworthy. Participants also mentioned religiously-focused coping, such as prayer or reading the Bible. At the same time, descriptions of coping while still in the group had the highest proportion of more avoidant forms of coping. These strategies included detachment and suppression, as well as non-disruptive coping. Non-disruptive coping was a non-resistant form of navigating difficulties by accepting the group's beliefs or attempting to rationalize them. It is likely that participants engaged in a higher percentage of avoidant coping due to group rules that restricted them from accessing more active forms of coping. This finding is meaningful for counseling psychologists in that it highlights the variety of adaptive coping approaches participants utilized. Individuals who are still members of a group that engages in ARA might be reluctant to dissent, as this may represent a coping mechanism. Counseling psychologists can assist such individuals by first creating a safe, non-judgmental environment 
that does not exert pressure on the individual to disagree with the group. The next step would be to gradually assist the individual to explore thoughts and feelings about the group and its practices, without the expectation that the individual will choose to exit the group. If the individual does acknowledge doubts about the group, it will be critical for the counseling psychologist to facilitate the use of alternate coping strategies to manage negative emotions that could arise.

The majority of participants described active coping immediately after leaving the group. This type of coping was very similar to the active coping that was utilized while still a member of the group. However, this form of active coping tended to include reading that was focused on cults. It also involved fostering new social connections and re-establishing former relationships with other ex-members. A few participants described attempting to avoid their emotions or dissociating. If a counseling psychologist encounters an individual in this stage of the process, it will be important to recognize that he or she might not be prepared to process the ARA. On the other hand, the individual might require assistance with negotiating relationships in a new social context. He or she might also wish to discuss literature, and counseling psychologists might be able to facilitate this by incorporating reading selections into bibliotherapy.

Finally, participants described a broad range of coping mechanisms for their current lives. Many of these strategies included talking to others and reading or studying about abusive religious leadership. Coping also began to adopt a more philosophical focus, as participants described attempts to concentrate on the present. Participants also developed an emphasis on advocacy to assist other survivors of ARA. Aside from these themes, there were multiple methods of actively and currently coping with the ARA experience. With this information, counseling psychologists can be prepared to respond to the diversity of coping styles ARA 
survivors will likely present. Remaining open to a spectrum of healthy coping methods will help the counseling psychologist to assist such individuals to discover adaptive strategies. It will also be important to remember that some, though not all, individuals may wish to become involved in anti-cult advocacy or ex-member support groups.

\section{Response to Interview}

Participants reported a range of responses to engaging in the interview process. Six participants described experiencing negative emotions, such as anger or fear. One stated: "I felt sad. I felt angry. I felt pain. I felt incredulity that this had ever happened." At the same time, over half of these participants joined other interviewees in discussing their desire to be of assistance. There was a sense of wishing to help others who had similar experiences, as one participant summarized by saying, "I'm glad to help contribute to the body of information, and because this is...knowledge is power, and this is...when I think of how I read that book and light bulbs came on about breaking free from cult mind control, you know, who knows what power will be if you get this done and get it out there. Who knows how many people it will help."

Ten participants reported positive or neutral reactions to the interview process. For example, one participant stated: "Yeah, I mean, it's not the first time I've talked about any of it, but it feels good to talk about it. And to somebody with fresh ears, and I mean I'm happy that all of this is going to go somewhere too." There were also expressions of appreciation, such as the following quote: "I always appreciate the chance to tell people about what it was like so that they're more aware, and I am very thankful that you're actually researching this, because I haven't heard of many people that are." Finally, two participants expressed surprise that their response to the interview was different from what they had expected. One of these participants was surprised at feeling emotional, while the other was surprised that the interview process was 
not upsetting.

\section{Participants' Recommendations for Helping Professionals}

A few participants shared their observations of important considerations for helping professionals. One critical building block was the necessity of professional helpers possessing knowledge of ARA and its impact. As one participant stated: “... and see that's one of the issues in present day counseling and psychology is not really understanding the effects of spiritual abuse of authority. Thought reform is that, I think, it's not belittled, but it's put in a secondary mode." Another participant strongly emphasized the importance of countertransference issues. Specifically, this participant discussed the negative impact of a professional helper who was unable to contain the "reality" of the ARA. In that participant's words: “... but every time I go to therapy it feels like, oh, my God. The therapist has had really bad reactions to them. They don't have context for it. They don't have experience with it."

Another recommendation included allowing the client to disagree with the therapist. Given the power imbalance that is inherent in the therapeutic relationship, as well as the misuse of power that is a central feature of ARA, it is understandable why this would be crucial to many individuals. One participant noted that individuals who experienced ARA might be more sensitive to feeling abandoned by the helping professional. The same participant noted that helping professionals should be aware that survivors of ARA might have an ambivalent approach to depending on the helping professional. Therefore, it would likely be helpful for helping professionals to explicitly and regularly emphasize the collaborative nature of therapy. Connected to the issue of dependence is the issue of trust. As one participant explained: "I just can't trust whether or not they're really interested in me. So in a counseling situation, that would be a barrier that I would have to get over. Could I really trust that person? Is there something 
behind it? Is there an ulterior motive?" Therefore, helping professionals should not view difficulty trusting as pathological; rather, given the circumstances involved in ARA, mistrust of an authority figure may well be adaptive and self-protective. Helping professionals can help to establish a sense of trust by demonstrating integrity and setting realistic expectations. One participant illustrated this advice as follows: “And not make promises, which is, 'I'm always going to be here for you. I really care.' Well, not make promises that they might have to renege on, but realistic kinds of things, like, 'I might disappoint you. I might have to cancel an appointment because of having surgery."”

\section{Clinical Applications}

The most critical clinical application of the current study is the necessity of comprehending the negative impact of ARA. This impact entails consequences that involve multiple aspects of personal functioning, including emotional, physical, psychological, social, and spiritual health. Furthermore, the psychological distress generated by ARA can lead to suicidal and self-destructive behavior in a minority of individuals. Therefore, clinicians who work with an individual who experienced ARA should be especially vigilant for suicidal ideation or self-harming behavior. The clinician should approach these topics in an open and nonjudgmental manner, assisting the individual to identify sources of support and safe coping strategies to soothe overwhelming emotions. Regardless of the presence or absence of suicidal ideation and self-harming behaviors, treating survivors of ARA will likely require a multidimensional, integrative case conceptualization. This conceptualization should be dynamic in nature, maintaining flexibility in keeping pace with the client's process of recovery from and perceptions about the experience of ARA. The conceptualization should also include the multicultural component of spirituality. 
The question of whether individuals who experience ARA meet criteria for a specific psychological disorder is difficult to answer. Participants' descriptions of negative self-views, feelings of guilt and hopelessness, and a pervasive sadness fit a profile of a depressive disorder. It is likely that these individuals may suffer from Major Depressive Disorder, especially during and immediately after involvement in the group. In addition, some participants reported being diagnosed with Post-Traumatic Stress Disorder. Some participants endorsed psychological symptoms that are consistent with features of PTSD, such as hyperarousal, re-experiencing, and active avoidance or avoidance through dissociation. The data collected from this study suggested that ARA is sufficiently threatening to qualify as a potential Criterion A stressor. However, clinicians should carefully consider whether an individual's experience of ARA constitutes a Criterion A stressor. Other individuals may suffer from an Adjustment Disorder in response to the stressor of being in the group, leaving the group, or adjusting to life outside the group.

Given the range of potential emotions and psychological responses to ARA, clinicians should conduct thorough assessments of depressive and anxiety disorders. A complete evaluation should also include assessment of impulse control and substance use disorders, as these might function as coping mechanisms for survivors of ARA. Treatment should be offered utilizing evidence-based criteria (e.g., Cognitive Processing Therapy for PTSD symptoms related to guilt and shame, Cognitive Behavioral Therapy for Depression for depressive symptoms, etc.). However, given individuals' prior experience of excessive control and diminished autonomy, clinicians should offer multiple options with respect to treatment planning. Clinicians can then encourage individuals to build decision-making skills through the process of establishing treatment goals and selecting treatment approaches. 


\section{Ethical Considerations}

During the interview process, several participants disclosed past child abuse or neglect. The researcher advised participants prior to beginning the interview of the limits of confidentiality with regard to mandated reporting. The reported abuse or neglect frequently occurred in the past to individuals who were over the age of 18 at the time of the current study. In some instances, participants reported abuse that had occurred to individuals who were currently under the age of 18 . In all cases of reported abuse or neglect, the researcher consulted with the academic advisor without disclosing the identity or gender of the participants. As this study indicates, it is important for counseling psychologists to be cognizant of the possibility of child abuse or neglect. There is the likelihood that such abuse and neglect is justified by spiritual rationales.

In addition, several participants disclosed past suicidal ideation and, in one instance, a past suicide attempt. When this occurred, the researcher always inquired about current suicidal ideation. All participants for whom this inquiry was made denied current suicidal ideation. Counseling psychologists should be aware of the possibility that individuals who experienced or are experiencing ARA might cope through suicidal ideation. Appropriate precautions, safety plans, and means reduction should be implemented to minimize lethality.

\section{Strengths, Limitations, and Directions for Future Research}

The current study was designed to elicit data-rich, qualitative descriptions of individuals' experiences of ARA. The study had a strong sample size for qualitative research, with a total of 17 participants. The participants were fairly evenly distributed with respect to gender, and similar numbers of participants identified as religious and non-religious. The interview protocol was based not only upon the literature, but also upon the feedback of an outside reviewer. The 
research employed an approach that constructed themes based on participants' perspectives, rather than relying on preconceived theoretical models. This permitted the construction of a participant-driven definition and model of ARA. Finally, in contrast to prior research related to ARA, the current study requested that participants review the results of their interview analyses and provide corrective feedback, strengthening the internal validity of the research.

At the same time, as a qualitative study, this research did not employ an experimental or longitudinal design that would permit definitive conclusions to be drawn about causal relationships. Furthermore, it did not include inquiry into participants' pre-group experiences and how those experiences might have impacted perceptions of ARA and psychological adjustment. Conducting experimental research to parse out the casual relationship between ARA and negative psychological effects would certainly be unethical. However, future research could utilize a prospective, longitudinal, qualitative design to more thoroughly understand how individuals' perceptions of ARA change over time. This would improve the accuracy of selfreport beyond the retrospective design employed in the current study.

The current study is limited in that the researcher, who identifies as having been a member of a group that exercised ARA, conducted the sole analysis of the qualitative data. It is possible that the researcher's experiences and personal opinions biased the results. Future research could employ multiple reviewers or a different qualitative design, such as Consensual Qualitative Research, to address this issue. In addition, the current sample was limited in that it was a convenience sample of individuals who had regular access to the Internet and a telephone. Due to lack of response, the sample was restricted to individuals who were listserv members of the International Cultic Studies Association (ICSA). Individuals who choose to participate in an organization such as ICSA might have more upsetting religious group experiences, or they might 
perceive those experiences more negatively. However, this appears to be unlikely as a review of participants' own statements revealed that the severity of their experience ranged from mild to severe. At the same time, the current study might suffer from a self-selection bias, in that only individuals who perceived their overall experience to be negative were willing to participate in the study. The current sample was also limited in that it was predominantly Caucasian and female. This limits the generalizability of the findings. Future research should attempt to include the perspectives of males and individuals of minority racial backgrounds. Additionally, the current study required participants to engage in retrospective recall of various experiences, some of which had occurred more than a decade earlier. Future research should adopt a prospective, longitudinal research design to address this limitation. Moreover, future research should investigate the presence of ARA in non-Christian religious groups. This type of research would help to validate and modify the definition and model of ARA. Future research should also seek to understand whether the psychological distress associated with ARA represents specific psychiatric diagnoses, as well as which evidence-based therapies are most effective in treating post-ARA symptoms. Finally, the current study represents only the beginning steps in a complete grounded theory approach to the topic of ARA. The directions for future research outlined above should seek counter examples to the proposed definition and model of ARA. This research should purposively sample individuals from a variety of religious groups - both those who are currently members and those whose time since exiting the groups varies. In addition, research should be undertaken to investigate whether the experiences of individuals born into groups that exhibit ARA are different from those of individuals who join in adolescence or adulthood. If such research is qualitative, it can be integrated into the current 
definition and model of ARA until data saturation is achieved, thereby producing a true, grounded theory of ARA. 


\section{Appendix A}

\section{When the Sacred Hurts: Using Grounded Theory to Understand How Former Members Experienced Abuse of Religious Authority in Christian Groups}

\section{Demographic Form}

INSTRUCTIONS: Please complete each of the items to the best of your ability. If there is an item that you do not wish to answer, you are free to leave it blank. However, it is helpful to have the most complete information possible.

How old are you?

Gender (please check one):

$\begin{array}{ll}\text { Male } & \text { Transgendered } \\ \text { Female } & \text { Other (please explain): }\end{array}$

\section{Marital/Relationship Status}

Current Marital/Relationship Status (please check one):

Single
Cohabiting
Married/Partnered
Separated/Divorced
Widowed

\section{Ethnicity/Race}

Ethnicity/Race (please check one):

African/African-American

American Indian or Alaska Native

Asian/Asian-American

Caucasian, non-Hispanic/non-Latino(a)

Caucasian, Hispanic/Latino(a)

Hispanic/Latino(a)

Middle Eastern

Native Hawaiian or Other Pacific Islander

Multiracial (please indicate which ethnicities/races you identify with):

\section{Education}

Highest Grade Completed (please check one):

$\begin{array}{ll}1^{\text {st }} & 7^{\text {th }} \\ 2^{\text {nd }} & 8^{\text {th }} \\ 3^{\text {rd }} & 9^{\text {th }} \\ 4^{\text {th }} & -10^{\text {th }} \\ 5^{\text {th }} & -11^{\text {th }} \\ 6^{\text {th }} & -12^{\text {th }}\end{array}$


Did you attend college, graduate, or professional school?

Yes

If yes, how many credits did you complete?

Did you earn a degree or certificate?

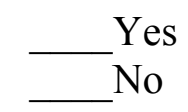

If you earned a degree or certificate, what is the highest degree or certificate you earned (for example, associate's degree, bachelor's degree, etc.)?

\section{Employment}

Are you currently employed for compensation?

Yes

If yes, what is your current occupation?

If you are not employed for compensation, are you currently (please check all that apply):

Working as a homemaker

$$
\begin{aligned}
& \text { Unemployed } \\
& \text { Volunteering }
\end{aligned}
$$

\section{Household Income}

Yearly Household Income (please check one): $\$ 0-\$ 9,999$

$\$ 10,000$ - \$19,999

$\$ 20,000$ - \$29,999

$\$ 30,000$ - \$49,999

$\$ 50,000$ - \$69,999

$\$ 70,000$ - $\$ 89,999$

$\$ 90,000+$

\section{Current Religious/Spiritual Information}

How do you currently identify yourself religiously/spiritually?

Agnostic

Atheist

Buddhist

Christian (Catholic/Protestant)

Other Christian (please describe):

Hindu

Jewish

Muslim

Other (please describe): 
Do you current attend religious/spiritual services or meetings?

Yes

If yes, how does the group that you attend identify itself?

Agnostic

Atheist

Buddhist

Christian (Catholic/Protestant)

Other Christian (please describe):

Hindu

Jewish

Muslim

Other (please describe):

\section{Past Religious/Spiritual Information}

Please answer the following questions about the group(s) in which you experienced abuse of religious authority (ARA). If you experienced ARA in more than one group, please complete a section for each group. For example, if you experienced ARA in two different groups, you would answer the questions in "GROUP 1" about the first group. You would then answer the questions in "GROUP 2" about the second group.

\section{GROUP 1}

What was the name of the group?

How did the group identify itself religiously/spiritually?

Agnostic
Atheist
Buddhist
Christian (Catholic/Protestant)
Other Christian (please describe):
Hindu
Jewish
Muslim
Other (please describe):

Was the group part of a larger organization?

$\underset{\text { No }}{\mathrm{No}}$

If so, what was the larger organization?

How old were you when you joined the group? 
How many people attended the local group/congregation?

How many hours a week (on average) did you spend at formal or informal group events?

How many hours a week (on average) did you spend performing group-related activities or obligations (examples include prayer, meditation, working on projects, talking to potential members, etc.)?

How long were you in the group/How long have you been in the group?

If you left the group, how long has it been since you exited the group?

Did you hold a leadership position in the group?

Yes

No

If yes, please provide a brief description of that position:

\section{Group 2}

If you were part of two groups that engaged in ARA, please also answer the questions in this section about the second group.

What was the name of the group?

How did the group identify itself religiously/spiritually?

Agnostic

Atheist

Buddhist

Christian (Catholic/Protestant)

Other Christian (please describe):

Hindu

Jewish

Muslim

Other (please describe):

Was the group part of a larger organization?

Yes
No


If so, what was the larger organization?

How old were you when you joined the group?

How many people attended the local group/congregation?

How many hours a week (on average) did you spend at formal or informal group events?

How many hours a week (on average) did you spend performing group-related activities or obligations? Examples include prayer, meditation, working on projects, and talking to potential members.

How long were you in the group/How long have you been in the group?

If you left the group, how long has it been since you exited the group?

Did you hold a leadership position in the group?

Yes

No

If yes, please provide a brief description of that position:

\section{Group 3}

If you were part of three groups that engaged in ARA, please also answer the questions in this section about the third group.

What was the name of the group?

How did the group identify itself religiously/spiritually?

Agnostic

Atheist

Buddhist

Christian (Catholic/Protestant)

Other Christian (please describe):

Hindu

Jewish

Muslim

Other (please describe): 
Was the group part of a larger organization?

Yes

If so, what was the larger organization?

How old were you when you joined the group?

How many people attended the local group/congregation?

How many hours a week (on average) did you spend at formal or informal group events?

How many hours a week (on average) did you spend performing group-related activities or obligations? Examples include prayer, meditation, working on projects, and talking to potential members.

How long were you in the group/How long have you been in the group?

If you left the group, how long has it been since you exited the group?

Did you hold a leadership position in the group?

Yes

No

If yes, please provide a brief description of that position: 


\section{Appendix B}

\section{When the Sacred Hurts: Using Grounded Theory to Understand How Former Members Experienced Abuse of Religious Authority in Christian Groups}

\section{Interview Protocol}

\section{Introduction}

\section{a. Welcome}

"Hello. Thank you for your interest in helping me with my research. Again, I'm Karianne Bilsky, the researcher for this interview project, which is approved by the West Virginia University Institutional Review Board."

\section{b. Informed Consent}

i. Clarification/Questions (after reviewing the Informed Consent)

"Do you have any questions about the study?"

"Do you have any concerns about the study?"

\section{Interview}

a. Form Requesting Demographic Data and Information About Group That Abused Religious Authority

i. Clarification/Questions

"Do you have any questions or concerns about the form?"

"Would you like to clarify or explain any response you gave on this form?"

\section{b. Open-Ended Questions}

i. "What was it like for you being a member of religious group?"

ii. "Could you tell me about some of the positive experiences, if any, that you had as a member of this religious group?"

iii. Could you tell me about some of the negative experiences, if any, that you had as a member of this religious group?"

iv. "How did you first become involved as a participant or member of (name of religious group?"

v. "What did you believe about your religious group when you first joined it? What expectations did you have about your religious group when you joined it?

1. "Did these beliefs and expectations change while you were in the group?"

a. "If so, what led to this change?"

vi. "What kind of rules did the group have? How did you learn them? How were they enforced?"

vii. "What kinds of group-related activities were you involved in? Please describe your involvement?" 
viii. "Did you ever have any experiences in your group where you felt like your religious leaders, of those in positions of religious authorities, engaged in behaviors that were abusive?"

ix. "What are some examples of abuse of religious authority that happened to you?"

1. "How did this affect you while you were in the group?"

2. "At the time, how did you cope with these effects?"

x. "Please describe the decision to leave the group. How did you leave and what was that experience like (i.e., how did the group respond, how did you feel, etc.)?"

xi. "How did your experience with this group affect you immediately after you left? What did you find difficult? What did you find easy, if anything?"

1. "At the time, how did you cope with these effects?"

xii. "How does your experience in the group affect you currently?"

1. "How do you cope with these effects today?"

xiii. "Please describe how your experience in this group impacted your faith or spirituality."

\section{c. Closing}

i. Further invitation

"Is there anything else you would like to tell me about today's discussion?"

\section{ii. Debriefing}

"How did you feel discussing these topics?"

"What are your thoughts about today's discussion?"

\section{iii. Appreciation}

"Thank you for sharing your story with me. The information that you shared with me today will be very helpful for me to learn more about the experience of people who identify as experiencing ARA."

\section{iv. Invitation for the outcome and information for future contact}

"Is it okay for me to contact you if I need to clarify your responses or need further information?"

\section{v. Appreciation}

"Thanks again!" 


\section{Appendix C}

\section{When the Sacred Hurts: Using Grounded Theory to Understand How Former Members Experienced Abuse of Religious Authority in Christian Groups}

\section{Forum Post/Email Message Text}

We are forwarding information about an opportunity to participate in psychological research on the topic of abuse of religious authority (ARA). The research is being conducted by Karianne D. P. Bilsky, M.S., a doctoral candidate at West Virginia University, as part of her dissertation research. It has been approved by the West Virginia University Institutional Review Board. The purpose of the research is (1) to develop a definition of ARA based on the perspective of people have who experienced it, and (2) to begin to form a theory about how ARA impacts people. Participating in the research would involve completing an interview that should take approximately 1.5 to 2 hours and that will be audio recorded. Any information that is gathered as a result of participation in the study will be kept as confidential as legally possible. Audio recordings of interviews will be password-protected, stored in a locked container, and destroyed as soon as possible after the research is finished.

Your participation in this study is completely voluntary. If you are interested in participating in this study, please review the attached information; then contact Karianne Bilsky at Karianne.Bilsky@mail.wvu.edu to discuss your interest. If you have any questions about the study, you can contact Ms. Bilsky using the contact information listed above. You can also contact her research advisor, Dr. Jeff Daniels, at Jeffrey.Daniels@mail.wvu.edu. 


\section{Appendix D}

\section{When the Sacred Hurts: Using Grounded Theory to Understand How Former Members Experienced Abuse of Religious Authority in Christian Groups}

\section{Summary of Research Project}

I am a Ph.D. candidate in Counseling Psychology at West Virginia University (WVU), and I am conducting dissertation research on abuse of religious authority (ARA). The study has been approved by the West Virginia University Institutional Review Board. The purpose of the study is to understand what ARA is, and to learn how people experience and cope with ARA. I am requesting your assistance in informing potential participants about my research.

There has been very little psychological research on the topic of ARA, which is why I would like to conduct research that involves interviewing people who experienced ARA. Participants will be asked to complete an interview that should take approximately 1.5 to 2 hours. The interviews will take place by phone. The interviews will be audio recorded, transcribed, and analyzed for themes.

To participate in the study, participants must meet the following criteria:

1. They experienced emotional and spiritual distress that occurred in a Christian religious or spiritual organization or group

2. They believe that the distress was the result of controlling leadership in the organization or group

3. They are at least 18 years old

4. They live in the United States

5. They speak English fluently

Individuals who want to participate in the study will be asked to complete a brief informational telephone conversation. The purpose of the conversation is to provide them with complete information about the study so that they can make an informed choice about whether to participate. They will be encouraged to wait at least 24 hours after the informational telephone conversation to inform me of their decision about participation. They can discontinue their participation at any time, and there is no penalty for not participating in or withdrawing from the study.

For your convenience, I have provided the following documents that can be used when communicating with potential participants:

1. A letter that explains the research to potential participants

2. An informed consent form for potential participants to review

3. Text that can be used for a forum post or email message

4. A script for telephone or face-to-face communication with potential participants

I greatly appreciate any assistance you can provide in informing potential participants about this research. If you have any questions or concerns about this research, you may contact me at Karianne.Bilsky@mail.wvu.edu. You can also contact my research advisor, Dr. Jeff Daniels, at Jeffrey.Daniels@mail.wvu.edu. If you know of other people who might be interested in participating, please forward this information to them as well.

Thank you,

Karianne D. P. Bilsky, M.S.

Doctoral Candidate

West Virginia University 
Department of Counseling, Rehabilitation Counseling and Counseling Psychology 502 Allen Hall, P.O. Box 6122

Morgantown, WV 26506

Karianne.Bilsky@mail.wvu.edu 


\section{Appendix E}

\section{When the Sacred Hurts: Using Grounded Theory to Understand How Former Members Experienced Abuse of Religious Authority in Christian Groups}

\section{Verbal Script for Direct Participant Recruitment}

Hello, my name is I have been asked to provide you with information about an opportunity to participate in psychological research on the topic of abuse of religious authority (ARA). It has been approved by the West Virginia University Institutional Review Board. Participation in this study is completely voluntary. The research is being conducted by Karianne D. P. Bilsky, M.S., who is a doctoral candidate at West Virginia University. The purpose of the research is (1) to develop a definition of ARA based on the perspective of people who experienced it, and (2) to begin to form a theory about how ARA impacts people. Participating in the research would involve completing an interview that should take approximately 1.5 to 2 hours and that will be audio recorded. Any information that is gathered as a result of participation in the study will be kept as confidential as legally possible. Audio recordings of interviews will be password-protected, stored in a locked container, and destroyed as soon as possible after the research is finished.

Your participation in this study is completely voluntary. If you are interested in participating in this study, please review the letter that explains the research and the informed consent form. Then contact Karianne Bilsky at Karianne.Bilsky@mail.wvu.edu to discuss your interest. If you have any questions about the study, you can contact Ms. Bilsky using the contact information listed above. You can also contact her research advisor, Dr. Jeff Daniels, at Jeffrey.Daniels@mail.wvu.edu. 


\section{Appendix F}

\section{When the Sacred Hurts: Using Grounded Theory to Understand How Former Members Experienced Abuse of Religious Authority in Christian Groups}

\section{INFORMED CONSENT FORM}

You, , have been asked to participate in this research study, which has been explained to you by Karianne D. P. Bilsky, M.S. This study is being conducted by Karianne D. P. Bilsky, M.S., in the Department of Counseling, Rehabilitation Counseling, and Counseling Psychology at West Virginia University.

\section{Purpose of the Study}

The purpose of this study is to learn more about what abuse of religious authority (ARA) is. Another purpose is to understand how people experience and cope with ARA. A total of approximately 25 participants are expected to participate in this study.

\section{Description of Procedures}

This study involves an interview in which you will be asked to talk about your experience of ARA and how you define ARA. The interview will take approximately 1.5 to 2 hours for you to complete. You will also be asked to complete an informational form about yourself and your religious/spiritual experiences. You do not have to answer all of the questions. You will have the opportunity to see the questions you will be asked before signing this consent form. The interview will be audio recorded and transcribed. To ensure accuracy, you will be asked to review the researcher's analysis of your interview transcript.

\section{Risks and Discomforts}

There are no known or expected risks from participating in this study, except for the mild frustration associated with answering questions about traumatic events. Should you experience any emotional upset, a list of local mental health providers will be given to you.

\section{Alternatives to Participation}

You do not have to participate in this study. Your involvement is completely voluntary. If you choose to participate, you are allowed to stop at any time and ask that your information not be used. However, once the interview results are written up as a report, it is not possible to ask that your information not be used.

\section{$\underline{\text { Benefits }}$}

You may not receive any direct benefit from this study. The knowledge gained from this study may eventually benefit others. For example, the information from this study might help health care professionals improve treatment for people who experienced ARA. Some people might experience positive feelings that they participated in a study that may benefit others. You might benefit from being able to view results, which can be sent to you if you request them.

\section{Financial Considerations}

There are no anticipated costs to you to participate in this study. 


\section{Confidentiality}

Any information about you that is gathered as a result of your participation in this study will be kept as confidential as legally possible. Your research records, just like hospital records, may be subpoenaed by court order. They might be inspected by federal regulatory authorities without your additional consent.

Audio recordings of your interview will be password-protected and will be destroyed as soon as possible after the research is finished. The demographic form and audio recordings and written transcripts of your interview will be labeled with a number, not your name. The demographic form and all materials from your interview will be stored in a locked container. Your signed informed consent form will be stored in a separate locked container.

In any publications or presentations that result from this research, your name will not be used without your consent. Also, any information that might identify you will not be published or presented without your consent.

\section{Voluntary Participation}

Participation in this study is completely voluntary. You are free to withdraw your consent to participate in this study at any time. Withdrawal or refusal to participate will not affect you, and you will not be penalized. If new information becomes available that may affect your willingness to participate in this study, this information will be given to you so that you can make an informed decision about whether or not to continue your participation. You have been given the opportunity to ask questions about the research, and you have received answers concerning areas you did not understand.

\section{Contact Persons}

In the event that you experience any side effects or injury related to this research, you should contact Karianne D. P. Bilsky, M.S., at Karianne.Bilsky@mail.wvu.edu. If you have any questions, concerns, or complaints about this research, you can contact Ms. Bilsky's research advisor, Dr. Jeff Daniels, at 304-293-2235 or at Jeffrey.Daniels@,mail.wvu.edu. You can also contact Dr. Margaret Glenn, Department Chair, at 304-293-2276.

If you have any questions, concerns, or complaints about this research that are not answered by the researcher, you can contact the West Virginia University Institutional Review Board Office at 304-293-7073. You can also call this number if you cannot talk to the researcher or want to talk to someone else.

\section{Participant's Signature}

\section{Date}

\section{Participant's Name (please print)}




\section{Appendix G}

\section{When the Sacred Hurts: Using Grounded Theory to Understand How Former Members Experienced Abuse of Religious Authority in Christian Groups}

\section{Letter of Explanation to Participants}

Dear

I am a Ph.D. candidate in Counseling Psychology at West Virginia University (WVU). I am writing to ask for your participation in a study that I am conducting for my dissertation. The study has been approved by the West Virginia University Institutional Review Board. The purpose of this study is to understand what abuse of religious authority (ARA) is, and to learn how people experience and cope with ARA.

There has been very little psychological research on the topic of ARA. I would like to do a study that involves interviewing people who experienced ARA. Your participation in this interview project will take approximately 1.5 to 2 hours, and your participation is greatly appreciated. The interviews will take place by phone. The interviews will be audio recorded, transcribed, and analyzed for themes.

To participate in the study, you must meet the following criteria:

1. You experienced emotional and spiritual distress that happened in a Christian religious or spiritual organization or group

2. You believe the distress was the result of controlling leadership in the organization or group

3. You are at least 18 years old

4. You live in the United States

5. You speak English fluently

If you choose to participate in this study, you will be asked to complete a brief informational telephone conversation. The purpose of the conversation is to tell you more about the study so that you can make an informed choice about whether you want to participate. You can discontinue your participation at any time. There is no penalty for withdrawing or not participating.

Any information about you that is gathered as a result of your interest or participation in this study will be kept as confidential as legally possible. Your research records, just like hospital records, may be subpoenaed by court order. They might be inspected by federal regulatory authorities without your additional consent.

If are interested in participating, please contact me by emailing me at Karianne.Bilsky@mail. wvu.edu. Please provide your name and telephone number so that I can arrange a time for a brief informational telephone conversation with you. Please note that there is a potential loss of confidentiality in any Internet or email transaction. 
If you have any questions or concerns about this letter or the research, you may contact me at Karianne.Bilsky@mail.wvu.edu. You can also contact my research advisor, Dr. Jeff Daniels, at Jeffrey.Daniels@mail.wvu.edu. I would very much appreciate your help with my research. If you know of other people who might be interested in participating, please forward this letter to them as well.

Thank you,

Karianne D. P. Bilsky, M.S.

Doctoral Candidate

West Virginia University

Department of Counseling, Rehabilitation Counseling and Counseling Psychology

502 Allen Hall

P.O. Box 6122

Morgantown, WV 26506

Karianne.Bilsky@mail.wvu.edu 


\section{Appendix $\mathbf{H}$}

\section{When the Sacred Hurts: Using Grounded Theory to Understand How Former Members Experienced Abuse of Religious Authority in Christian Groups}

\section{Text of Email to Forum Administrators, International Cultic Studies Association (ICSA), The National Association for Christian Recovery (NACR), and Wellspring Retreat and Resource Center (WRRC)}

Dear

I am a Ph.D. candidate in Counseling Psychology at West Virginia University (WVU). I am writing to ask for your assistance in distributing a request for participants for my dissertation research. The purpose of my study is to understand what abuse of religious authority (ARA) is and to learn how people experience and cope with ARA. This study has been approved by the West Virginia University Institutional Review Board.

I have attached/enclosed a one-page summary of the research study, a letter to potential participants, and an informed consent form.

(For forum administrators: I am requesting that you post the letter explaining the research and the informed consent form to your forum. For your convenience, I have included text for the forum post. I would ask that you attach the letter explaining the research and the informed consent form to the forum post.)

(For ICSA and NACR: I am requesting that you distribute the letter explaining the research and the informed consent form to your member listserv. For your convenience, I have included text for an email message to your members. I would ask that you attach the letter explaining the research and the informed consent form to the email.)

(For WRRC: I am requesting that you distribute the letter explaining the research and the informed consent form to current clients, unless clinically contraindicated. For your convenience, I have included a script that can be used to explain the research to potential participants. If you are aware of any mental health professionals who offer therapy to individuals who have experienced ARA, I would greatly appreciate if you could share their contact information with me so that I can discuss this research with them as well.)

If you have any questions or concerns about the research, you may contact me at Karianne.Bilsky@mail.wvu.edu. You can also contact my research advisor, Dr. Jeff Daniels, at Jeffrey.Daniels@mail.wvu.edu. I would very much appreciate your assistance with my research. If you know of other people who might be interested in participating, please forward the letter explaining the research and the informed consent form to them as well.

Thank you,

Karianne D. P. Bilsky, M.S., Doctoral Candidate

West Virginia University 
Department of Counseling, Rehabilitation Counseling and Counseling Psychology 502 Allen Hall, P.O. Box 6122

Morgantown, WV 26506

Karianne.Bilsky@mail.wvu.edu 


\section{Appendix I}

\section{When the Sacred Hurts: Using Grounded Theory to Understand How Former Members Experienced Abuse of Religious Authority in Christian Groups}

\section{Telephone Information Conversation Protocol}

Hello, , my name is Karianne Bilsky. I am a doctoral candidate in the Department of Counseling, Rehabilitation Counseling, and Counseling Psychology at West Virginia University. I appreciate your interest in assisting me in my research study on abuse of religious authority (ARA). Have you received a copy of the letter that explains the research and the informed consent form?

May I ask you some brief screening questions to see whether my research is a good fit for your experience?

1. Did you experience emotional and spiritual distress in a Christian religious or spiritual organization or group?

2. What or who do you think caused this distress?

3. What is your date of birth?

4. What country do you live in?

5. What language(s) do you speak fluently?

\section{(If the potential participant meets criteria for the research study):}

There has been very little psychological research on the topic of ARA. I would like to do a study that involves interviewing people who experienced ARA. My goals in this research are (1) to develop a definition of ARA based on the perspective of people who experienced it, and (2) to begin to form a theory about how ARA impacts people. I have four research questions:

1. How do individuals from Christian traditions who identify as abused define the term "abuse of religious authority"?

2. What do abused people think about their experiences with ARA? What did they think about it at the time it happened?

3. How are abused people coping with their ARA now? How did they cope with it when it was happening?

4. How does the religious/spiritual aspect of ARA affect people's psychological wellbeing?

If you are interested, I would like to talk with you more about your experiences with ARA. I will schedule an interview time for people who are interested in participating. The interview should take approximately 1.5 to 2 hours, and will be audio recorded. The questions you will be asked are:

1. How would you define abuse of religious authority (ARA)?

2. How did you first become involved as a participant or member of (name of group)?

3. What did you believe about the group when you first joined it? What expectations did you have about the group when you joined it? 
a. Did these beliefs and expectations change while you were in the group?

i. If so, what led to this changed?

4. What kind of rules did the group have? How did you learn them? How were they enforced?

5. What kinds of group-related activities were you involved in? Please describe your involvement.

6. Thinking about your personal experience with the group, please describe how ARA occurred in the group.

a. How did this affect you while you were in the group?

b. At the time, how did you cope with these effects?

7. Please describe the decision to leave the group. How did you leave and what was that experience like (i.e., how did the group respond, how did you feel, etc.)?

8. How did your experience with this group affect you immediately after you left? What did you find difficult? What did you find easy?

a. At the time, how did you cope with these effects?

9. How does your experience in the group affect you currently?

a. How do you cope with these effects today?

10. Please describe how your experience in this group impacted your faith or spirituality.

Your name will be removed from the data and will not be reported in any research reports that result from this study.

Please know that your participation is strictly voluntary. If you choose not to participate, I will not contact you again. To avoid feeling pressured, I also encourage you to take 24 hours before making a decision about whether you would like to participate. If you choose to participate, you can let me know by emailing me at Karianne.Bilsky@mail.wvu.edu. I will then contact you again to schedule a date and time when we can speak by telephone. I will also mail you a demographic form to complete, as well as a copy of all of the interview questions. In the meantime, if you have any questions you can contact me. You can also contact my research advisor, Dr. Jeff Daniels, at 304-293-2235 or at Jeffrey.Daniels@mail.wvu.edu.

Do you have any questions?

\section{(If the potential participant does not meet criteria for the research study):}

Thank you very much for your interest in assisting me with my research. At this time, my research is limited to (list the inclusion criteria that are not met). I appreciate your time for this informational conversation. 


\section{Appendix J}

\section{When the Sacred Hurts: Using Grounded Theory to Understand How Former Members Experienced Abuse of Religious Authority in Christian Groups}

\section{INFORMED CONSENT FORM}

You, , have been asked to participate in this research study, which has been explained to you by Karianne D. P. Bilsky, M.S. This study is being conducted by Karianne D. P. Bilsky, M.S., in the Department of Counseling, Rehabilitation Counseling, and Counseling Psychology at West Virginia University.

\section{Purpose of the Study}

The purpose of this study is to learn more about what abuse of religious authority (ARA) is. Another purpose is to understand how people experience and cope with ARA. A total of approximately 25 participants are expected to participate in this study.

\section{Description of Procedures}

This study involves an interview in which you will be asked to talk about your experience of ARA and how you define ARA. The interview will take approximately 1.5 to 2 hours for you to complete. You will also be asked to complete an informational form about yourself and your religious/spiritual experiences. You do not have to answer all of the questions. You will have the opportunity to see the questions you will be asked before signing this consent form. The interview will be audio recorded and transcribed. To ensure accuracy, you will be asked to review the researcher's analysis of your interview transcript.

\section{Risks and Discomforts}

There are no known or expected risks from participating in this study, except for the mild frustration associated with answering questions about traumatic events. Should you experience any emotional upset, a list of local mental health providers will be given to you.

\section{Alternatives to Participation}

You do not have to participate in this study. Your involvement is completely voluntary. If you choose to participate, you are allowed to stop at any time and ask that your information not be used. However, once the interview results are written up as a report, it is not possible to ask that your information not be used.

\section{$\underline{\text { Benefits }}$}

You may not receive any direct benefit from this study. The knowledge gained from this study may eventually benefit others. For example, the information from this study might help health care professionals improve treatment for people who experienced ARA. Some people might experience positive feelings that they participated in a study that may benefit others. You might benefit from being able to view results, which can be sent to you if you request them.

\section{Financial Considerations}

There are no anticipated costs to you to participate in this study. 


\section{Confidentiality}

Any information about you that is gathered as a result of your participation in this study will be kept as confidential as legally possible. If you state that you are going to harm yourself or someone else, the researcher will need to inform appropriate professionals to ensure safety. If you report ongoing or unreported child abuse or elder abuse, the researcher is required to report this by law. Your research records, just like hospital records, may be subpoenaed by court order. They might be inspected by federal regulatory authorities without your additional consent.

Audio recordings of your interview will be password-protected and will be destroyed as soon as possible after the research is finished. The demographic form and audio recordings and written transcripts of your interview will be labeled with a number, not your name. The demographic form and all materials from your interview will be stored in a locked container. Your signed informed consent form will be stored in a separate locked container.

In any publications or presentations that result from this research, your name will not be used without your consent. Also, any information that might identify you will not be published or presented without your consent.

\section{Voluntary Participation}

Participation in this study is completely voluntary. You are free to withdraw your consent to participate in this study at any time. Withdrawal or refusal to participate will not affect you, and you will not be penalized. If new information becomes available that may affect your willingness to participate in this study, this information will be given to you so that you can make an informed decision about whether or not to continue your participation. You have been given the opportunity to ask questions about the research, and you have received answers concerning areas you did not understand.

\section{Contact Persons}

In the event that you experience any side effects or injury related to this research, you should contact Karianne D. P. Bilsky, M.S., at kbilsky@mix.wvu.edu. If you have any questions, concerns, or complaints about this research, you can contact Ms. Bilsky's research advisor, Dr. Jeff Daniels, at 304-293-2235 or at Jeffrey.Daniels@mail.wvu.edu.

If you have any questions, concerns, or complaints about this research that are not answered by the researcher, you can contact the West Virginia University Institutional Review Board Office at 304-293-7073. You can also call this number if you cannot talk to the researcher or want to talk to someone else. 


\section{Appendix K}

\section{When the Sacred Hurts: Using Grounded Theory to Understand How Former Members Experienced Abuse of Religious Authority in Christian Groups}

\section{Letter of Clarification to Participants}

\section{Dear Participant,}

This letter is to provide you with written documentation to clarify the limits of confidentiality in the research study that you participated in. As noted in the informed consent form, any information about you that is gathered as a result of your participation in this study will be kept as confidential as legally possible. If you state that you are going to harm yourself or someone else, the researcher will need to inform appropriate professionals to ensure safety. If you report ongoing or unreported child abuse or elder abuse, the researcher is required to report this by law. Your research records, just like hospital records, may be subpoenaed by court order. They might be inspected by federal regulatory authorities without your additional consent.

Again, this letter is for informational purposes only. If you have any questions or concerns about this letter or the research, you may contact me at kbilsky@mix.wvu.edu. You can also contact my research advisor, Dr. Jeff Daniels, at Jeffrey.Daniels@mail.wvu.edu. I very much appreciate your help with my research.

Thank you,

Karianne D. P. Bilsky, M.S.

Doctoral Candidate

West Virginia University

Department of Counseling, Rehabilitation Counseling and Counseling Psychology

502 Allen Hall

P.O. Box 6122

Morgantown, WV 26506

kbilsky@mix.wvu.edu 


\section{Appendix L}

\section{When the Sacred Hurts: Using Grounded Theory to Understand How Former Members Experienced Abuse of Religious Authority in Christian Groups}

\section{Letter Requesting Review of Analysis}

\section{(Date of Letter)}

Dear Participant,

This letter is to request your continued help with this research study. Enclosed is a list of analyzed quotes from the interview. These quotes are coded with a label that tries to capture the theme of each quote. I have included a codebook with definitions of each code. Please review the codes to see if you would like to make any changes. If I do not receive a response from you by two weeks from the date of this letter, I will assume that you do not want to make any changes.

If you have any questions or concerns about this letter or the research, you may contact me at kbilsky@mix.wvu.edu. You can also contact my research advisor, Dr. Jeff Daniels, at Jeffrey.Daniels@,mail.wvu.edu. I very much appreciate your help with my research.

Thank you,

Karianne D. P. Bilsky, M.S.

Doctoral Candidate

West Virginia University

Department of Counseling, Rehabilitation Counseling and Counseling Psychology

502 Allen Hall

P.O. Box 6122

Morgantown, WV 26506

kbilsky@mix.wvu.edu 


\section{References}

Allport, G. (1950). Individual and his religion. New York, NY: The MacMillian Company.

Ano, G. G., \& Vasconcelles, E. B. (2005). Religious coping and psychological adjustment to stress: A meta-analysis. Journal of Clinical Psychology, 61(4), 461-480. doi: 10.1002/jclp.20049

Anthony, S., \& Jack, S. (2009). Qualitative case study methodology in nursing research: An integrative review. Journal Of Advanced Nursing, 65(6), 1171-1181.

Aronoff, J., Lynn, S. J., \& Malinoski, P. (2000). Are cultic environments psychologically harmful? Clinical Psychology Review, 20(1), 91-111.

Ash, S. M. (1985). Cult-induced psychopathology, Part I: Clinical picture. Cultic Studies Journal, 2(1), 31-90.

Baker, D. C. (2003). Studies of the inner life: The impact of spirituality on quality of life. Quality of Life Research, 12, 51-57.

Bartel, M. (2004). What is spiritual? What is spiritual suffering? The Journal of Pastoral Care \& Counseling, 58(3), 187-201.

Benkert, M., \& Doyle, T. P. (2009). Clericalism, religious duress and its psychological impact on victims of clergy sexual abuse. Pastoral Psychology, 58, 223-238. doi: 10.1007/s11089008-0188-0

Boychuk Duchscher, J. E., \& Morgan, D. (2004). Grounded theory: Reflections on the emergence vs. forcing debate. Methodological Issues in Nursing Research 48(6), $605-$ 612.

Bregman, L. (2004). Defining spirituality: Multiple uses and murky meanings of an incredibly popular term. The Journal of Pastoral Care \& Counseling, 58(3), 157-167. 
Bregman, L. (2006). Spirituality: A glowing and useful term in search of a meaning. Omega: Journal of Death \& Dying, 53(1/2), 5-26.

Bryant, A. N., \& Astin, H. S. (2008). The correlates of spiritual struggle during the college years. The Journal of Higher Education, 79(1), 1-27.

Burton, R. (2003). Spiritual pain: A brief overview and an initial response within the Christian tradition. The Journal of Pastoral Care \& Counseling, 57(4), 437-446.

Buxant, C., \& Saroglou, V. (2008). Joining and leaving a new religious movement: A study of ex-members' mental health. Mental Health, Religion \& Culture, 11(3), 251-271. doi: $10.1080 / 13674670701247528$

Chambers, W. V., Langone, M. D., Dole, A. A., \& Grice, J. W. (1994). The Group Psychological Abuse Scale: A measure of the varieties of cultic abuse. Cultic Studies Journal, 11(1), 88-117.

Corbin, J., \& Strauss, A. L. (1990). Grounded theory research: Procedures, canons, and evaluative criteria. Qualitative Sociology, 13, 3-21.

Creswell, J. W. (1998). Qualitative inquiry and research design: Choosing among five traditions. Thousand Oaks, CA: Sage Publications.

Cudmore, M. J. (2002). The experience of victim suffering and perception of leadership abuse in Christian organizations. (Doctoral dissertation). Retrieved from ProQuest Dissertations and Theses (PQDT). (MQ77420).

Cushman, P. (1986). The self besieged: Recruitment-indoctrination processes in restrictive groups. Journal for the Theory of Social Behavior, 16, 1-32.

Dehan, N., \& Levi, Z. (2009). Spiritual abuse: An additional dimension of abuse experienced by 
abused Haredi (ultraorthodox) Jewish wives. Violence Against Women, 15(11), 12941310. doi: $10.1177 / 1077801209347619$

Doyle, T. P. (2009). The spiritual trauma experienced by victims of sexual abuse by Catholic clergy. Pastoral Psychology, 58, 239-260. doi: 10.1007/s11089-008-0187-1

Dubrow-Eichel, S. K. (2002). Saying good-bye to the guru: Brief Intermittent Developmental Therapy with a young adult in a high demand group. In S. E. Cooper, J. Archer, Jr., \& L. C. Whitaker (Eds.), Case book of brief psychotherapy with college students (pp. 153170). City, ST: The Haworth Press.

Durkheim, E. (1915). The elementary forms of the religious life. New York, NY: Free Press.

Emmons, R. A. (1986). Personal strivings: An approach to personality and subjective well-being. Journal of Personality and Social Psychology, 51(5), 1058-1068.

Emmons, R. A. (2005). Striving for the sacred: Personal goals, life meaning, and religion. Journal of Social Issues, 61(4), 731-745.

Emmons, R. A., Cheung, C., \& Tehrani, K. (1998). Assessing spirituality through personal goals: Implications for research on religion and subjective well-being. Social Indicators Research, 45, 391-422.

Emmons, R. A., \& King, L. A. (1988). Conflict among personal strivings: Immediate and longterm implications for psychological and physical well-being. Journal of Personality and Social Psychology, 54(6), 1040-1048.

Enroth, R. M. (1992). Churches that abuse. Grand Rapids, MI: Zondervan Publishing House.

Exline, J. J. (2002). Stumbling blocks on the religious road: Fractured relationships, nagging vices, and the inner struggle to believe. Psychological Inquiry, 13(3), 182-189.

Exline, J. J., Yali, A. M., \& Lobel, M. (1999). When God disappoints: Difficulty forgiving God 
and its role in negative emotion. Journal of Health Psychology, 4(3), 365-379. doi:

$10.1177 / 135910539900400306$

Exline, J. J., Yali, A. M., \& Sanderson, W. C. (2000). Guilt, discord, and alienation: The role of religious strain in depression and suicidality. Journal of Clinical Psychology, 56(12), 1481-1496.

Festinger, L. (1957). A theory of cognitive dissonance. Stanford, CA: Stanford University Press.

Fischer, C. T. (2009). Bracketing in qualitative research: Conceptual and practical matters. Psychology Research, 19(4-5), 583-590. doi: 10.1080/10503300902709375

Flyvbjerg, B. (2006). Five misunderstandings about case-study research. Qualitative Inquiry, 12(2), 219-245. doi:10.1177/1077800405284363

Flynn, K. A. (2008). In their own voices: Women who were sexually abused by members of the clergy. Journal of Child Sexual Abuse, 17(3-4), 216-237. doi:

$10.1080 / 10538710802329684$

Fogler, J. M., Shipherd, J. C., Rowe, E., Jensen, J., \& Clarke, S. (2008). A theoretical foundation for understanding clergy-perpetrated sexual abuse. Journal of Child Sexual Abuse, 17(3/4), 301-328. doi: 10.1080/10438710802329874

Francis, P. C., Turner, N. R. (1995). Sexual misconduct within the Christian church: Who are the perpetrators and those they victimize? Counseling \& Values, 39(3), 218-228.

Freud, S. (1927/1961). The future of an illusion. New York, NY: Norton.

Gaines, M. J., Wilson, M. A., Redican, K. J., \& Baffi, C. R. (1984). Effects of cult membership on health status of adults and children. Update: A Quarterly Journal on New Religious Movements, 8(3/4), 9-17.

George, L. K., Ellison, C. G., \& Larson, D. B. (2002). Explaining the relationships between 
religious involvement and health. Psychological Inquiry, 13(3), 190-200.

Glaser, B. G., \& Strauss, A. L. (1967). The discovery of grounded theory: Strategies for qualitative research. New York, NY: Aldine Publishing Company.

Goldberg, L. (2006). Raised in cultic groups: The impact on the development of certain aspects of character. Cultic Studies Review, 5(1), 1-28.

Goldberg, L., \& Goldberg, W. (1982). Group work with former cultists. Social Work, March 1982.

Greene, J. C., Caracelli, V. J., \& Graham, W. F. (2008). Toward a conceptual framework for mixed-method evaluation designs. In V. L. Plano Clark \& J. W. Creswell (Eds.), The mixed methods reader (pp. 121-147). Thousand Oaks, CA: Sage Publications, Inc.

Gubi, P. M., \& Jacobs, R. (2009). Exploring the impact on counselors of working with spiritually abused clients. Mental Health, Religion \& Culture, 12(2), 191-204. doi: $10.1080 / 13674670802441509$

Guido, J. J. (2008). A unique betrayal: Clergy sexual abuse in the context of the Catholic religious tradition. Journal of Child Sexual Abuse, 17(3-4), 255-269. doi: $10.1080 / 10538710802329775$

Hays, P. A. (2008). Addressing cultural complexities in practice: Assessment, diagnosis, and therapy $\left(2^{\text {nd }}\right.$ ed.). Washington, DC: American Psychological Association.

Heppner, P. P., Wampold, B. E., \& Kivlighan, D. M. (2008). Research design in counseling (3 ${ }^{\text {rd }}$ ed.). Belmont, CA: The Thomson Corporation.

Hill, P. C., \& Hood, R. W. (1999). Affect, religion, and unconscious processes. Journal of Personality, 67(6), 1015-1046.

Hill, P. C., Pargament, K. I., Hood, R. W., McCullough, M. E., Swyers, J. P., Larson, D. B., \& 
Zinnbauer, B. J. (2000). Conceptualizing religion and spirituality: Points of commonality, points of departure. Journal for the Theory of Social Behavior, 30(1), 51-77.

Hill, C. E., Thompson, B. J., \& Williams, E. N. (1997). A guide to conducting consensual qualitative research. Counseling Psychologist, 25(4), 517-72.

Isely, P. J., Isely, P., Freiburger, J., \& McMackin, R. (2008). In their own voices: A qualitative study of men abused as children by Catholic clergy. Journal of Child Sexual Abuse, 17(34), 201-215. doi: 10.1080/10538710802329668

James, W. (2002). The varieties of religious experience. Retrieved from http://www2.hn.psu.edu/ faculty/jmanis/wjames/Varieties-Rel-Exp.pdf

Johnson, C. V., \& Hayes, J. A. (2003). Troubled spirits: Prevalence and predictors of religious and spiritual concerns among university students and counseling center clients. Journal of Counseling Psychology, 50(4), 409-419. doi: 10.1037/0022-0167.50.4.409

Jung, C. G. (1933). Modern man in search of a soul. Translated by W. S. Dell and Cray F. Baynes. San Diego, CA: Harcourt Brace Jovanovich, Publishers.

Khan, Z. H., \& Watson, P. J. (2006). Construction of the Pakistani Religious Coping Practices Scale: Correlations with religious coping, religious orientation, and reactions to stress among Muslim university students. The International Journal for the Psychology of Religion, 16(2), 101-112.

Kiesling, C., Sorell, G. T., Montgomery, M. J., \& Colwell, R. K. (2008). Identity and spirituality: A psychosocial exploration of the sense of spiritual self. Psychology of Religion and Spirituality, S(1), 50-62. doi: 10.1037/1941-1022.S.1.50

Lemoncelli, J., \& Carey, A. (1996). The psychospiritual dynamics of adult survivors of abuse. Counseling and Values, 40(3), 175-184. 
Leuba, J. H. (1925). The psychology of religious mysticism. New York, NY: Harcourt-Brace.

Leuba, J. H. (1933). God or man? A study of the value of God to man. New York, NY: Henry Holt and Company.

Lifton, R. J. (1961). Thought reform and the psychology of totalism: A studying of 'brainwashing' in China. New York, NY: W. W. Norton \& Co.

Lottick, E. A. (2008). Psychologist survey regarding cults. Cultic Studies Review, 7(1), 1-19.

Lyons, H.Z., \& Bike, D. H. (2010) Lyons, H. Z., and Bike, D. H. (2010). Designing and interpreting qualitative research in multicultural counseling. In J. G. Ponterotto, J. M. Casas, L. A. Suzuki, and C. M. Alexander (Eds.), Handbook of multicultural counseling ( $3^{\text {rd }}$ ed., pp. 413-426). Los Angeles, CA: Sage.

Mahoney, A., Pargament, K. I., Cole, B., Jewell, T., Magyar, G. M., Tarakeshwar, N., ..., \& Phillips, R. (2005). A higher purpose: The sanctification of strivings in a community sample. The International Journal for the Psychology of Religion, 15(3), 239-262.

Malinoski, P. T., Langone, M. D., \& Lynn, S. J. (1999). Psychological distress in former members of the International Churches of Christ and noncultic groups. Cultic Studies Journal, 16(1), 33-51.

Mart, E. G. (2004). Victims of abuse by priests: Some preliminary observations. Pastoral Psychology, 52(6), 465-472.

Martin, P. R., Langone, M. D., Dole, A. A., \& Wiltrout, J. (1992). Post-cult symptoms as measured by the MCMI before and after residential treatment. Cultic Studies Journal, 9(2), 219-250.

Masis, K. V. (2004). Compassion betrayed: Spiritual abuse in an American Zen center. Cultic Studies Review, 3(1), 28-55. 
McConnell, K. M., Pargament, K. I., Ellison, C. G., \& Flannelly, K. J. (2006). Examining the links between spiritual struggles and symptoms of psychopathology in a national sample. Journal of Clinical Psychology, 62(12), 1469-1484. doi: 10.1002/jclp.20325

McLaughlin, B. R. (1994). Devastated spirituality: The impact of clergy sexual abuse on the survivor's relationship with God and the church. Sexual Addiction \& Compulsivity, 1(2), $145-158$.

Melton, A. M. A., \& Schulenberg, S. E. (2008). On the measurement of meaning: Logotherapy's empirical contributions to humanistic psychology. The Humanistic Psychologist, 36, 3144. doi: $10.1080 / 08873260701828870$

Millspaugh, D. (2005a). Assessment and response to spiritual pain: Part I. Journal of Palliative Medicine, 8(5), 919-923.

Millspaugh, D. (2005b). Assessment and response to spiritual pain: Part II. Journal of Palliative Medicine, 8(6), 1110-1117.

Morrison, R. (1992). Diagnosing spiritual pain in patients. Nursing Standard, 6(25), 36-38.

Orlowski, B. M. (2010). Spiritual abuse recovery: Dynamic research on finding a place of wholeness. Eugene, OR: Wipf \& Stock.

Pargament, K. I. (1999). The psychology of religion and spirituality? Yes and no. The International Journal for the Psychology of Religion, 9(1), 3-16.

Pargament, K. I. (2002). Is religion nothing but...? Explaining religion versus explaining religion away. Psychological Inquiry, 13(3), 239-244.

Pargament, K. I. (2007). Spiritually integrated psychotherapy: Understanding and addressing the sacred. New York, NY: The Guilford Press. 
Pargament, K. I., Kennell, J., Hathaway, W., Grevengoed, N., Newman, J., \& Jones, W. (1988).

Religion and the problem-solving process: Three styles of coping. Journal for the Scientific Study of Religion, 27(1), 90-104.

Pargament, K. I., Koenig, H. G., \& Perez, L. M. (2000). The many methods of religious coping: Development and initial validation of the RCOPE. Journal of Clinical Psychology, 56(4), 519-543.

Pargament, K. I., Magyar, G. M., Benore, E., \& Mahoney, A. (2005). Sacrilege: A study of sacred loss and desecration and their implications for health and well-being in a community sample. Journal for the Scientific Study of Religion, 44(1), 59-78.

Pargament, K. I., Magyar-Russell, G. M., \& Murray-Swank, N. A. (2005). The sacred and the search for significance: Religion as a unique process. Journal of Social Issues, 61(4), $665-687$.

Pargament, K. I., \& Mahoney, A. (2005). Sacred matters: Sanctification as a vital topic for the psychology of religion. The International Journal For the Psychology of Religion, 15(3), 179-198.

Pargament, K. I., Murray-Swank, N., Magyar, G. M., \& Ano, G. (2005). Spiritual struggle: A phenomenon of interest to psychology and religion. In W.R. Miller \& H. D. Delaney (Eds.), Judeo-Christian perspectives on psychology: Human nature, motivation, and change (pp. 245-268). Washington, DC: American Psychological Association.

Pargament, K. I., Murray-Swank, N. A., \& Mahoney, A. (2008). Problem and solution: The spiritual dimension of clergy sexual abuse and its impact on survivors. Journal of Child Sexual Abuse, 17(3-4), 397-420. doi: 10.1080/10538710802330187

Pargament, K. I., Smith, B. W., Koenig, H. G., \& Perez, L. (1998). Patterns of positive and 
negative religious coping with major life stressors. Journal for the Scientific Study of Religion, 37(4), 710-724.

Pargament, K. I., Tarakeshwar, N., Ellison, C. G., \& Wulff, K. M. (2001). Religious coping among the religious: The relationships between religious coping and well-being in a national sample of Presbyterian clergy, elders, and members. Journal for the Scientific Study of Religion, 40(3), 497-513.

Pargament, K. I., Zinnbauer, B. J., Scott, A. B., Butter, E. M., Zerowin, J., \& Stanik, P. (1998). Red flags and religious coping: Identifying some religious warning signs among people in crisis. Journal of Clinical Psychology, 54(1), 77-89.

Piedmont, R. L. (1999). Does spirituality represent the sixth factor of personality? Spiritual transcendence and the Five-Factor Model. Journal of Personality, 67(6), 985-1013.

Piedmont, R. L. (2001). Spiritual transcendence and the study of spirituality. Journal of Rehabilitation, 67(1), 4-14.

Rank, O. (1998). Psychology and the soul: A study of the origin, conceptual evolution, and nature of the soul. (G.C. Richter \& E. J. Lieberman, Trans.). Baltimore, MD: The Johns Hopkins University Press. (Original work published 1930).

Rauch, M. (2009). Healing the soul after religious abuse: The dark heaven of recovery. Westport, Connecticut: Praeger Publishers.

Rosmarin, D. H., Pargament, K. I., Krumrei, E. J., \& Flannelly, K. J. (2009). Religious coping among Jews: Development and initial validation of the JCOPE. Journal of Clinical Psychology, 65(7), 670-683. doi: 10.1002/jclp.20574

Rossetti, S. J. (1995). The impact of child sexual abuse on attitudes toward God and the Catholic church. Child Abuse \& Neglect, 19(12), 1469-1481. 
Ryan, R. M., Rigby, S., \& King, K. (1993). Two types of religious internalization and their relations to religious orientations and mental health. Journal of Personality and Social Psychology, 65(3), 586-596.

Satterly, L. (2001). Guilt, shame, and religious and spiritual pain. Holistic Nursing Practice, 15(2), 30-39.

Schlosser, L.Z., Foley, P.F., Sein, E.P., \& Holmwood, J.R. (2010). Why does counseling psychology exclude religion? A content analysis and methodological critique. In J.G. Ponterotto, J. M. Casas, L.A. Suzuki, and C.M. Alexander (Eds.), Handbook of multicultural counseling ( $3^{\text {rd }}$ ed., pp. 453-465). Los Angeles, CA: Sage.

Schwartz, L. L. (1985). Leaving the cults. Update: A Quarterly Journal on New Religious Movements, 9(4), 3-10.

Skinner, B. F. (1953). Science and human behavior. New York, NY: Macmillan.

Smucker, C. (1996). A phenomenological description of the experience of spiritual distress. Nursing Diagnosis, 7(2), 81-91.

Sorin-Peters, R. (2004). The case for qualitative case study methodology in aphasia: An introduction. Aphasiology, 18(10), 937-949. doi:10.1080/02687030444000444

Swartling, G. (1992). Psychiatric problems in ex-members of Word of Life. Cultic Studies Journal, 9(1), 78-88.

Tarakeshwar, N., Pargament, K. I., \& Mahoney, A. (2003). Initial development of a measure of religious coping among Hindus. Journal of Community Psychology, 31(6), 607-628. doi: 10.1002/jcop. 10071

Tillich, P. (1957). Dynamics of faith. New York, NY: Harper \& Row.

Tix, A. P., \& Frazier, P. A. (1998). The use of religious coping during stressful life events: Main 
effects, moderation, and mediation. Journal of Consulting and Clinical Psychology, $66(2), 411-422$

Trenholm, P., Trent, J., \& Compton, W. C. (1998). Negative religious conflict as a predictor of panic disorder. Journal of Clinical Psychology, 54(1), 59-65.

VanVonderan, J., \& Johnson, D. (1991). The subtle power of spiritual abuse. Minneapolis, MN: Bethany House Publishers.

Walsh, Y. (2001). Deconstructing 'brainwashing' within cults as an aid to counselling psychologists. Counselling Psychology Quarterly, 14(2), 119-128.

Wehr, D. S. (2000). Spiritual abuse: When good people do bad things. In P. Young-Eisendrath \& M. E. Miller (Eds.), The psychology of mature spirituality: Integrity, wisdom, transcendence (pp. 47-61). London, England: Routledge.

Winocur, N., Whitney, J., Sorensen, C., Vaughn, P., \& Foy, D. (1997). The Individual Cult Experience Index: The assessment of cult involvement and its relationship to postcult distress. Cultic Studies Journal, 14(2), 290-306.

Yalom, I. D. (1980). Existential psychotherapy. New York, NY: Basic Books. 